\title{
Experimental Evidence on Adoption and Impact of the System of Rice Intensification*
}

\author{
Christopher B. Barrett (Cornell University) \\ Asad Islam (Monash University) \\ Abdul Malek (University of Tsukuba) \\ Debayan Pakrashi (IIT Kanpur) \\ Ummul Ruthbah (Dhaka University)
}

January 2021

\begin{abstract}
We report the results of a large-scale, multi-year experimental evaluation of the System of Rice Intensification (SRI), an innovation that first emerged in Madagascar in the 1980s and has now diffused to more than 50 countries. Using a randomized training saturation design, we find that greater cross-sectional or intertemporal intensity of direct or indirect training exposure to SRI has a sizable, positive effect on Bangladeshi farmers' propensity to adopt (and not to disadopt) SRI. We find large, positive and significant impacts of SRI training on rice yields and profits, as well as multiple household well-being indicators, for both trained and untrained farmers in training villages. Despite the significant farm-level impacts on rice productivity and labor costs, we find no evidence of significant general equilibrium effects on rice prices or wage rates. We also find high rates of disadoption, and clear indications of non-random selection into technology adoption conditional on randomized exposure to training, such that adopters and non-adopters within the same treatment arm experience similar outcomes. Rice yields, profits and household well-being outcomes do not, however, vary at the intensive margin with intensity of training exposure, a finding consistent with multi-object learning models.
\end{abstract}

Keywords: agricultural development, Bangladesh, BRAC, diffusion, innovation, learning, technology adoption

\footnotetext{
* We are grateful to Marcel Fafchamps and Sisira Jayasuriya for detailed discussions on many aspects of the project and to the International Growth Centre (IGC) for financial support. We thank the former executive director of BRAC, the late Mahabub Hossain, who gave us much encouragement and project support. Sakiba Tasneem provided excellent research assistance. Latiful Haque and Tanvir Shatil from BRAC Research and Evaluation Division (RED) were instrumental in conducting the field survey work, as were Abid Kabir and Sirajul Islam from BRAC Agriculture and Food Security Program (AFSP) in coordinating the SRI training treatment. Mohammad Abdul Malek was affiliated with BRAC Research and Evaluation Division (RED) during conducting field work and experiment. We thank Erich Battistin, Leah Bevis, Michael Carter, Paul Christian, Brian Dillon, Kyle Emerick, Yuki Higuchi, Garth Holloway, Molly Ingram, Heidi Kaila, Jeffrey LaFrance, Erin Lentz, Anke Leroux, Travis Lybbert, Annemie Maertens, Andy McDonald, Mushfiq Mobarak, Christine Moser, Vesall Nourani, Eleonora Patacchini, James Stevenson, Erika Styger, Norman Uphoff, Faraz Usmani, Michael Ward, Carrie Young, and seminar and conference participants at ANU, BRAC, Cornell, Department of Agriculture Extension of the Government of Bangladesh, IFPRI, IGC Dhaka, Japanese Association for Development Economics, Maryland, Melbourne, Monash, NC-1034, Stanford, and the World Bank for helpful comments and background conversations. An earlier version circulated under the title "The Effects of Exposure Intensity on Technology Adoption and Gains: Experimental Evidence from Bangladesh on the System of Rice Intensification.” Any remaining errors are ours alone.
} 


\section{Introduction}

Rice is the most widely cultivated and consumed crop in the world. So productivity growth in rice is especially important to promote food security, perhaps especially in low- and middleincome communities where many people depend on rice farming for their livelihoods. One prominent recent innovation, the System of Rice Intensification (SRI), first emerged in Madagascar in 1983, although agricultural scientists did not begin to publish studies of the agronomy or adoption patterns of SRI until the late 1990s and early 2000s (Stoop et al. 2002). SRI has spread widely, to more than 50 different countries now, with strong backing from major international agencies such as Africare, OXFAM, WWF, and the World Bank. For example, in a recent large-scale project across multiple countries in West Africa, more than 50,000 farmers were induced to try SRI (Styger and Traoré 2018).

SRI requires neither a new seed variety nor purchased inputs such as chemical fertilizers. Rather, SRI combines a suite of agronomic principles designed to increase rice productivity by changing plant, soil, and water management practices. Some observers therefore consider SRI a "system" rather than a "technology" because it involves no specific inputs, not even a fixed set of specific practices (e.g., transplant seedlings 12 days after nursery germination). Instead SRI advances a core set of principles for farmers to test and adapt to their specific circumstances, in particular, early transplanting of single seedlings with wider spacing into fields that are not continuously flooded, as well as soil that has more organic matter and is actively aerated, often using simple mechanical weeders (Stoop et al. 2002; Glober 2011). ${ }^{1}$ Several of these practices e.g., use of organic fertilizers, alternate wetting and drying (AWD) water management, or mechanical weeders - are familiar best management practices often recommended by extension agents, and are certainly not unique to SRI (McDonald et al. 2006). SRI thus exemplifies knowledge-intensive technologies that are increasingly commonplace, combining components from existing practices (Weitzman 1998; Arthur 2009; Stevenson et al. 2019).

A large literature - more than 1,200 journal articles to date (http://sri.ciifad.cornell.edu/research/) - reports widespread observational findings of dramatic rice yield and profitability gains of 30 or more percent, and even reduced water use and greenhouse gas emissions from SRI (e.g., Stoop et al. 2002; Uphoff 2003; Barrett et al. 2004; Moser and Barrett 2006; Randriamaiharisoa et al. 2006; Sinha and Talati 2007; Styger et al. 2011; Islam et al. 2012; Noltze et al. 2013; Takahashi and Barrett 2014; Gathorne-Hardy et al. 2016). The

\footnotetext{
${ }^{1}$ The distinction between broad principles and specific practices implicitly acknowledges heterogeneous conditions that may require customizing specific practices to particular farmers' context in order to adhere to the underlying principle(s) of the innovation. Agricultural and natural resources management researchers are therefore increasingly shifting from studying and promoting specific practices to broader principles instead (Stevenson et al. 2019).
} 
mainstream rice breeding community has nonethelees been vocally skeptical of such claims (Doberman 2004; Sheehy et al. 2004; Sinclair and Cassman 2004; McDonald et al. 2006). Critics have frequently decried the absence of experimental evidence from a large sample of farmers cultivating their usual fields, as distinct from purposively-collected samples, trials on experiment station plots, or observational data of non-random diffusion processes. These "rice wars" have induced calls for careful empirical work to assess the uptake and performance of SRI (Glover 2011).

This paper responds to that plea, reporting the results of a large-scale, multi-year, randomized controlled trial (RCT) evaluation of SRI carried out in Bangladesh in conjunction with BRAC, the world's largest non-governmental organization (NGO). ${ }^{2}$ In 2014-15 and 2015-16 we randomized exposure to SRI training among 5,486 farmers in 182 villages that had no prior SRI experience. As explained in greater detail below, the experimental design randomized villages into treatment (i.e., SRI training) and control, and then of farmers into treated (i.e., trainees) and untreated (i.e., not trainees) cohorts within treatment villages, coupled with randomized saturation (i.e., number of trainees) within treated villages, and randomized repetition of training for a second year in half of the treatment villages. ${ }^{3}$ This design enables us to estimate the causal effects of randomized SRI training on SRI uptake and disadoption rates, ${ }^{4}$ as well as on rice yields and profits, and on multiple measures of household well-being, all as a function of the cross-sectional and intertemporal intensity of treatment. This design also permits us to estimate the spillover effects of SRI training on untrained farmers within treatment villages, again as a function of crosssectional and intertemporal intensity of treatment. The size and structure of the study also permits exploration of the endogenous adoption behaviors of farmers within treatment arms, and their productivity, profitability, and well-being outcomes, also provides important insights on smallholder farmer technology adoption behaviors. Finally, insofar as intensity of exposure to training relates to learning, this design offers some insights on how and what farmers learn about new technologies.

\footnotetext{
${ }^{2}$ After fielding the experiment and analyzing our data, we learned of a parallel RCT on SRI in Haiti by Michael Carter, Travis Lybbert, Abbie Turiansky and collaborators at UC-Davis and OXFAM. As of yet, no paper reports results from that field research so we believe ours is the first report of experimental evidence on farmers' uptake and use of SRI.

${ }^{3}$ Given that agricultural production depends on many exogenous and largely unobservable factors, such as weather, disease, pathogen and pest pressure, etc. (Sherlund et al. 2002), multiple observations over time enable us to average out the noise in measuring yields, revenues, and costs of agricultural production, generating estimates less vulnerable to bias that might arise due to unusual conditions for all subjects during the experimental period (McKenzie 2012; Rosenzweig and Udry 2019).

${ }^{4}$ We use the terms 'adoption' and 'uptake' interchangeably to refer to use of SRI and 'disadoption' for discontinuation of use after initial uptake.
} 
We find that SRI training sharply increases the likelihood of SRI adoption and decreases the likelihood of disadoption, and has spillover effects, promoting uptake by untreated farmers in training villages. We find large, positive, statistically significant intent to treat (ITT) effects of SRI training on rice yields and profits, as well as multiple household well-being indicators. The qualitative findings of the large observational literature on SRI seem largely correct in their claims that SRI boosts farm-level rice productivity and profitability. Given SRI's global diffusion without large-scale experimental evaluation, these impact findings are the paper's primary contribution.

Despite rates of SRI uptake and estimated yield and profit gains that are both statistically significant and of meaningful magnitudes, most farmers adopt SRI on only part of their rice plots and many farmers disadopt SRI after trying it for a year. This echoes prior observational studies' findings (Moser and Barrett 2006). Partial adoption and disadoption could signal heterogeneous returns to SRI. But we cannot identify any observable source of heterogeneity. We do observe, however, that returns distributions are statistically indistinguishable between SRI adopters and non-adopters or disadopters within each treatment arm of the experiment. This strongly suggests that farmers engage in near-optimal endogenous, non-random selection into SRI adoption.

We find no evidence of general equilibrium effects on rice prices or wage rates that might impact farmer outcomes due to SRI training exposure independent of the SRI adoption pathway. Nonetheless, we find strong evidence that training exposure has strong effects even among nonadopters in training villages, a puzzling result that serves as a caution for studies that rely on local average treatment effect (LATE) estimates of a technology's impact based on use of a randomized training treatment as an instrument shown to drive adoption.

We further find strong evidence that SRI adoption increases significantly - and disadoption decreases significantly - with greater intensity of (direct or indirect) training exposure to SRI. But the impacts of training intensity appear limited to uptake decisions. The ITT estimates of SRI training's impacts on rice yields, profits and household well-being are statistically indistinguishable among treatment arms with varying exposure intensities. The finding that the intensity of SRI training exposure significantly affects only farmers' propensity to adopt (and not to disadopt) SRI but has no significant effect on farmers' performance with the new technology reinforces recent work on learning in the process of technology adoption. Our results reconcile most easily with multi-object learning, including rational inattention models that may be especially pertinent to combinatorial innovations such as SRI, most natural resources management practices, or digital platforms, as such technologies require learning about multiple objects or practices at once (e.g., Hanna et al. 2014; Nourani 2019; Maertens et al. forthcoming). 


\section{System of Rice Intensification}

The System of Rice Intensification (SRI) ${ }^{5}$ offers an exceptionally good candidate innovation for studying questions about technology diffusion, learning processes, and impacts among smallholder farmers. ${ }^{6}$ SRI is a combinatorial innovation based on a few core principles: early, careful transplanting of single seedlings with wider spacing into fields that have careful water management but are not continuously flooded, as well as soil that has more organic matter and is actively aerated, often using simple mechanical weeders. Practices that adhere to these principles seem to improve the growth and functioning of rice plants' root systems and to enhance the number and diversity of the soil biota that contribute to plant health and productivity (Stoop et al. 2002; Uphoff 2003; Randriamiharisoa et al. 2006), although the exact bio-physio-chemical mechanisms behind the claimed performance improvements remain poorly understood by agricultural scientists. Some agronomists hold that SRI merely represents good agronomy: full use of organic inputs, regular plant geometry, judicious use of water, good weed control, etc., thus the label really just reflects best management practices, not a new technology (McDonald et al. 2006). Indeed, the use of organic fertilizers, alternate wetting and drying (AWD) water management, and mechanical weeders are common recommendations, not unique to SRI. Each of those practices existed already (at varying prevalence levels) in our Bangladesh survey villages. The most distinguishing features of SRI are three practices: (i) early transplanting, of (ii) a single seedling per spot, with (iii) much wider spacing. Those were novel in our study sites and differentiate SRI from other agronomic practices already in use.

We adapt the approach taken by BRAC through its own SRI experimentation over the prior several years elsewhere in Bangladesh. ${ }^{7}$ SRI is most appropriate during the Boro season (JanuaryJune), when irrigation management is easier. Heavy rainfall during the Aus/Aman season (April-

\footnotetext{
${ }^{5}$ For a brief introduction to SRI, see http://sri.ciifad.cornell.edu/aboutsri/origin/. A large online library of studies on SRI is available at http://sri.ciifad.cornell.edu/research/.

${ }^{6}$ See the excellent reviews by Feder et al. (1985), Sunding and Zilberman (2002), Foster and Rosenzweig (2010), and Chavas and Nauges (2020) for detailed discussion of these literatures.

${ }^{7}$ BRAC previously worked on SRI in two other sub-districts of Bangladesh, including a pilot project in association with Cornell University, on a small scale (among just 80 farmers). BRAC provided interest free credit (and in some cases grants) to farmers who agreed to adopt SRI. However, BRAC used a 'block' approach in which all farmers with neighbouring plots of lands within a village needed to agree to cultivate using the SRI approach. These blocks were typically large, 20-30 acres in size, and blocks often contained 50 or more farmers. Yield gains were observed, but it proved difficult for BRAC to convince such a large number of farmers to coordinate, especially around water management, so as to practice SRI (Karmakar et al. 2004). Further, other trials in Bangladesh concluded existing best management practices outperformed SRI (Latif et al. 2005). BRAC therefore wanted to change this approach, as its prior efforts seemed neither financially sustainable nor effective. The approach we developed with BRAC, described in section 3, differs dramatically from its prior design. We did follow, however, the SRI principles that BRAC validated during these prior several years of experimentation elsewhere in Bangladesh. None of the control or treatment villages in our study were previously involved with BRAC efforts to promote SRI, nor with any other SRI promotion activities of which we are aware.
} 
August) makes careful AWD water management harder. As Boro coincides with winter, when plants grow more slowly, BRAC recommends transplanting seedlings when they are much younger than the local convention, at about 20 days rather than 40-50 days, but a bit later than is typically recommended in SRI systems elsewhere (10-15 days). The basic SRI principles and specific practices advanced by BRAC in Boro season are: (1) transplanting younger (20-days-old) seedlings; (2) transplanting 1-2 seedlings per hill; (3) wide spacing of transplanted seedlings (25 $\times 20 \mathrm{~cm}$ ); (4) providing organic matter amendments (e.g., compost, manure) to the soil; (5) following the AWD method of irrigation; and (6) mechanically weeding at regular intervals. The first three practices define SRI uptake as implemented in this study, with findings robust to different precise ways of measuring uptake, as we explain below.

\section{Experimental design}

The RCT was conducted in 182 villages across seven upazillas in five districts ${ }^{8}$ in two successive years (2014/15 and 2015/2016) during the Boro rice seasons. ${ }^{9}$ We used a multi-stage randomization in year $1(2014 / 15)$. First, 120 villages were selected randomly for training to introduce farmers to SRI; the remaining 62 villages served as controls and received no SRI training. BRAC already operates in these villages for other activities, so is a well-known and respected organization in all of the survey communities. ${ }^{10}$ SRI had not been practiced in any of these villages, nor in neighbouring villages.

While the SRI intervention was coordinated by BRAC's Agriculture and Food Security Program (AFSP), the research reported here was implemented by BRAC Research and Evaluation Division (RED), established in 1975 as an independent research unit within BRAC, expressly tasked with conducting a credible, independent evaluation of BRAC interventions free of conflicts of interest (Chowdhury et al. 2014). ${ }^{11}$

At the very beginning of the research program RED conducted a census before the 2014 Boro season to list all farmers in the sample villages who cultivated rice in the previous Boro season, and owned at least 0.5 but not more than 10 acres of land. ${ }^{12}$ We then selected $30-40$ farmers randomly from each village, including from the control villages, for the baseline survey. ${ }^{13}$ In total,

\footnotetext{
${ }^{8}$ The five districts are Kishoreganj, Pabna, Lalmonirat, Gopalgonj and Shirajgonj. See map in Figure A1.

${ }^{9}$ As this study was undertaken before pre-analysis plans became popular, it was not formally pre-registered.

${ }^{10}$ BRAC works across all of Bangladesh, offering a range of education, health, microfinance, skills training and legal support services.

${ }^{11}$ RED facilitated the evaluation of BRAC's well-known ultra-poor (Bandiera et al. 2017), and tenant farmers credit programs (Hossain et al. 2019).

${ }^{12}$ Farmers with less than 0.5 acres of land were excluded as they are usually seasonal farmers. Those with more than 10 acres are considered land rich in this context and not part of BRAC's target clientele.

${ }^{13}$ In a few very large villages, we divided the village into two or more paras/neighborhoods for both the baseline
} 
we surveyed 5,486 farmers, 1,856 from the control villages and 3,630 from the treatment villages (Appendix Table A1). The second stage randomization involved selecting farmers randomly for SRI training within each of the 120 treatment villages. The SRI training took place just before the season started each year (during November-December of 2014 and 2015). In the first year, BRAC provided training and information on SRI following its standard farmer training curriculum model.

The number of farmers trained within each treatment village varied randomly following a randomized saturation design that generates experimental variation in the (cross-sectional) intensity of within-village-and-period exposure to treatment among treated farmers and villages. We randomly varied the number of farmers trained between 10 and 30 (Appendix Figure A3), so that the fraction of sampled farmers in training villages ranges from 25-80 percent, averaging just over 60 percent of the sample farmers in training villages. Randomized saturation can help identify spillover effects from the treated to the untreated (Baird et al. 2018), although as we show, it can also affect the treatment effect on the treated. In total, 2,226 sample farmers received the standardized SRI training in 2014. Another 1,404 reside in treatment villages but did not receive BRAC SRI training (Appendix Table A1). ${ }^{14,15}$

Following the selection of farmers for training, local BRAC AFSP field workers and RED enumerators visited the farmers' homes and presented them with a letter from BRAC inviting them to a one-day SRI training. The farmers were also briefly informed orally about the purpose of the training. All farmers received a small payment (BDT 300 24 USD) to participate in the training, worth slightly more than the average daily wage. ${ }^{16}$ The training content was standardized across villages, involving both oral and multimedia presentations, including a video demonstrating the principles and practices of SRI used in other areas of Bangladesh, and interactive question-andanswer sessions to clarify the practices and principles. The trainers were existing AFSP agricultural officers trained by agricultural scientists who had previously worked on SRI elsewhere in Bangladesh. ${ }^{17}$ The trainers were supported by RED enumerators and AFSP field workers in conducting the training session and the pre- and post-training interviews, while all other surveys (census, baseline, midline and endline surveys) were done by RED enumerators.

\footnotetext{
survey and the training. We surveyed only one neighborhood from each such village such that the farmers are geographically close to each other, mimicking more typical village settings.

${ }^{14}$ The random selection of villages and farmers was done by computer using STATA to make sure the randomization was conducted blindly without any influence of BRAC AFSP officials.

15 The treatment villages were also divided equally into different categories to incentivize (or not) farmers to refer future trainees. For more details on the referrals experiment, see Fafchamps et al. (2020a, b), which focus on peer-topeer dissemination in networks, not the agronomic or economic outcomes of the SRI training RCT.

${ }^{16}$ In addition, the farmers were given lunch, refreshments and snacks for the day. All farmers who attended the training were also given a certificate from the BRAC in recognition of their participation in the training.

${ }^{17}$ These scientists previously worked at the Bangladesh Rice Research Institute (BRRI), whose experience with SRI is documented in Latif et al. (2005).
} 
The third stage randomization occurred in the second year, generating experimental variation in the (intertemporal) intensity of exposure among treated farmers and villages. In 2015/16 (year 2) AFSP repeated the training only in half (60) of the treatment villages, selected randomly from the 120 year 1 treatment villages, inviting all (and only) the farmers who were offered training in year 1. Year 2 training consisted of two one day sessions. In the first session, case studies on successful adoption from first year of intervention were discussed. The session also included discussion with local farmers about the training in year 1 and rice cultivation practices as well as constraints that affected their decision to adopt (or not adopt) SRI in year 1. In the $2^{\text {nd }}$ session, AFSP trainers provided the exact same training as in year 1, and tried to ensure farmers clearly understood the key principles and practices of SRI. In the remaining 60 villages treated in year 1, there were no follow up training or information sessions. No training or information about SRI was provided in the control villages in either year.

The experimental design involves randomization of villages into treatment and control, and then of farmers into treated and untreated within treatment villages, coupled with randomized saturation within treated villages, and randomized repetition of training for a second year. This enables us to estimate the causal effects of SRI training (the experimental treatment) on SRI uptake and disadoption rates as a function of the cross-sectional and intertemporal intensity of treatment. This design also permits us to estimate the spillover effects of SRI training on untreated (i.e., within-village control) farmers within treatment villages, again as a function of cross-sectional and intertemporal intensity of treatment. Because we find that SRI training sharply increases the likelihood of adoption and decreases the likelihood of disadoption (as we discuss below), precisely as one would expect, and that there are spillover effects on uptake by untreated farmers in treatment villages, we can then use the randomized intensity of exposure as an instrument to estimate the local average treatment effects (LATE) of SRI uptake on rice productivity, costs of production, profitability and broader indicators of household well-being.

We label the farmers that received training in both years 1 and 2 as T2 (for two rounds of training), and their villages as V2. The farmers that received training in the remaining 60 treatment villages in year 1 only we label T1 (for one round of training) and their villages V1. The surveyed farmers who were not selected for SRI training but reside in the V2 villages we label U2 (for untreated in two training rounds villages), with U1 the analogous group of untreated farmers in the V1 villages where SRI training occurred only in year one. The control village farmers are denoted C. Comparisons among these five randomly assigned groups enables causal inference.

This two-dimensional (cross-sectional and intertemporal) randomization of intensity of treatment appears uncommon. Randomization in cross-sectional treatment intensity (i.e., within 
the village) generates exogenous variation in how many members of one's social network get SRI training, which may enhance learning from others, social acceptability, awareness of SRI, etc. In the time series dimension, the randomized intensity of training manufactures exogenous variation over time in sustained exposure that creates opportunities to learn through formal training and discussion with experts, sustained exposure to a message, a useful reminder, etc.

Appendix Table A1 reports sample sizes in the two years of intervention. Most of the invited farmers who were present in the villages on the training day attended the training. Only 4 farmers in year 1 refused to participate in the training while 3 farmers in year 2 did not attend the training. Thus, overall, we do not have a compliance issue with take-up or participation in the training program. ${ }^{18}$ There is some attrition in the sample over time, which we discuss below.

Before beginning any SRI training, we conducted a baseline survey among all control and treatment households. Then, following each year's training, after each seedling transplant period but still during the growing season, we conducted a short survey to observe adherence to SRI practices and principles. SRI adoption was determined on the basis of plot visits by RED enumerators who were also supported by AFSP field workers, who verified visually whether the farmer adopted SRI techniques on any of his ${ }^{19}$ cultivable rice plots during the Boro season. A farmer is considered an SRI adopter if the BRAC field officer observed that the farmer practiced at least three of the six key SRI practices on at least one plot of land. Note that we use the midseason verified observations of SRI practice, not farmer self-reports, when studying SRI adoption and disadoption. As a robustness check, we also use several other definitions of adoption, but find no qualitative differences among measures. ${ }^{20}$

Following each year's harvest, RED conducted a thorough survey to capture further details on rice inputs and output, including various measures of well-being that we discuss below. The outcome measures we study - other than SRI adoption or disadoption - come from the post-season surveys. ${ }^{21}$ Therefore, besides the baseline survey data and the mid-season checks on SRI uptake,

\footnotetext{
${ }^{18}$ BRAC's prior and ongoing presence in the study villages is both an advantage and a prospective source of bias. Because BRAC had previously worked extensively with these communities, albeit not on SRI, they were (and remain) a trusted partner. This enabled implementation of this study with very high rates of compliance, leading to the clean results reported in the appendix balance and attrition checks. On the other hand, an implementing organization's prior relationships with study subjects can causally increase the estimated impact of an intervention (Usmani et al. 2018). Trust in BRAC might introduce an upward bias in uptake rates, relative to diffusion from a random source, if farmers place greater weight on information from BRAC than from other agencies. Likewise, upwardly biased ITT estimates could arise if farmers (mistakenly) perceive any quid pro quo, that if BRAC is promoting SRI a farmer had better try it or risk losing out on other services BRAC provides. Note, however, that if anything, that would downwardly bias LATE estimates of the causal impact of SRI on rice or household outcomes.

${ }^{19}$ We use male pronouns because all of our sample farmer respondents were male.

${ }^{20}$ In particular, we also use farmers' self-assessed SRI adoption, as reported in the post-harvest survey, enumerators' evaluation of the extent of SRI adoption on a scale of 0 to 100 , and the percentage of cultivated rice land under SRI. None of these alternate measures meaningfully change any of our results.

${ }^{21}$ RED made multiple post-transplanting visits to check on different SRI principles that need verification at different
} 
we have household survey data for two more post-harvest rounds, one at the end of year 1 harvest (midline) and one at the end of year 2 harvest (endline).

The appendix provides evidence that the randomization was successful in both years (Tables A2, A3, and A4). Indeed, as shown in Figure 1, not only was there no mean difference between control and the four (i.e., T1, T2, U1, U2) treatment groups in rice yields at baseline, the distributions were effectively indistinguishable, with no stochastic dominance of any order among the RCT arms. Appendix Tables A5 and A6 also indicate attrition is not a significant concern.

\section{Empirical Strategy}

\subsection{ITT and LATE estimates}

We use random selection into one of the four non-control group categories as dummy variables (T1, T2, U1, U2) to estimate intent to treat (ITT) effects of SRI training. The randomized saturation design also enables us to exploit the continuous variation in treatment intensity to estimate treatment effects as a function of intensity of exposure, in cross-section, time series, or both.

Our main rice-specific outcomes of interests are SRI adoption, and yields, costs of production, revenue, and profits, defined as the difference between revenue and costs. SRI is arguably more labor intensive, and observational studies frequently suggest that SRI farmers might engage more family labor in rice cultivation (Moser and Barrett 2006). Since labor valuation is problematic in settings where most labor is not hired, we consider costs with and without family labor so as to ensure that findings are not distorted by unobserved heterogeneity in shadow wages.

We first estimate the ITT effects of SRI training exposure. Let $T_{i 1}=1$ if a farmer $i$ is trained and lives in village $j$ that was treated only in year 1 (V1 village), $T_{i 2}=1$ if the farmer is trained and lives in a village treated in both years (V2 village), $U_{i 1}=1$ if the farmer lives in a V1 village and was not trained, and $U_{i 2}=1$ if he lives in a V2 village and was not treated; all variables take value zero otherwise. These groups are mutually exclusive by design. To estimate the ITT effect of offering SRI training we run the following analysis of covariance (ANCOVA) estimation ${ }^{22}$ :

$$
Y_{i j, p o s t}=\alpha_{1}+\delta_{1} Y_{i j, b a s e}+\beta_{11} U_{i 1}+\beta_{12} T_{i 1}+\beta_{13} U_{i 2}+\beta_{14} T_{i 2}+\Pi_{1} X_{i j}+\varepsilon_{i j}
$$

$Y_{i j, p o s t}$ is the endline outcome of interest (e.g., SRI adoption, rice yields, cost, profits, etc.) for farmer $i$ in village $j$ at the end of year $2 ; Y_{i j, b a s e}$ is the pre-intervention (baseline) level outcome; $X_{i j}$ includes control variables such as age, education of farmer, land size, household composition,

\footnotetext{
times within season. The adoption (disadoption) sample size therefore differs from post-harvest survey.

22 ANCOVA estimation has more power than more conventional difference-in-differences estimation, especially for outcomes with relatively low autocorrelation (McKenzie 2012). Autocorrelation estimates vary from -0.08 to 0.22 for our outcome measures, with the lone exception of midline-to-endline adoption (0.55), where the baseline-to-midline autocorrelation is necessarily zero since there was no SRI cultivation at baseline.
} 
and income (an imperfect proxy for liquidity constraints and risk preferences). In this and all subsequent regression equations, we assume the error term, $\varepsilon$, has the usual properties, we cluster standard errors at the village level at which we sampled, and adjust for sampling weights. We also adjust for multiple hypothesis testing using both randomization inference (Young 2019) and permutations-based familywise error rate (Westfall and Young 1993).

For rice-focused outcome variables - SRI adoption, yields, costs, profits - we use plotspecific observations. We omit the plot subscripts from equation (1) because for household wellbeing indicators we use household-specific observations. The parameters $\beta_{12}$ and $\beta_{14}$ estimate the two year (i.e., endline) ITT effects of directly receiving SRI training once (T1) and twice (T2), respectively, whereas the $\beta_{11}$ and $\beta_{13}$ parameters are the ITT estimates of the spillover effects of living in one-time and two-time training villages, respectively. ${ }^{23}$ The omitted category is control villages in which SRI training was not available in either round, for which $U_{i 1}=U_{i 2}=T_{i 1}=T_{i 2}=0$.

Equation (1) also allows us to test if there is any incremental effect of receiving an additional year of training by comparing the ITT estimates between $\mathrm{T}_{1}$ and $\mathrm{T}_{2}$ farmers, i.e., testing the null hypothesis that $\beta_{14}=\beta_{12}$ versus the alternate hypothesis. We can likewise investigate whether repeated training induces faster diffusion or improved spillover outcomes than one-time training by comparing $\mathrm{U}_{1}$ with $\mathrm{U}_{2}$ farmers, i.e., testing the null hypothesis that $\beta_{13}=\beta_{11}$ versus the alternate hypothesis.

We also estimate equation (1) adding as an additional explanatory variable the intensity of treatment, represented by the fraction of farmers treated in the village. Figure A2 shows the number of farmers treated across treatment villages. We define the village treatment intensity $\left(T_{i j}\right)$ for a farmer $i$ living in village $j$ as the share of the village sample treated:

$$
T_{i, j}^{\text {treated }} \equiv \frac{N_{i, j}^{\text {treated }}}{N_{i, j}^{\text {treated }}+N_{i, j}^{\text {untreated }}}
$$

where $N_{i, j}^{\text {treated }}$ refers to the number of treated sample farmers, and $N_{i, j}^{\text {untreated }}$ refers to the number of untreated sample farmers in village $j$. Then the continuous treatment intensity variables are simply the product of the village-level treatment intensity and the individual group assignment, e.g., $T 2 F_{i j} \equiv T_{i, j}^{\text {treated }} * T_{i 2}$, where we use the $\mathrm{F}$ suffix to indicate the continuous fraction of sample farmers trained in the village. Controlling for treatment status, the coefficient estimate on the continuous measure reflects the impact of moving from no to complete within-village saturation. $^{24}$

\footnotetext{
${ }^{23}$ Because more than $99 \%$ of those randomly selected for training attended the training, the effects of treatment on the treated (TOT) are effectively the same as the ITT effects, so we ignore the TOT effects here.

${ }^{24}$ If we instead use estimates of village population - which is less precisely measured, thereby introducing measurement error into the exogenous intensity variable - we get qualitatively identical results.
} 
The crucial questions in the ongoing SRI debate concern its impacts on various farmer productivity and well-being measures. For both practical and ethical reasons, we cannot randomize farmers into SRI use. The object of randomization was a standardized training intended to induce SRI uptake. In order to determine the causal impacts of SRI from an experiment that could not randomize SRI use directly, we use the randomized treatment intensity as an instrument for SRI use to estimate the Local Average Treatment Effect (LATE) of SRI via the following regression:

$$
Y_{i j, p o s t}=\alpha_{2}+\delta_{2} Y_{i j, b a s e}+\beta_{2} \text { Adoptlo }{ }_{\imath \jmath}+\Pi_{2} X_{i j}+\vartheta_{i j}
$$

where, Adoption $=1$ if farmer $i$ in village $j$ adopted SRI in year 2 (endline). The first-stage is just equation (1) with SRI adoption as the dependent variable. Equation (3) would be our preferred specification for estimating the impact of SRI adoption if we could confirm that randomized exposure to SRI training affects outcomes only through SRI adoption, i.e., that the randomized training exposure serves as an excludable instrument for SRI adoption. We find no significant general equilibrium effects of SRI training on village-level rice prices or wage rates that would generate an alternative mechanism for training to impact outcomes independent of SRI uptake. While $\beta_{2}$ provides a valid estimate of the LATE of randomized exposure to SRI training that operates through the SRI adoption pathway, our results suggest that the unconfoundness assumption may not hold to support interpretation of the LATE as consistent, unbiased estimates of the impacts of SRI adoption itself on these various outcomes. So we favor the ITT estimates from equation (1) as our most reliable causal estimates, along with the LATE estimates from equation (3), noting the important nuance of how to interpret the latter results.

Note that a farmer could cultivate rice in more than one plot of land. He might have selected a particular plot suitable for SRI. The SRI plot could well differ from non-SRI plots along multiple unobservable dimensions. ${ }^{25} \mathrm{We}$ address this issue by including pre-intervention level plotspecific yield, cost, and profit in the regression as, for example, higher quality of land of a given size should have a higher yield in the absence of SRI.

Because we observe multiple plots per household, ${ }^{26}$ in discussing farmer adaptation of SRI principles over time and in robustness checks we also use a difference-in-differences (DiD) estimator to control for unobservables, time invariant plot characteristics. More precisely, we

\footnotetext{
${ }^{25}$ Barrett et al. (2004) found that farmer and plot characteristics account for more than half of the observed yield difference between SRI and traditional rice plots in Madagascar.

${ }^{26}$ We obtained information for at most three plots of cultivable land. If a farmer cultivated more plots, we randomly picked three plots on which to collect the information. $65.7 \%$ of farmers have 3 plots in the sample, $21.1 \%$ have 2 plots, and 13.2\% have just 1 plot. We collected adoption, yield, input cost, and revenue data for the same plot(s) of land from each farmer in all three rounds. Plots were visited with farmers to verify SRI uptake and the correspondence of the plot to the prior round of data.
} 
estimate a plot-level panel regression using all three waves of data (i.e., baseline, midline, endline):

$$
Y_{i p j t}=\alpha+\sum_{t=1}^{2} \sum_{j=1}^{2} \partial_{j t} U_{i j t}+\sum_{t=1}^{2} \sum_{j=1}^{2} \gamma_{j t} T_{i j t}+\sum_{t=1}^{2} \pi_{t}+\vartheta_{i p j}+e_{i p j t}
$$

where $Y_{i p j t}$ represents an outcome variable of interest from farmer $i$ cultivating plot $p$ in village type $j$ at time $t$, where time period refers to 2014 baseline $(t=0), 2015$ midline $(\mathrm{t}=1)$ and 2016 endline (t=2). $U_{i j t}=1$ for untrained farmers in village type $j=1$ (one year of training) or $j=2$ (two years of training) post-baseline (i.e., $t \in\{1,2\}$ ); $T_{i j t}=1$ for trained farmers in village type $j=1$ (one year of training) or $j=2$ (two years of training) post-baseline; $\pi_{t}$ is a period fixed effect common to all farmers - capturing, for example, annual average prices and growing conditions - and $\vartheta_{i p j}$ is a plot fixed effect. Now the indicator variables reflect both the treatment arm to which a farmer - and thus his plot - was assigned (the first two characters, per our earlier notation) with the survey round appended as a third, numeric character. For example, U11 and U12 indicate an untrained farmer in a single treatment village at midline and endline, respectively. ${ }^{27}$

In regressions estimating equation (4), $\partial_{j t}$ is the ITT estimate of the impact of the SRI training on the outcome variable for the untrained farmers indirectly exposed to SRI in training villages of type $j$ in period $t$, while $\gamma_{j t}$ is the ITT estimate of the impact of direct SRI training on the outcome variable for farmers randomly selected into SRI training. These estimates compare changes in outcomes among trained and untrained farmers residing in training villages post-SRI training, relative to changes among farmers in control villages, while controlling for average period-on-period changes. This method has the advantage of controlling for unobserved, time invariant (household and) plot level heterogeneity (e.g., in drainage, slope, soil type, distance from the home, farmer skill) that may impact productivity, costs, etc. But time-varying, plot-specific factors such as water availability, pest or disease pressure, etc. heavily influence productivity and such time-varying unobservables get amplified in the plot-level analysis (Sherlund et al. 2002). In addition, using plots as the unit of observation when households were sampled reweights the sample by the number of rice plots a sample farmer cultivates, and since the decision of how many plots to cultivate in rice could be endogenous to SRI training, this may introduce subtle selection bias into the plot-level model. We therefore focus on the ITT and LATE estimates at the household level, and treat the estimates of equation (4) as robustness checks.

The other benefit of this estimation strategy is that it disaggregates the effects between midline - the impact of initial exposure - and endline - so as to better capture the impact of

\footnotetext{
${ }^{27}$ We also estimate equation (4) using continuous treatment intensities in addition to the treatment dummies.
} 
sustained exposure to SRI, through additional direct training to T2 farmers, or through additional indirect exposure via trainees and adopters in both V1 and V2 villages. The $\partial_{12}$ and $\gamma_{12}$ parameters reflect learning-by-doing and learning-from-others effects entirely within the village, without any further BRAC training in the $j=1$ villages. By contrast, the $\partial_{22}$ and $\gamma_{22}$ parameter estimates will include those same intra-village learning effects as well as any marginal benefits from the second year of BRAC training in the V2 villages.

\subsection{Disadoption and delayed adoption}

Our research design also allows us to study disadoption - SRI uptake in year 1 that is discontinued in year 2 - and persistent adoption - i.e., farmers who practiced SRI in both years 1 and 2. We can also identify farmers who adopted SRI only in year 2 - delayed adopters - and see how they differ from disadopters and persistent adopters. Foster and Rosenzweig (1995) point to the strategic gains from delayed adoption if one can observe neighbors' experimentation with a new technology. If learning from others is cheaper than learning by doing, then farmers with less capacity or willingness to experiment (e.g., lower education, less financial liquidity, smaller farm size, etc.) may be more likely to delay adoption. Because adoption is endogenous to various farmer-level unobservables, we cannot make causal inferences around disadoption, persistent adoption, and delayed adoption, but we can examine the correlates associated with each cohort.

We study persistent adoption, disadoption, and delayed adoption using the multinomial logit regression model:

$$
\left(Y_{i j}\right)=\alpha_{4}+\delta_{4} \text { Yield }_{i j, \text { base }}+\beta_{4} \operatorname{Cost}_{i j, \text { base }}+\theta_{11} U_{i 1}+\theta_{12} T_{i 1}+\theta_{13} U_{i 2}+\theta_{14} T_{i 2}+\Pi_{4} X_{i j}+\mu_{i j}
$$

where $Y_{i j}$ is a dummy variable indicating the status of adoption of farmer $i$ in village $j$ at the end of year 2: persistent adopter, delayed adopter or disadopter. The omitted base category is neveradopters. The polychotomous options are mapped by the multinomial predictor function $\mathrm{f}(\cdot)$ onto the explanatory variables. The $X_{i j}$ vector includes the household head's age, education, income, and farm size. Yield ${ }_{i j, b a s e}$ reflects baseline productivity, Cost $_{i j, b a s e}$ is baseline cost, since a farmer's propensity to continue to practice SRI, or to delay adoption, should depend on his initial conditions. ${ }^{28,29}$ We also separately run a logit regression model comparing only disadopters with persistent adopters, i.e., looking just at the (non-random) sub-sample of midline adopters. This

\footnotetext{
${ }^{28}$ Note that we omit control villages from this regression as there was no SRI adoption in control villages.

${ }^{29}$ We repeated the same analysis using the continuous treatment intensity measures in equation (4) with no qualitative change in results, which are available by request.
} 
helps identify the correlates of those who abandon the practice while their neighbors continue. These regressions all rely on a strong independence of irrelevant alternatives assumption, thus we emphasize the parameter estimates concerning disadoption and delayed adoption reflect only correlations not causal estimates.

\section{Results}

\subsection{Summary Statistics}

Table 1 presents midline and endline summary statistics for each treatment arm. As seen in panel A, SRI training caused statistically significant SRI adoption. Uptake rates at midline were almost identical among T1 and T2 farmers, at 49.7 and 49.2 percent, respectively, as compared to a true zero among the control village farmers. But SRI adoption then fell among T1 farmers by endline, to 38.1 percent due to disadoption (on which, more below), while adoption among T2 farmers increased further, to 53.0 percent. The endline difference between the two groups is statistically significant $(p=0.00)$ although the midline adoption rates, when there was no difference between the two arms, are not significantly different.

The same pattern holds between the U1 and U2 treatment groups, the training village farmers who were not themselves trained. Statistically significant spillover occurred among untrained farmers, as compared to control village farmers, with 7-8 percent SRI uptake at midline among U1 and U2 households. After a second year of training in V2 villages, U2 households exhibited higher SRI adoption (12.38\%) as compared to U1 $(8.80 \%)(p=0.000)$. Overall, trained T2 farmers adopted SRI on about $26 \%$ of the land in V2 villages in year 2 as compared to $21 \%$ for T1 farmers in V1 villages (panel B). Thus, even adopters experiment with SRI, not fully adopting it on all plots. ${ }^{30}$ A qualitatively identical story emerges if we use the other adoption measures.

The extent to which farmers adhere to the SRI principles as taught varies by treatment exposure and intensity, but is generally low. Table 1 Panel B shows a larger percentage of (T1 and T2) farmers exposed to the SRI training followed each of the six rules of SRI cultivation than untrained (UI and U2) farmers. Perhaps most strikingly, there was negligible increase in adherence to practices from midline to endline by farmers in V1 villages, except for U1 farmers' use of organic fertilizer and T1 farmers' space of seedlings and mechanical weeding. This suggests limited adaptation through learning by doing or learning from other farmers' initial experiences with SRI beyond the initial adoption decision. In V2 villages, increase in compliance from midline to endline was consistently stronger after a second year of training, among both U2 and T2 farmers.

\footnotetext{
${ }^{30}$ At endline, only $6.8 \%$ of T2 farmers and $3.5 \%$ of T1 farmers adopted SRI on all of their rice land.
} 
A key takeaway is that the vast majority of farmers who adopt SRI practice it on only part of their rice land, they only partially adhere to the principles as taught, and they scarcely update their practices following their initial experience unless further training occurs. The robust response at the extensive margin to SRI training - adoption and a significant shift in rice cultivation practices - contrasts with the modest response at the intensive margin.

Table 1 Panel C reports summary statistics on rice yields, revenues, cost and profits, all of which are significantly higher among both trained and untrained farmers in the treatment villages than in the control villages. The simple descriptive statistics suggest significant productivity and profitability impacts of exposure to SRI training, although the differences among treatment groups are rarely statistically significant. This suggests that the main impact of SRI training exposure occurs at the extensive margin, by inducing adoption, more than by impacting performance at the intensive margin through the enhanced learning opportunities that come from greater exposure. We return to this issue, and its implications for learning models, later in the paper.

\subsection{Estimated Effects}

\section{SRI Adoption}

Table 2 (Panel A) column $1^{31}$ reports the ITT estimates of SRI training at endline. SRI training appears quite effective at inducing adoption, as T1 and T2 farmers are 39 and 53 percent, respectively, more likely to practice SRI two years after baseline than were farmers in control villages. Under the defensible assumption that participation in SRI training represents more intense exposure to the method than non-participation does, exposure intensity clearly matters to uptake. Training is the main mechanism for diffusing the method as the differences between the treated and untreated farmers within villages (T1 vs. U1 and T2 vs. U2) are quite large - 30-40 percentage points - and highly statistically significant. Repetition of SRI training had a positive effect on uptake as well - a statistically significant 14 percentage point difference in adoption between $\mathrm{T} 1$ and $\mathrm{T} 2$ farmers.

There is also statistically significant spillover of SRI training to untrained farmers in the treatment villages, 9-12 percent among U1 and U2 farmers. The added year of training had no significant impact on the diffusion of SRI beyond the trained farmer cohort.

Recall that the training sessions were only one day long, the method is relatively complex, and farmers had no prior exposure to SRI. Considering this, the estimated adoption impacts of SRI

\footnotetext{
${ }^{31}$ For reasons already explained, the post-harvest survey used for outcomes other than adoption included fewer rice plots than did the post-transplanting survey used to determine SRI adoption. Column 1' reports the analog to column 1 , but restricted to just the observations used for the other outcome variables. No significant differences exist between the results. So, we focus our discussion on the larger sample reported in column 1.
} 
training appear quite strong and sharply increasing with intensity of training exposure, both from zero exposure to one training session and from one annual training to two years of training, as well as between directly trained farmers and their neighbors who may pick up the practice informally through observation or discussion.

The same pattern holds when we supplement the binary treatment variable with the continuous measure of village-specific treatment intensity, exploiting our randomized saturation experimental design. ${ }^{32}$ Appendix Table A7 presents the ITT estimates adding in the continuous treatment measure so as to test for saturation effects. The ITT estimates of training treatments are now the sum of the coefficient estimate on the dummy variable for that treatment arm, as in Table 2, plus the coefficient estimate on the continuous measure multiplied by the treatment intensity (in the $[0,1]$ interval). The training saturation rate has a positive but insignificant effect on uptake in the V1 villages - and, if anything, an insignificantly negative impact on performance (yield, revenue, cost or profit) measures. ${ }^{33}$ The sample training saturation rate has a very strongly positive impact on SRI adoption in V2 villages, however, among both the T2 and U2 households, although it again has no significant effect on performance with SRI. Training intensity in cross-section and over time appear complements, reinforcing each other in inducing uptake.

Figure 2 offers a nonparametric look at the impact of treatment intensity on SRI adoption. Adoption impacts appear invariant up to or slightly beyond the sample mean/median of 0.60 , after which point the slope of the relationship increases sharply and roughly linearly. We take account of this nonlinearity by adding a dummy variable indicating if treatment intensity is above 0.70 , roughly the $60^{\text {th }}$ percentile of the distribution. The results, presented in Table 3 , indicate that high saturation rates boost uptake effects dramatically and significantly in the case of $\mathrm{T} 1$ farmers those trained only one year - and among the U2 cohort, those farmers who were not trained directly but who live in villages where training occurred in both years. T2 farmers' adoption propensity also increases sharply but is imprecisely estimated. ${ }^{34}$ This reinforces the evidence of strong synergistic effect of cross-sectional and intertemporal intensity of exposure on uptake of innovations. Assuming diminishing marginal returns to learning, uptake would typically be a concave function in training saturation if the effect worked solely through social learning. The observed convex relationship between training saturation and SRI uptake appears more likely due to social conformity effects, consistent with prior findings from Madagascar (Moser and Barrett

\footnotetext{
32 Treatment intensity is necessarily zero for all farmers in control villages.

${ }^{33}$ Multicollinearity exists between the dummy and continuous intensity variables. All dummy-intensity pairs are jointly highly significant. We get qualitatively identical results using midline data (Tables A8 and A9).

${ }^{34}$ When we repeat this analysis with a 0.60 cut-off in treatment intensity we find broadly similar, but weaker results, which is consistent with Figure 2 as the kink occurs between treatment intensity of 0.65-0.70 (Table A10).
} 


\section{ITT Impacts on Rice Yields, Costs and Profits}

The ITT estimates also show statistically significant and agronomically and economically meaningful impacts on rice yields (14-17 percent), revenues (17-18 percent), and input costs (per decimal of land, 13-16 percent), resulting in profits ${ }^{35}$ that are 21-34 percent higher relative to farmers in the control villages, noting that rice was profitable at baseline (Table 2). Remarkably, no statistically significant differences exist between any of the four treatment arms, despite variation in impact on SRI adoption. This result holds when we control for exogenous variation in training saturation rates, even allowing for the nonlinear effect observed with above-median crosssectional training intensity (Table 3). Although intensity of SRI training exposure has a big, statistically significant effect on the likelihood of SRI adoption, it has no differential ITT impact at the intensive margin on performance-related outcomes - e.g., yields, profits - across treatment arms, only at the extensive margin of any (direct or indirect) exposure versus pure control households. We come back to this important finding below.

Since SRI training exposure increases the costs of rice cultivation, we next explore precisely which costs increase. Recall that SRI principles call for increased use of organic soil amendments and mechanical weeders, and more frequent wetting and drying of plots - which requires increased operation of pumps to flood or drain fields - and that earlier seedling transplanting, more regular and careful water management, the possibility of more robust weed growth on unflooded fields, and increased harvests may increase labor demands, especially for the household managers of the SRI plot(s). We would therefore expect increased costs to be concentrated in those domains. Conversely, we might expect reduced herbicide and pesticide expenses due to mechanical weeding and better water management practices.

The data exhibit precisely those patterns. As shown in Table 4, the ITT estimates (panel A) of the impact of SRI training exposure and the LATE estimates (panel B) clearly signal sizable and significant increases in family labor, irrigation and organic fertilizer costs and sharply reduced pesticide costs, especially among the T2 farmers most intensively trained on SRI. Other than for

\footnotetext{
${ }^{35}$ We value unpaid household labor at village mode wage rates, but the results are qualitatively identical when valued at mean or median wage rates. At midline, wage data were collected for each individual worker in a sample household, by different types of work, including nursery bed preparation/seeding/seed treatment; land preparation; transplanting/sowing; irrigation/watering; weeding; applying fertilizer/pesticide; harvesting; and post-harvest threshing. Because the differences by task were minimal, at endline, wage data were collected only for two categories: the pre- and harvest/post-harvest periods. Imputed wages for unpaid family labor during were calculated based on the modal hired wage in the district for each type of work. The average imputed wage for midline was 301.48BDT/day and for endline was 313.27BDT/day.
} 
pesticide costs, however, these effects are not statistically significantly different among the distinct treatment cohorts.

Cumulatively, the findings reported in Tables 2-4 tell a clear story that SRI adoption increases significantly with the intensity of training exposure, whether measured as trained vs. untrained, trained twice versus trained once, by village treatment intensity, or even indirect exposure in a training village versus no exposure in a control village, and that SRI training has a large, positive impact on productivity and profitability indicators, even while driving up costs of production. Our core results all hold as well in panel regression estimates using the plot level difference-in-differences specification reflected in equation (4), both using the binary and continuous treatment intensity indicators (Tables A11 and A12). These experimental findings confirm the mass of observational findings of gains from SRI uptake around the world.

\section{SRI Impacts on Household Well-Being}

Previous observational studies found that rice productivity or profitability gains associated with SRI adoption do not translate into improved household well-being. This seems to result from reallocation of farm household labor from nonfarm activities to SRI rice cultivation, such that the loss of non-farm income largely offsets the gains from increased rice productivity (Noltze et al. 2013; Takahashi and Barrett 2014). ${ }^{36}$ Our findings differ.

Table 5 reports the ITT (Panel A) and LATE (Panel B) estimates of SRI training exposure on self-reported measures of savings, social status (relative to others in the village), food security and life satisfaction. ${ }^{37}$ Because the latter three variables are scored on five to ten point Likert scales, we report ordered probit marginal effects estimates. All the ITT point estimates are positive and mostly (but not all) statistically significant for treated households, as compared to control village households. But the expected gains are again not significantly different among the T1, T2, $\mathrm{U} 1$ and $\mathrm{U} 2$ farmers. So the well-being gains from SRI occur at the extensive margin of training exposure and do not significantly vary at the intensive margin based on exposure intensity.

\section{LATE Estimates and General Equilibrium Effects}

Because we randomized SRI training, not SRI adoption, and less than half of trained farmers adopted SRI, the ITT estimates of the impacts of training necessarily underestimate the impacts of SRI adoption on the various outcome measures. Panel B of Tables 2 and 5 present the

\footnotetext{
${ }^{36}$ In another observational and simulation study, Gathorne-Hardy et al. (2016) find that the gains that accrue to SRI farming households come at the expense of landless workers.

${ }^{37}$ See the notes at the bottom of Table 5 for details on the construction of these variables.
} 
LATE estimates of SRI training exposure. The first-stage uses treatment dummies as instruments for SRI adoption (per column 1' of Table 2, Panel A). We observe large and highly statistically significant estimated gains in rice yields ( 24 percent), revenues, costs, and especially profits (47 percent), as well as on household welfare indicators (Panel B, Table 5). Those point estimates fall well within the range reported in the observational SRI literature summarized earlier. These are considerable yield and profit gains, especially from training on an innovation that requires no purchased inputs. ${ }^{38}$ Although SRI induces increased demand for family labor (Table 4), the gains from SRI are not offset through reallocation of family labor into rice production.

Interpretation of the LATE estimates as the causal impact of SRI adoption depends, however, on the exclusion restriction on the instrument, the randomized intensity of exposure to SRI training. A coarse way to explore the (untestable) exclusion restriction is to add interaction terms between each treatment arm and an indicator variable for (endogenous) SRI adoption to the Table 2 ITT specification. If the impact of SRI training on outcomes runs solely through SRI uptake, then the coefficient estimates on the uninteracted treatment indicator variables should go to zero and become statistically insignificant, especially given their multicollinearity with the interacted variables, as there should be no conditionally independent effect of SRI training exposure on the outcomes of those farmers who (endogenously) chose not to adopt SRI. Table A13 shows that, on the contrary, the coefficient estimates on the uninteracted terms change insignificantly from the Table 2 estimates and retain their statistical significance, while the interacted terms suggest negligible, if any, added impacts from SRI adoption. For this reason, we favor the ITT estimates as conservative, but unbiased and consistent estimates of the impacts of SRI training on agronomic and economic outcomes and emphasize understanding the LATE estimates as relating to SRI training exposure, as distinct from SRI uptake. The ITT estimates are of greater interest as the policy relevant parameters, as BRAC or another agency can only promote uptake through training (or other) interventions; it cannot directly mandate technology adoption.

The apparent violation of the exclusion restriction is puzzling. General equilibrium effects on local factor and product market prices offer the most obvious candidate reason why SRI training might be associated with rice yields and profits other than through SRI uptake. Indeed, given the significant impacts SRI training had on rice output, labor demand, profits and household wellbeing, it could plausibly affect local rice or labor market equilibria. If added demand for labor drives higher wage rates, or if increased rice supply manifests in lower rice prices, then the gains from SRI promotion might diffuse far more broadly, beyond just rice farmers, as was true of earlier

\footnotetext{
${ }^{38}$ We get statistically significant positive results on all outcomes when we perform the same analysis using midline data but using endline treatment status (Tables A8 and A9).
} 
Green Revolution technologies (David and Otsuka 1994; Evenson and Gollin 2003). Those effects would also attenuate the estimated profit gains to SRI adopters, as reported in Tables 2-5.

Therefore, following Burke et al. (2019), we look across the treatment intensity continuum to identify prospective general equilibrium effects on local factor and product markets. Table 6 reports the ITT estimates of the impact of SRI training intensity on village-level wage rates computed as the average of activity-specific village modal wage rates for land preparation, transplanting, weeding, and harvesting labor - and rice prices - computed as the average price for each of several rice varieties available in village markets. At the median training saturation rate of 60 percent of the sample, SRI training has no economically or statistically significant effect on either rice prices or wage rates, an imprecisely estimated -4.3 and -3.0 percent, respectively, relative to control villages. The negative point estimate on the wage effect runs counter to what one would expect given the manifest increase in labor demand sparked by SRI training, reinforcing our interpretation of the labor market effects as effectively zero. The -1.09 BDT point estimate on village rice prices is only significant at the ten percent level and if the effect is truly negative, then our ITT and LATE estimates of the profit effects - and the wellbeing effects for the (majority) net rice seller farmers - are conservative, underestimates. Given considerable labor mobility and rice market integration in densely populated rural Bangladesh, the lack of any meangingful factor or product market price effects is intuitive. But these findings leave the apparent violation of the LATE exclusion restriction as an unanswered (for now) puzzle, as we cannot identify a mechanism through which SRI training should have affected outcomes other than through SRI adoption; yet it seems to have done so.

\subsection{Insights from Non-random Selection into SRI Uptake}

The lack of statistically significant ITT differences among treatment groups in productivity, profitability or well-being outcomes despite statistically significant differences in SRI adoption nicely illustrates non-random selection into SRI adoption conditional on training exposure. If the information conveyed by training exposure induces selection both into and out of SRI uptake, however, the selection process could help resolve the apparent violation of the exclusion restriction essential to unbiased and consistent LATE estimates. If training exposure conveys information to farmers, thereby improving performance regardless of whether they choose to practice SRI, that would reconcile these seemingly-puzzling results. We cannot directly test that hypothesis. But we can establish that farmers within the same treatment arm seem to optimally select into SRI uptake, based on outcome realizations, consistent with this mechanism. 
Simply dividing the Table 2 ITT estimates of yield impacts by the corresponding treatmentarm-specific ITT estimate of uptake - i.e., the group-specific indirect least squares (ILS) LATE estimate of impacts - generates a clear ordering, from 148 percent expected yield gains for U1 farmers who adopt, down to 33 percent for T2 farmers. The treatment cohort-specific ILS LATE estimates correlate inversely with exposure to the method through training. This occurs because ILS LATE estimates reflect performance impacts conditional on training treatment intensity. We would expect positive assortative matching in which those farmers likely to benefit most are most likely to adopt SRI for any given level of training exposure. Differences in training exposure afford us crucial insights into the differences among the farmers most likely to adopt a new technology quickly, based on limited, indirect learning through social connections, versus those likely to take up an innovation following more substantial, direct training exposure from extension agents. Given the experiment's successful balance on observables (Tables A2-A4), the patterns we observe suggest that farmer propensity to adopt SRI conditional on treatment intensity is strongly associated with unobservables (e.g., ambition, skill, social connectivity) that complement the new technology, even controlling for baseline outcomes. And we find no significant heterogeneity in returns to SRI conditional on observables such as land and labor endowments, as shown below. ${ }^{39}$ That suggests the differences must arise from farmer (or plot) unobservables.

Given strong selection on unobservables, greater exposure induces more farmers to adopt SRI, and to thereby benefit from the method, but with diminishing marginal gains from adoption. We can understand this is as follows. Imagine farmer productivity-enhancing unobservables as summarized by a scalar variable, call it SRI-relevant ability, with a standard, unimodal distribution. Farmers at the upper end of the SRI-relevant ability distribution enjoy greater gains from any new technology than do those further down that distribution. At the same time, higher SRI-relevant ability farmers are more likely to learn and adopt the new technology at any level of training exposure. Their SRI-relevant ability makes them quicker to identify and adopt promising technologies based on limited information. It takes fewer new observations - i.e., less intense exposure to the new technology - to induce adoption by farmers who expect to benefit more.

The implication is that a light training intervention is more likely to induce uptake by high SRI-relevant ability farmers who enjoy greater expected gains conditional on adoption, while a heavier training intervention will induce greater uptake by all farmer types, in particular inducing more farmers of moderate or lesser ability to adopt, resulting in lower expected gains conditional

\footnotetext{
${ }^{39}$ The only dimension in which we observe heterogeneity of returns is with respect to pre-treatment rice yield, with the cost of production impacts appreciably lower for those with higher baseline yields, albeit again with no significant difference among treatment groups (Table A15). This seems likely to reflect farmer skill and other unobservables that confer higher expected gains from using the new technology conditional on exposure level.
} 
on adoption in the higher training intensity state. Randomization into training treatment arms means the distribution of high ability farmers should be balanced across training arms. But treatment intensity should induce proportionately greater uptake among farmers as their ability level falls. Increased training exposure thereby has a scaling effect - inducing greater adoption but not necessarily an impact effect - no higher performance conditional on treatment intensity.

Of course, the information conveyed by SRI training exposure may also be relevant to nonSRI-relevant unobservables and thereby induce rational nonadoption of SRI yet still boost the farmer's productivity. For example, SRI training emphasizes good water management practices. Exposure to SRI training likely induces farmers to reflect on their ability to manage water effectively in their rice field. Some may then adopt SRI. Others may then realize that SRI would not work for them, given the physical geography of water access (e.g., soil depth, slope, peculiarities of local irrigation systems) for their plot(s), but they nonetheless modify rice cultivation practices in some other way that boosts performance, despite not adopting SRI. The implication is that information conveyed by randomized training induces endogenous selection into technology adoption, as intended, but can also directly impact performance independently of uptake. This is a variant of the 'heterogeneous treatments' problem intrinsic to information-based RCTs, wherein the experimenter cannot actually know what the subject learns from the treatment and learning is likely heterogeneous among subjects within the same treatment arm (Barrett and Carter 2010, 2020). Such heterogeneity violates the stable unit treatment value assumption, thereby violating the exclusion restriction necessary for an unbiased LATE estimate.

The data strongly suggest exactly such endogenous selection with independent effects of training on non-adopters' performance. Figures 3 and 4 plot the ordered distribution of endline rice profits and yield, respectively, for SRI adopters within each treatment arm. The dotted horizontal line shows the control group mean. The leftmost observation - i.e., the most profitable (Figure 3) or highest yield (Figure 4) farmer - of each group-specific schedule, and all the subsequent observations within that cohort, follow a clear ordering that corresponds to the extent of SRI training exposure. ${ }^{40}$ For any rank $\mathrm{n}$ in the outcome ordering (reflected on the horizontal axis), the $\mathrm{n}^{\text {th }}$ farmer in a treatment arm exhibits higher rice profitability or yield as shown by the vertical ordering of the treatment-arm-specific outcome curves: the U1 locus lies everywhere beneath the U2 locus, which is itself everywhere beneath the T1 schedule, that is in turn strictly dominated by T2. The most productive SRI adopters who had only indirect training exposure (U1 and U2) are slightly less productive than those adopters who received direct training (i.e., at the leftmost edge

\footnotetext{
${ }^{40}$ Keep in mind that at baseline each treatment arm and the control group had statistically indistinguishable distributions (Figure 1), and thus would exhibit near-identical orderings if depicted as in Figures 3 and 4.
} 
of the figures). But the productivity difference between, for example U1 and T2 adopters, as reflected in the vertical gap between the treatment-specific curves, grows quickly as one moves down the ordering. We loosely interpret that ordering as an SRI-relevant ability ranking, although it could equally reflect other unobservables such as social connections, land quality, etc. Greater training exposure boosts the likelihood of farmer adoption, but the magnitude of induced uptake increases as farmer technology-relevant ability level falls.

The vast majority of SRI adopters outperform the control group mean. This merely reflects the gains attributable to SRI training that we established earlier. The endline differences between $\mathrm{T} 2$ and $\mathrm{U} 2$ and between $\mathrm{T} 1$ and $\mathrm{U} 1$ are large, consistent with the inference that most of the gains come from direct learning from the BRAC extension agents. The difference between the U1 and U2 farmers is negligible. Increased intensity of SRI training exposure boosts adoption by farmers who realize a given yield or profit level (i.e., treatment arm schedules move rightward in training intensity). But it does not change the average expected outcome (yield or profit or well-being) because expected impacts decrease in unobservable ability while greater training exposure probabilistically propagates diffusion further down the ability distribution.

This can also be seen in the treatment arm-specific conditional outcome distributions. As shown in Figure 1, no stochastic dominance existed at baseline among the rice yield distributions among the control group, the directly trained, and the untrained within training villages. After training, the yield distributions for all four treatment arms first order stochastically dominate the control group, at both midline and endline (Figures A3 and A4). But no (first, second or third order) stochastic dominance exists among any of the treatment arms (Figures A5 and A6). The distribution of outcomes is effectively identical, as reflected by the ITT estimates. But increased training exposure sharply expands the scale of SRI uptake, as reflected in Figures 3 and 4.

The non-random nature of selection into SRI adoption is also apparent in comparison of the yield distributions of adopters and non-adopters within each treatment arm. As depicted in Figure 5, the endline yield distribution of SRI adopters does not statistically significantly stochastically dominate (at first, second or third order) that of non-adopters within any of the treatment arms. ${ }^{41}$ The p-values for the tests of first order dominance decrease in intensity of exposure to SRI training, consistent with the prior findings that greater exposure leads to slightly greater adherence to recommended practices and thus better performance. But the fact that within each treatment arm these differences are not statistically significant indicates that farmers make reasonably rational uptake decisions based on unobservables that affect performance outcomes.

\footnotetext{
${ }^{41}$ Figure A7 shows the same for midline yield.
} 
Conditional on their unobservable-to-the-experimenter ability and the intensity of their exposure to the new method, farmers make reasonable adoption decisions such that as a treatment arm cohort, they endogenously sort into equally performing sub-groups.

\subsection{Disadoption, Delayed Adoption, and Farmer Heterogeneity}

The multi-year design of our experiment also permits us to study different adoption behaviors by farmers. More specifically, we distinguish among farmers who never practiced SRI (nonadopters), those who adopted SRI in both post-training periods (persistent adopters), those who adopted in the first year but then disadopted (disadopters), and those who only adopted in the second year (delayed adopters). Among the 2,648 treatment village farmers for whom we have both year 1 and year 2 observations, 36\% (313) of farmers who adopted SRI in year 1 disadopted in year 2 (disadopters) (Table 7). ${ }^{42}$ On its surface, this high rate of disadoption - similar to prior observations (Moser and Barrett 2006) - is puzzling given the substantial estimated gains from SRI adoption. ${ }^{43}$ Might this reflect heterogeneous marginal returns to SRI adoption?

First, we consider the impact of intensity of exposure on disadoption. As shown in Table 7 , not only is adoption higher in V2 villages, as established above, but persistent adoption is higher and disadoption lower in the villages that randomly received two years of training rather than just one. Disadoption conditional on year 1 SRI uptake was 64, 53 and 47 percent among U2, U1 and $\mathrm{T} 1$ farmers, respectively, two to three times the 22 percent disadoption rate among T2 farmers. Clearly, added exposure to SRI training induced farmers to continue with the practice after initial uptake. Social spillover effects resulting in delayed adoption were modest, with just 6 and 10 percent of U1 and U2 farmers, respectively, adopting SRI only in year 2. Having been directly trained substantially increased the likelihood of delayed adoption, as 25 percent of $\mathrm{T} 1$ farmers only adopted in year 2. Additional training did not affect the likelihood of delayed uptake; a statistically similar 30 percent of T2 farmers who did not adopt in the initial year tried it in year two. Not only did the intertemporal intensity of SRI training exposure affect SRI adoption at the end of both year 1 (Tables A8 and A9) and year 2 (Table 3), but it matters to the likelihood that initial non-adopters eventually take up the method and that initial adopters persist in the practice of SRI.

Appendix Table A14 presents the characteristics of these different groups of farmers by

\footnotetext{
42975 farmers from 120 villages adopted SRI in year 1. At the end of year 2, we collected or verified the SRI adoption status on only 869 of those farmers; 106 year 1 adopters attritted from the sample. As reported previously (Tables A5A6), attrition appears random, so should not impact our analysis.

${ }^{43}$ Duflo et al (2011) also show that in western Kenya, adoption of fertilizers among farmers receiving a one-time subsidy dropped back to the same rate as among the comparison group as soon as the subsidy stopped, suggesting that such a one-time subsidy does not lead to persistent technology adoption but only has a temporary effect.
} 
adoption/disadoption status. ${ }^{44}$ The descriptive statistics are revealing, if only indicative. Those who adopted SRI in year 1 (persistent adopters and disadopters) had larger land holdings, did better on simple memory tests ${ }^{45}$, and were slightly more risk averse ${ }^{46}$ before the intervention began as compared to those who did not adopt SRI in year 1 (delayed adopters and never adopters). The midline non-adopters - delayed adopters and never adopters - had lower baseline cost of production and higher baseline profits (including family labor) compared to persistent adopters. Although their yields and profits increased from baseline to year 1 (a good growing year), both yields and profits were now inferior among the midline non-adopters as compared to those who adopted SRI in year 1 .

Delayed adopters had lower baseline and midline yields, costs, and profits per decimal than never adopters, and they were less profitable than never adopters at midline. Delayed adopters' yields, costs, and profits surpassed those of never adopters at endline, implying that the decision to switch paid off.

The never adopters did not significantly differ from persistent adopters in terms of baseline cost of production but they had higher profits compared to the persistent adopters and delayed adopters. They were also at least as well off (in baseline income terms) as the other three groups of farmers, relatively older, less educated, but with stronger memory, and greater appetite for risk. They also had the smallest land holdings among the four groups.

The cost of production was relatively low and profits high for all groups in year 1 (midline) compared to the baseline for all groups, reflecting a good growing year. However, at the end of year 1, the persistent adopters had the same cost of production as at baseline. The disadopters had significantly higher costs of production in year 1 than delayed adopters. The midline rice profits per decimal from cultivating Boro rice were, if anything, slightly higher for disadopters than for persistent adopters. But the change in profits from baseline to midline was almost the same for persistent adopters and disadopters. It does not appear that cross-sectional heterogeneity in returns to SRI explains disadoption so much as heterogeneity in the observed changes in returns.

\footnotetext{
${ }^{44}$ When we conduct the analysis for the trained and T1 and T2 villages separately, we find similar patterns.

${ }^{45}$ We test short term memory using memory span exercise. The farmers heard ten words in a row, which they were asked to repeat immediately, and the number of words that they could repeat correctly was recorded. We then, after ten minutes, asked them to repeat the words for the second time, and again recorded the total number of correct words, using it as a measure of their short-term memory. The farmers had average memory spans of 5.4 words and 4.6 words in the immediate and ten-minute afterward tests, respectively.

46 The baseline survey included a standard lottery game (Binswanger 1980) in order to elicit individual risk preferences. In this lottery game, famers were asked to choose an option from among six options that are basically various combinations of amounts of BDT as payoffs. Option one ensures a payment of BDT 100, whereas options two to six each involve a coin toss that gives an outcome of heads or tails with a 50-50 chance. The degree of riskiness of the lottery options increases in ascending order, with option 6 being the riskiest. A farmer is considered as risktakers if he chooses option 6 , otherwise he is risk-averse. Overall, 69\% of the farmers in our sample are risk averse.
} 
Disadoption (or delayed adoption) could arise from unobserved shocks to farmers' conditions (e.g., to family labor availability or external employment options). Our qualitative observation, however, is that this reflects how farmers respond to their lived experiences. Building on our prior observation that training conveys information that induces endogenous selection on farmer unobservables, these findings similarly suggest that experience - i.e., learning by doing does the same, that farmer learn about the heterogeneity of returns conditional on unobservables through experience, leading to non-trivial disadoption even of a technology that yields significant average gains.

We further explore the possibility of heterogeneous returns based on exposure intensity by interacting the treatment dummies in equation (1) with baseline (i.e., pre-treatment) (i) production, (ii) cultivable land, (iii) household size, (iv) number of working adults in the household, and (v) household income. SRI might have differential effects based on farmer skill manifest in baseline productivity (Barrett et al. 2004), on land or labor availability or income (per the pro-smallholder claims of some SRI advocates), and labor as often been cited as a bottleneck to (persistent) adoption (Moser and Barrett 2006). As reported in Appendix Tables A15 and A16, no consistent, statistically significant heterogeneity exists in SRI adoption or profitability along any baseline observable dimension. We do find that SRI exposure significantly reduces production costs and revenues in proportion to baseline rice output, consistent with the earlier hypothesis that unobserved farmer skill affects performance. As shown in Appendix Figures A8-A11 and Table A16, quantile regressions provide only a slight suggestion of heterogeneity of impact according to baseline profitability. No broad, general pattern of heterogeneous treatment effects based on observables appears in the data.

Table 8 (columns 1-3) reports the multinomial logit regression estimates (per equation 4) associating the (delayed or persistent) adoption or disadoption decision - relative to the never adopter comparison group in V1 and V2 villages - to both the experimental treatments and to baseline farmer characteristics. The U1 treatment arm serves as the comparison group. Column 4 reports the logit regression of disadoption conditional on year 1 uptake of SRI. Direct SRI training exposure sharply increases the likelihood of ever trying SRI. For T2 farmers, the effect is significantly larger on the likelihood of persistent adoption than of delayed adoption or disadoption. T1 farmers are far more likely to be persistent adopters than delayed adopters, but more likely to adopt with a delay than are untrained (U1 or U2) farmers. The higher a farmer's baseline production, the less likely he was to adopt SRI with a delay and the greater the likelihood that he disadopted. Conversely, the higher a farmer's baseline costs, the more likely he was to adopt at midline. Older farmers and those with higher baseline income were much less likely to 
become persistent adopters and more likely to disadopt conditional on midline use of SRI. By contrast, farmers with more land, younger and lower income were more likely to become persistent adopters. Overall, these estimates are consistent with the simple descriptive patterns found in Table 7. ${ }^{47}$ Farmers are far more likely to experiment with SRI and are more likely to continue trying it the more exposed they have been to the method through training. But although SRI appears to generate real productivity gains on average, farmers make adoption and disadoption decisions consistent with their personal experience of gains (or not) from their own experimentation. They do not appear, however, to treat experimentation as a means of learning how best to use the technology, so that they improve performance via learning by doing.

\section{Implications for Learning Models in the Technology Adoption Literature}

A striking contrast exists between the strong impact of SRI training we observe at the extensive margin on adoption - as farmers go from complete unfamiliarity with the method to some exposure - and the modest-to-negligible effects we observe at the intensive margin, in the performance differences among treatment arms based on exposure intensity. Increased SRI training exposure has a big impact on adoption rates but beyond the lowest level of indirect exposure, more training does not consistently and significantly boost performance with the innovation. Given non-random selection into uptake based on unobservables, we find training intensity exposure mainly generates a diffusion scaling effect. Meanwhile, non-adopters likewise seem to have learned something from training exposure as their performance improves as well. And farmers appear to learn from their own experience, as manifest in relatively high disadoption rates. Farmers seem to sort between adoption or non-adoption, and between continued or discontinued use after initial uptake, in a highly rational way, as manifest, for example, in the absence of any stochastic dominance ordering between adopters and non-adopters within any treatment arm.

These findings have implications for how economists understand learning in the context of technology adoption in developing countries. In particular, they seem inconsistent with core predictions of workhorse target-input models of technology adoption, but are consistent with newer multi-object learning models, with potentially important implications for the study of the adoption of agricultural (and other) technologies.

A rich literature has followed the pathbreaking work of Foster and Rosenzweig (1995), which builds on prior information theoretic work on learning (Wilson 1975; Jovanovic and Nyarko

\footnotetext{
${ }^{47}$ We estimate the same models using only the sub-sample of farmers who received training and find similar results.
} 
1995) to model a producer choosing among multiple technologies that exhibit uncertain and endogenous profitability. As farmers accrue more observations of a new technology that, if used correctly, is expected to be more profitable than the incumbent practice - e.g., an improved seed, a new fertilizer - the additional information helps them steadily approach optimal expected practices, leading to consistently higher expected profits and therefore well-being. Each additional observation of an application of the new technology, whether by the farmer himself - i.e., learning by doing - or by other farmers, extension agents or agro-input dealers - i.e., learning from others - creates another opportunity to learn and thereby to make better, more profitable production decisions. A farmer optimally adopts the new technology only once he has learned enough that the expected profitability of adopting the new technology - including the future returns from learning by doing - exceeds that of sticking with the incumbent, traditional practices. As further information arrives through his own experience with the technology, he continues to learn and thereby further improves his expected performance. The profitability of the new technology is thus endogenous to farmer learning and is itself the single, performance-based object of that learning.

A considerable literature has used this conceptualization, with the optimal technology use - most commonly summarized by profits - as the unique object of learning. For example, Conley and Udry (2010) model stochastic profits as the object of Ghanaian pineapple farmers' learning as they seek to optimize fertilizer application. Farmers learn as new information arrives from a farmer's own experiments with fertilizer and from observing others' practices and outcomes, and they respond by adjusting fertilizer application rates. As they learn more, information-driven adjustments lead to higher profits.

The target input model carries two directly testable implications. First, the more farmers learn, the better they should perform with the new technology, on average. To quote Foster and Rosenzweig (1995, p. 1178), "the profitability of any new technology grows over time as knowledge accumulates." One should be able to reject the null hypothesis that profit - or any performance-based object of learning, e.g., crop yield - is invariant with respect to a farmers' exposure to the technology in favor of the one-sided alternate hypothesis that performance improves with learning about the technology. We consistently fail to reject that null in our data.

The second prediction is that a farmer should use a new technology if and only if he has learned enough about how to apply the new technology optimally such that he enjoys positive expected profits from adoption, up to the discounted future value of gains from subsequent learning-by-doing. Once a farmer has adopted, subsequent learning-by-doing should only further increase the expected profitability from the technology, implying that the farmer should never disadopt unless there is some shock to other covariates relevant to profitability. Indeed, Conley 
and Udry (2010, p.62) expressly state that farmer "movements from positive to zero fertilizer use are mistakes." We find high rates of SRI disadoption, however, despite strongly positive and statistically significant expected profit gains and no significant heterogeneity in estimated returns conditional on observables that could generate disadoption. This finding likewise seems inconsistent with target-input models of learning.

Overall, our findings suggest that intensity of SRI training exposure impacts learning about whether to use the method far more than it does how best to use the technology. These findings are supported by detailed analysis of how intensity of SRI training exposure affects farmer adherence to the precise principles BRAC extension agents communicated in the training, as reported in Tables A17 and A18 and the accompanying appendix text. Few farmers commit much land to SRI, and adherence to principles as taught is limited and does not adjust much, if at all, with additional experience with or exposure to SRI from midline to endline.

As farmers increasingly confront more complex technologies that, like SRI, may require learning about multiple objects simultaneously, newer, multi-object learning models may prove more suitable than the workhorse target-input model. These models draw a key distinction between learning whether a new technology is likely to boost performance, versus learning how best to employ that same technology so as to boost performance (Fafchamps et al. 2016; Banerjee et al. 2019; Nourani 2019; Maertens et al. forthcoming). Learning whether it is worthwhile to try a new technology may be less costly than is learning how to use the technology to maximal effectiveness.

Indeed, this is the fundamental problem of marketing. Sales agents aim to provide enough information to convince a prospective customer to try a product. The objective is not necessarily to optimize the customer's experience of the new technology. Similarly, agricultural extension agents directed (and rewarded) to promote uptake of a new technology that is, on average, superior, provide information that helps induce farmer uptake. But more exposure to that same information does not necessarily improve farmer performance with the new technology nor induce farmers to adjust their practices to optimize performance. This distinction between single object learning about performance and multi-object learning matters to the design of effective agricultural information systems, such as extension services.

A related thread of this literature further hypothesizes that in the face of costly learning, agents might fail to improve their performance with a technology because they do not pay attention to the right pieces of available information. Such 'rational' or 'selective' inattention models (Gabaix et al. 2006; Schwartzstein 2014; Hanna et al. 2014; Ghosh 2016; Wolitzky 2018; Gabaix 2019) generate a prediction similar to multi-object learning models. Increased information access may favourably impact uptake but not performance. Having learned that a new technology is, on 
average, more productive than one's traditional practice, a farmer might rationally confirm that belief with further information, doubling down on the initial adoption choice, but not paying attention to other available data that might help him improve his performance with the technology.

For example, Hanna et al. (2014) study Indonesian seaweed farmers who optimize with respect to some of many production choice variables but underperform by failing to notice and adjust a key technology feature. As with SRI, seaweed farmers face a suite of multiple variables that matter to performance and might not be able, or willing, to pay attention to them all. In a world of selective inattention, greater farmer exposure to information may reinforce beliefs that lead farmers to try a new practice, like SRI, yet farmers might not pay attention to key information as to how they might improve their use of the new technology, perhaps especially if they enjoy (perhaps sub-optimal) gains from the new practice. This can result in satisficing-like behaviour.

We cannot directly test whether Bangladeshi rice farmers pay attention to particular pieces of information or not. But we do find that practices and performance - as distinct from adoption respond modestly, often insignificantly, to additional information beyond the extensive margin of initial exposure to SRI training. We cannot identify the right learning model in our data. But our findings reinforce the prospective importance of emergent models of multi-object learning and selective or rational inattention to processes of agricultural development. ${ }^{48}$

The distinction between single and multi-object learning models is a subtle but important one. The simple reason is that promoting diffusion of a technology differs from advancing optimal performance as the method diffuses. Extension services in the developing world commonly organize (and are evaluated and compensated) simply around diffusion of new methods, rather than around farmers' performance in employing new methods. That approach works in a targetinput world, in which learning sufficient to induce uptake will necessarily lead to continued learning and further productivity and profitability improvements. But in a world of multi-object learning, rational inattention, or both, the learning that induces uptake may not generate satisfactory, sustained productivity or profitability with the innovation. Farmers can then persist in implementation errors or even disadopt when disappointed by their (perhaps suboptimal) performance with the new technology. Our evidence strongly supports the value of further research on multi-object learning among farmers.

\section{Conclusions}

\footnotetext{
${ }^{48}$ Wolitzky (2018) shows that for outcome-improving innovations, such as the one we study, adoption increases the greater one's exposure to (i.e., data on) the new technology. He also demonstrates how rational agents can fail to learn from more observations of cost-reducing technologies. That latter result is superficially consistent with our empirical findings, except that the technology we study is demonstrably outcome-improving and cost-increasing.
} 
Although the system of rice intensification (SRI) has now spread to more than 50 countries, the existing evidence on the purported gains from SRI previously relied exclusively on observational data without especially rigorous causal identification. Partly for that reason, claims of gains from SRI have remained contentious within the international agricultural research community. This paper offers the first SRI impact evaluation based on a large-scale, multi-year RCT.

We find that providing Bangladeshi farmers relatively brief training on the key principles and practices of SRI induces significant farmer adoption of the method in villages previously unexposed to the technology. The extent of SRI adoption increases with the intensity of exposure to SRI training. Significant spillovers arise from training. Untrained farmers in training villages are significantly more likely to adopt SRI than are farmers in pure control villages where no training took place. Farmers directly trained are nonetheless four to five times more likely to adopt SRI than untrained farmers within the training villages, indicating that farmers learn more from extension agents than from each other.

Our findings strongly support the extant observational evidence on SRI's impacts. The ITT estimates of SRI training's impacts on rice yields and profits are statistically significant and very large: 14-17 and 21-34 percent, respectively. The LATE estimates of the impacts of SRI training are significantly larger still and, if anything, underestimates given the possibility of modest negative impacts on local rice prices. We also find positive and statistically significant gains in multiple household well-being measures among farmers in training villages.

Yet SRI disadoption rates are also high, likewise confirming key findings of prior observational studies. Roughly one-third of the farmers adopt SRI and about $60 \%$ of early adopters continue the practice a year later, while almost identical numbers of farmers adopted SRI with a one-year lag as disadopted after an initial year's experience with the method. Disadoption patterns directly reflect pre-treatment conditions and post-adoption experiences, with farmers who did well prior to the introduction of SRI, or who saw little or no improvement from SRI in their first season's trial, far more likely to disadopt.

These disadoption patterns, and the apparent direct impact of SRI training on the performance of non-adopters within treatment arms, are consistent with the apparent non-random selection into SRI adoption conditional on SRI training exposure intensity and farmer- or farmspecific unobservables. The main effect of greater exposure to SRI training occurs at the extensive margin, in scaling up the number of farmers practicing SRI rather than at the intensive margin, in improving farmers' performance with SRI or in increasing adherence to the principles taught by extension agents. The result is seemingly-rational self-selection into SRI use, both in cross-section, 
comparing adopters and non-adopters within a given period, and over time, looking at patterns of delayed adoption or disadoption.

These results may help settle intense debates around SRI as a tool for boosting rice productivity and rice farmers' well-being in the Global South. But our findings also raise several important issues, including about how economists conceptualize and model farmer learning about new technologies in the adoption process, even for practices that appear to deliver considerable productivity and welfare gains.

\section{References}

Arthur, W.B. 2009. The Nature of Technology. New York: Free Press.

Chowdhury, A, M. R., Jenkins, A., \& Nandita, M.M. 2014. Measuring the effects of interventions in BRAC, and how this has driven 'development', Journal of Development Effectiveness 6(4), 407-424.

Baird, S., Bohren, J. A., McIntosh, C., \& Özler, B. 2018. Optimal design of Experiments in the Presence of Interference. Review of Economics and Statistics 100(5): 844-860.

Bandiera, O., R. Burgess, N. Das, S.Gulesci, I. Rasul \& M. Sulaiman. 2017. Labor Markets and Poverty in Village Economies, Quarterly Journal of Economics, 132(2), 811-870.

Banerjee, A., Breza, E., Chandrasekhar, A. G., \& Mobius, M. 2019. "Naïve Learning with Uninformed Agents.” NBER Working Paper No. 25497.

Barrett, C.B. \& Carter, M.R. 2010. "The Power and Pitfalls of Experiments in Development Economics: Some Non-random Reflections," Applied Economic Perspectives and Policy 32(4): 515-548.

Barrett, C.B. \& Carter, M.R. 2020. "Finding Our Balance? Revisiting the Randomization Revolution in Development Economics Ten Years Further On," World Development 127: 104789.

Barrett, C.B., Moser, C., McHugh, O., \& Barison, J. 2004. Better technology, better plots, or better farmers? Identifying changes in productivity and risk among Malagasy rice farmers. American Journal of Agricultural Economics, 86(4), 869-888.

Berkhout, E., \& Glover, D. 2011. The evolution of the System of Rice Intensification is a socioeconomic phenomenon: A report to the Bill and Melinda Gates Foundation. Retrieved from https://ssrn.com.abstract=1922760

Binswanger, H. P. 1980. Attitudes toward risk: Experimental measurement in rural India. American Journal of Agricultural Economics, 62(3), 395-407.

Burke, M., Bergquist, L.F. and Miguel, E., 2019. Sell low and buy high: Arbitrage and local price effects in Kenyan markets. Quarterly Journal of Economics, 134(2), 785-842.

Chavas, J.-P., \& Nauges, C. 2020. Uncertainty, Learning, and Technology Adoption in Agriculture. Applied Economic Perspectives and Policy. in press.

Conley, T., \& Udry, C. 2010. Learning about a New Technology: Pineapple in Ghana. The American Economic Review, 100(1), 35-69.

David, C.C. and Otsuka, K. eds., 1994. Modern Rice Technology and Income Distribution in Asia. Boulder, CO: Lynne Rienner Publishers.

Doberman, A. 2004. A critical assessment of the system of rice intensification (SRI), Agricultural Systems 79: 261-281.

Duflo, E., Kremer, M. and Robinson, J. 2011. Nudging Farmers to Use Fertilizer: Theory and Experimental Evidence from Kenya. American Economic Review, 101(6): 2350-2390

Evenson, R.E. and Gollin, D. 2003. Assessing the impact of the Green Revolution, 1960 to 
2000. Science, 300(5620), 758-762.

Fafchamps, M. Islam, A., Malek, A. \& Pakrashi, D. 2020a. Can Referral Improve Targeting? Evidence from a Vocational Training Experiment. Journal of Development Economics 144: 102436.

Fafchamps, M., Isalm, A., Malek, A. \& Pakrashi, D. 2020b. "Mobilizing P2P Diffusion for New Agricultural Practices: Experimental Evidence from Bangladesh," Stanford University working paper.

Fafchamps, M., Soderbom, M., \& Boogaart. M. V. 2016. "Adoption with Social Learning and Network Externalities.” NBER Working Paper No. 22282

Feder, G., Just, R. E. \& Zilberman, D. 1985. Adoption of Agricultural Innovations in Developing Countries: A Survey. Economic Development and Cultural Change 33(2): 255-298.

Foster, A., \& Rosenzweig, M. 1995. Learning by doing and learning from others: Human capital and technical change in agriculture. Journal of Political Economy, 103(6), 1176-1209.

Foster, A., \& Rosenzweig, M. 2010. Microeconomics of Technology Adoption. Annual Review of Economics, 2, 395-424.

Gabaix, X. 2019. Behavioral Inattention. In B.D Bernheim, S. DellaVigna and D. Laibson, eds., Handbook of Behavioral Economics: Applications and Foundations 1 Vol. 2. NorthHolland.

Gabaix, X., Laibson, D., Moloche, G. \& Weinberg, S.2006. Costly Information Acquisition: Experimental Analysis of a Boundedly Rational Model. American Economic Review, 96(4), 1043-1068.

Gathorne-Hardy, A., Reddy, D., Venkatanarayna, M., \& Harris-White, B. 2016. System of Rice Intensification provides environmental and economic gains at the expense of social sustainability: A multidisciplinary analysis in India. Agricultural Systems, 143, 159-168.

Ghosh, S. 2016. Costly Social Learning and Rational Inattention. Working Paper.

Glover, D. 2011. The system of rice intensification: Time for an empirical turn. NJAS Wageningen Journal of Life Sciences 57: 217-224.

Hanna, R., Mullainathan, S. and Schwartzstein, J. 2014. Learning by Noticing: Theory and Experimental Evidence in Farming. Quarterly Journal of Economics, 129(3): 1311-1353.

Hossain, M., M.A. Malek, M A. Hossain, M. H. Reza, M S. Ahmed. 2019. Agricultural Microcredit for Tenant Farmers: Evidence from a Field Experiment in Bangladesh. American Journal of Agricultural Economics 101(3),692-709.

Islam, S., Islam, J., Faruk, O., \& Kabir, A. 2012. System of Rice Intensification (SRI) - A supplementary way for sustainable rice production. Working paper.

Jovanovic, B., \& Nyarko, Y. 1995. A Bayesian learning model fitted to a variety of empirical learning curves. Brookings Papers on Economic Activity. Microeconomics 1995: 247-305.

Karmakar, B., Latif, M.A., Duxbury, J., \& Meisner, C. 2004. "Validation of System of Rice Intensification (SRI) Practice through Spacing, Seedling Age and Water Management, " Bangladesh Agronomy Journal 10 (1\&2): 13-21.

Latif, M.A., Islam, M.R., Ali, M.Y., \& Saleque, M.A. 2005. "Validation of the system of rice intensification (SRI) in Bangladesh," Field Crops Research 93: 281-92.

Maertens, A., Michelson, H., \& Nourani, V. Forthcoming. How do Farmers Learn from Extension Services? Evidence from Malawi. American Journal of Agricultural Economics

McDonald, A., Hobbs, P., \& Riha, S. 2006. Does the system of rice intensification outperform conventional best management? A synopsis of the empirical record. Field Crop Research, 96, 31-36.

Mckenzie, D. 2012. Beyond baseline and follow-up: The case for more T in experiments. Journal of Development Economics, 99, 210-221.

Moser, C., \& Barrett, C. 2003. The disappointing disadoption dynamics of yield increasing, lowexternal input technology: The case of SRI in Madagascar. Agricultural Systems, 76(3), 1085-1100. 
Moser, C., \& Barrett, C. 2006. The complex dynamics of smallholder technology adoption: The case of SRI in Madagascar. Agricultural Economics(35), 376-388.

Noltze, M., Schwarze, S., \& Qaim, M. 2013. Impacts of natural resource management technologies on agricultural yield and household income: The system of rice intensification in Timor Leste. Ecological Economics, 85, 59-68.

Nourani, V. 2019. Multi-object Social Learning and Technology Adoption in Ghana: Learning from Friends and Reacting to Acquaintances. MIT working paper.

Randriamiharisoa, R., Barison, J., \& Uphoff, N. 2006. Soil biological contributions to the System of Rice Production. In N. U. al (Ed.), Biological Approaches to Sustainable Soil Systems (pp. 409-424). Boca Raton, FL: CRC Press.

Rosenzweig, M. R., \& Udry, C. 2019. External Validity in a Stochastic World: Evidence from Low-Income Countries, Review of Economic Studies, forthcoming.

Schwartzstein, J. 2014. Selective Attention and Learning. Journal of the European Economic Association 12(6): 1423-1452.

Sheehy, J., Peng, S., Doberman, A., Mitchell, P., Ferrer, A., Yang, J., . . Hang, J. 2004. Fantastic yields in the system of rice intensification: Fact or fallacy? Field Crop Research, 88, 1-8.

Sheehy, J., Sinclair, T. R., \& Cassman, K. G. 2005. Curiosities, Nonsense, Non-science and SRI. Field Crop Research(91), 355-356.

Sherlund, S.M., Barrett, C.B. and Adesina, A.A. 2002. Smallholder technical efficiency controlling for environmental production conditions. Journal of Development Economics, 69(1), 85-101.

Sinclair, T. R., \& Cassman, K. G. 2004. Agronomic UFOs. Field Crop Research, 86, 9-10.

Sinha, S., \& Talati, J. 2007. Productivity impact of System of Rice Intensification (SRI): A case study in West Bengal of India. Agricultural Water Management, 871, 55-60.

Stevenson, J., Vanlauwe, B., Macours, K., Johnson, N., Krishnan, L., Place, F., Spielman, D., Hughes, K., \& Vlek, P. 2019. Farmer adoption of plot-and farm-level natural resource management practices: Between rhetoric and reality. Global Food Security 20: 101-104.

Stoop, W., Uphoff, N. \& Kassam, A. 2002. A review of agricultural research issues raised by the System of Rice Intensification (SRI) from Madagascar: Opportunities for improving farming systems for resource-poor farmers. Agricultural Systems, 71, 249-274.

Stygler, E., Malick, A., Hamidou, G., Harouna, I., Mahamane, D., Ibrahim, A., \& Mohammed, T. 2011. Application of system of rice intensification practices in the arid environment of the Timbuktu region in Mali. Paddy and Water Environment, 9(1), 137-144.

Styger E., \& Traoré, G. 2018. 50,000 Farmers in 13 Countries: Results from Scaling up the System of Rice Intensification in West Africa; Achievements and Regional Perspectives for SRI; SRI-WAAPP Project Summary Report, 2014-2016; West Africa Agriculture Productivity Program (WAAPP). Dakar: West and Central Africa Council for Agricultural Research and Development.

Sunding, D., \& Zilberman, D. 2002. The agricultural innovation process: research and technology adoption in a changing agricultural sector. in B. Gardner and G. Rausser, eds., Handbook of Agricultural Economics, Volume 1 (pp. 207-261) Amsterdam: Elsevier.

Takahashi, K., \& Barrett, C. 2014. The System of Rice Intensification and its impacts on household income and child schooling: Evidence from rural Indonesia. American Journal of Agricultural Economics, 96(1), 269-289.

Uphoff, N. 2003. Higher yields with fewer external inputs? The System of Rice Intensification and potential contribution to agricultural sustainability. International Journal of Agricultural Sustainability, 1, 38-50.

Usmani, F., Jeuland, M., \& Pattanayak, S. K. 2018. NGOs and the effectiveness of interventions, UNU WIDER working paper 2018/59.

Weitzman M.L. 1998. Recombinant Growth. Quarterly Journal of Economics 113 (2): 331-360.

Westfall, P. H., \& Young, S. S. 1993. Resampling-based multiple testing. New York: John Wiley 
\& Sons.

Wilson, R. 1975. Informational economies of scale. Bell Journal of Economics 6(1): 184-195.

Wolitzky, A. 2018. Learning from Others' Outcomes. American Economic Review 108(10), 2763-2801.

Young, A. 2019. Channeling fisher: Randomization tests and the statistical insignificance of seemingly significant experimental results. Quarterly Journal of Economics, 134(2), 557598. 
Table 1: Summary statistics of SRI adoption, yield and profits

\begin{tabular}{|c|c|c|c|c|c|c|c|c|c|c|c|c|c|c|}
\hline \multirow[t]{2}{*}{ Panel A: SRI Adoption } & \multicolumn{2}{|c|}{ Control (C) } & \multicolumn{2}{|c|}{ U1 } & \multicolumn{2}{|c|}{$\mathrm{T} 1$} & \multicolumn{2}{|c|}{$\mathrm{U} 2$} & \multicolumn{2}{|c|}{$\mathrm{T} 2$} & \multicolumn{2}{|c|}{ p-value (U2-U1) } & \multicolumn{2}{|c|}{ p-value (T2-T1) } \\
\hline & Midline & Endline & Midline & Endline & Midline & Endline & Midline & Endline & Midline & Endline & Midline & Endline & Midline & Endline \\
\hline SRI adoption & 0.00 & 0.00 & 6.94 & 8.80 & 49.72 & 38.05 & 8.24 & 12.38 & 49.15 & 52.96 & 0.20 & 0.00 & 0.69 & 0.00 \\
\hline Plot level observations & 3973 & 3551 & 1469 & 1261 & 2307 & 2063 & 1298 & 1147 & 2468 & 2264 & & & & \\
\hline \multicolumn{15}{|l|}{ Panel B: Other measures of adoption } \\
\hline Self-assessed SRI adoption & 1.01 & 0.00 & 7.16 & 8.41 & 50.28 & 37.86 & 8.80 & 12.03 & 49.25 & 52.74 & 0.11 & 0.00 & 0.48 & 0.00 \\
\hline Enumerator-assessed SRI adoption & 0.45 & 0.00 & 5.12 & 7.11 & 38.00 & 32.66 & 6.56 & 11.01 & 39.33 & 47.85 & 0.10 & 0.00 & 0.34 & 0.00 \\
\hline Extent of SRI adoption & 0.00 & 0.00 & 4.70 & 7.34 & 36.74 & 31.86 & 5.78 & 9.16 & 37.07 & 45.88 & 0.15 & 0.08 & 0.78 & 0.00 \\
\hline$\%$ of land used for SRI & 0.50 & 0.00 & 3.66 & 4.50 & 22.84 & 21.47 & 4.05 & 7.32 & 19.04 & 25.80 & 0.51 & 0.00 & 0.00 & 0.00 \\
\hline No of principles adopted & 0.69 & 0.72 & 0.86 & 0.96 & 1.32 & 1.45 & 0.94 & 1.17 & 1.29 & 1.74 & 0.02 & 0.00 & 0.45 & 0.00 \\
\hline Age of seedlings ${ }^{1}$ & 0.43 & 0.56 & 0.27 & 2.43 & 3.88 & 4.63 & 0.46 & 1.07 & 2.72 & 6.25 & 0.41 & 0.02 & 0.03 & 0.03 \\
\hline Age of seedlings (days) & 42.81 & 41.74 & 45.23 & 43.88 & 40.54 & 40.34 & 42.00 & 42.58 & 38.45 & 37.79 & 0.00 & 0.08 & 0.00 & 0.00 \\
\hline No of seedlings per bunch ${ }^{1}$ & 12.50 & 10.11 & 14.39 & 12.85 & 27.15 & 30.72 & 17.68 & 17.49 & 27.39 & 34.60 & 0.02 & 0.00 & 0.85 & 0.01 \\
\hline Distance among seedlings ${ }^{1}$ & 0.43 & 0.50 & 2.18 & 6.02 & 15.56 & 24.49 & 4.63 & 9.23 & 14.63 & 29.80 & 0.00 & 0.00 & 0.37 & 0.00 \\
\hline Alternate drying \& wetting ${ }^{1}$ & 46.94 & 53.48 & 59.14 & 57.05 & 66.45 & 63.87 & 57.30 & 71.43 & 64.12 & 75.45 & 0.33 & 0.00 & 0.09 & 0.00 \\
\hline Use of organic fertilizer ${ }^{1}$ & 8.87 & 7.74 & 10.30 & 17.70 & 18.87 & 21.13 & 13.59 & 17.49 & 20.40 & 27.55 & 0.01 & 0.90 & 0.18 & 0.00 \\
\hline Mechanical weeding ${ }^{1}$ & 3.02 & 0.44 & 1.16 & 9.61 & 3.31 & 12.24 & 0.77 & 4.96 & 2.23 & 9.05 & 0.30 & 0.10 & 0.02 & 0.00 \\
\hline \multicolumn{15}{|c|}{ Panel C: Production, Cost and Profit (per decimal) } \\
\hline Yield (kg) & 22.36 & 21.28 & 25.16 & 24.46 & 25.90 & 24.84 & 25.70 & 24.81 & 25.78 & 25.01 & 0.03 & 0.23 & 0.55 & 0.47 \\
\hline Estimated revenue & 825.60 & 800.57 & 967.98 & 939.89 & 1003.88 & 954.25 & 980.24 & 952.50 & 973.75 & 952.39 & 0.25 & 0.28 & 0.00 & 0.84 \\
\hline Input cost & 148.14 & 135.85 & 157.13 & 155.36 & 162.22 & 155.74 & 156.52 & 154.03 & 156.74 & 155.43 & 0.71 & 0.57 & 0.00 & 0.85 \\
\hline Labor cost & 294.44 & 369.17 & 311.96 & 421.00 & 324.25 & 446.40 & 302.92 & 429.13 & 318.61 & 440.58 & 0.03 & 0.42 & 0.11 & 0.50 \\
\hline Total cost & 442.58 & 505.02 & 469.08 & 576.41 & 486.48 & 602.50 & 459.44 & 583.20 & 475.34 & 596.04 & 0.06 & 0.52 & 0.01 & 0.47 \\
\hline Estimated profit & 383.02 & 295.55 & 496.53 & 347.24 & 503.77 & 354.92 & 506.00 & 376.22 & 509.11 & 386.27 & 0.35 & 0.04 & 0.51 & 0.00 \\
\hline
\end{tabular}

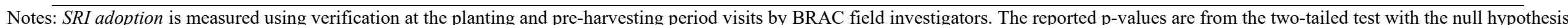

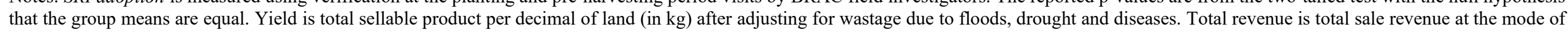

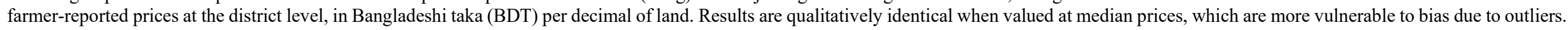

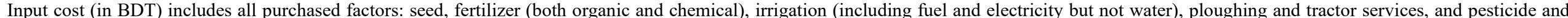

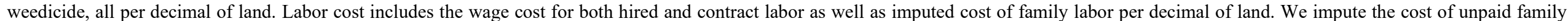

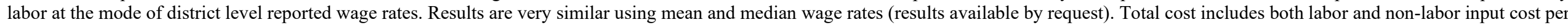

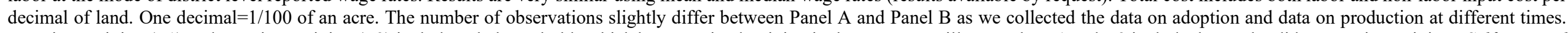

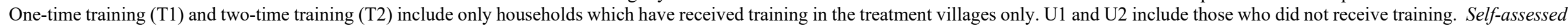

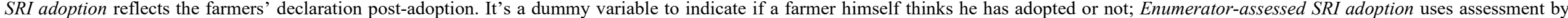

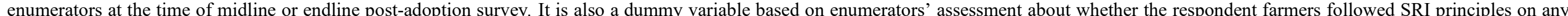

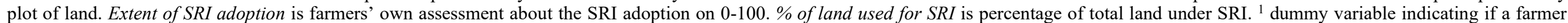
followed that principle as recommended by BRAC for SRI. Age of seedlings (days) is the average number of days of seedlings used for transplantation. 
Table 2: ITT and LATE Effects at Endline

\begin{tabular}{|c|c|c|c|c|c|c|}
\hline & (1) & $\left(1^{\prime}\right)$ & (2) & (3) & (4) & (5) \\
\hline Panel A: ITT & \multicolumn{2}{|c|}{ SRI Adoption (\%) } & Yield & Revenue & Total Cost & Profit \\
\hline One-time untreated (U1) & $\begin{array}{c}9.487 * * * \\
(1.846)\end{array}$ & $\begin{array}{c}10.250^{* * *} \\
(2.106)\end{array}$ & $\begin{array}{c}0.141 * * * \\
(0.031)\end{array}$ & $\begin{array}{c}0.166 * * * \\
(0.033)\end{array}$ & $\begin{array}{c}0.125 * * * \\
(0.046)\end{array}$ & $\begin{array}{l}0.209^{*} \\
(0.116)\end{array}$ \\
\hline One-time treated (T1) & $\begin{array}{c}38.658 * * * \\
(3.436)\end{array}$ & $\begin{array}{c}38.380 * * * \\
(3.768)\end{array}$ & $\begin{array}{c}0.145^{* * *} * \\
(0.033)\end{array}$ & $\begin{array}{c}0.168^{* * *} * \\
(0.035)\end{array}$ & $\begin{array}{c}0.161 * * * \\
(0.049)\end{array}$ & $\begin{array}{l}0.220^{*} \\
(0.120)\end{array}$ \\
\hline Two-time untreated (U2) & $\begin{array}{c}12.368 * * * \\
(2.701)\end{array}$ & $\begin{array}{c}13.437 * * * \\
(2.949)\end{array}$ & $\begin{array}{c}0.146^{* * *} \\
(0.034)\end{array}$ & $\begin{array}{c}0.169 * * * \\
(0.037)\end{array}$ & $\begin{array}{c}0.143 * * * \\
(0.049)\end{array}$ & $\begin{array}{l}0.285^{*} \\
(0.145)\end{array}$ \\
\hline Two-time treated (T2) & $\begin{array}{c}52.543 * * * \\
(4.276)\end{array}$ & $\begin{array}{c}51.584 * * * \\
(4.302)\end{array}$ & $\begin{array}{c}0.166^{* * *} \\
(0.031)\end{array}$ & $\begin{array}{c}0.181 * * * \\
(0.033)\end{array}$ & $\begin{array}{c}0.156^{* * *} \\
(0.050)\end{array}$ & $\begin{array}{c}0.344 * * * \\
(0.129)\end{array}$ \\
\hline $\begin{array}{l}\text { Baseline } \\
\text { outcome }\end{array}$ & & & $\begin{array}{c}0.215^{* * *} \\
(0.032)\end{array}$ & $\begin{array}{c}0.212 * * * \\
(0.030)\end{array}$ & $\begin{array}{c}0.023 \\
(0.034)\end{array}$ & $\begin{array}{c}0.261 * * * \\
(0.052)\end{array}$ \\
\hline $\begin{array}{l}\text { Observations } \\
\mathrm{R}^{2}\end{array}$ & $\begin{array}{c}10,286 \\
0.281\end{array}$ & $\begin{array}{l}8,626 \\
0.274\end{array}$ & $\begin{array}{l}8,626 \\
0.084\end{array}$ & $\begin{array}{l}8,626 \\
0.097\end{array}$ & $\begin{array}{l}8,626 \\
0.051\end{array}$ & $\begin{array}{l}8,626 \\
0.039\end{array}$ \\
\hline $\begin{array}{l}\mathrm{p} \text {-value (U1-T1) } \\
\mathrm{p} \text {-value (U1-U2) } \\
\text { p-value (T1-T2) } \\
\text { p-value (U2-T2) }\end{array}$ & $\begin{array}{l}0.00 \\
0.37 \\
0.01 \\
0.00\end{array}$ & $\begin{array}{l}0.00 \\
0.38 \\
0.02 \\
0.00\end{array}$ & $\begin{array}{l}0.82 \\
0.87 \\
0.50 \\
0.28\end{array}$ & $\begin{array}{l}0.94 \\
0.95 \\
0.70 \\
0.53\end{array}$ & $\begin{array}{l}0.18 \\
0.70 \\
0.93 \\
0.66\end{array}$ & $\begin{array}{l}0.86 \\
0.61 \\
0.36 \\
0.54\end{array}$ \\
\hline $\begin{array}{l}\text { RI p-values (U1) } \\
\text { RI p-values (T1) } \\
\text { RI p-values (U2) } \\
\text { RI p-values (T2) } \\
\text { WY multiple test of significance }\end{array}$ & $\begin{array}{l}0.00 \\
0.00 \\
0.00 \\
0.00 \\
0.00\end{array}$ & $\begin{array}{l}0.00 \\
0.00 \\
0.00 \\
0.00 \\
0.00\end{array}$ & $\begin{array}{l}0.00 \\
0.00 \\
0.00 \\
0.00 \\
0.00\end{array}$ & $\begin{array}{l}0.00 \\
0.00 \\
0.00 \\
0.00 \\
0.00\end{array}$ & $\begin{array}{l}0.01 \\
0.00 \\
0.00 \\
0.00 \\
0.03\end{array}$ & $\begin{array}{l}0.08 \\
0.07 \\
0.06 \\
0.01 \\
0.00\end{array}$ \\
\hline Adopted SRI (IV=Treatment status & & & $\begin{array}{c}0.242 * * * \\
(0.047)\end{array}$ & $\begin{array}{c}0.262 * * * \\
(0.052)\end{array}$ & $\begin{array}{c}0.255^{* * *} \\
(0.074)\end{array}$ & $\begin{array}{c}0.474 * * * \\
(0.179)\end{array}$ \\
\hline Baseline outcome & & & $\begin{array}{c}0.238^{* * *} \\
(0.033)\end{array}$ & $\begin{array}{c}0.238 * * * \\
(0.032)\end{array}$ & $\begin{array}{c}0.045 \\
(0.039)\end{array}$ & $\begin{array}{c}0.289 * * * \\
(0.051)\end{array}$ \\
\hline Observations & & & 8,626 & 8,626 & 8,626 & 8,626 \\
\hline Adjusted $\mathrm{R}^{2}$ & & & 0.0365 & 0.0276 & -0.0108 & 0.0104 \\
\hline Hansen $\mathbf{J}$ & & & 0.0864 & 0.247 & 0.502 & 0.198 \\
\hline Prob $>J$ & & & 0.769 & 0.619 & 0.479 & 0.657 \\
\hline F-stat & & & 116 & 117.5 & 115.4 & 118.7 \\
\hline Control Mean & 0.00 & 0.00 & 21.28 & 800.57 & 505.02 & 295.55 \\
\hline
\end{tabular}

Notes: $* * * \mathrm{p}<0.01, * * \mathrm{p}<0.05, * \mathrm{p}<0.1$. The treatment effects indicate the treatment status within the treatment villages where the base category is control group. The SRI adoption status variable was collected in multiple posttransplantation visits while the other outcome variables were obtained from a post-harvest survey. Hence, the difference in sample size between column 1 and the others. Control mean indicates raw (not log-transformed) mean for the variable at the baseline. All regressions are weighted using inverse of proportion of village farmers in our sample.

Family labor cost is included in the variables total cost and profit using self-assessed wage at the district level. Yield, cost and revenue are expressed in logarithms. To accommodate observations with negative profits we ran regressions using untransformed profit data, and then divide the estimated coefficients by the control group mean to obtain percentage change estimate comparable to those in the log-based regressions. The controls used in the regressions are as follows: dummy indicating whether household head's age $>45$, whether above primary level education, land size $>$ median (120 decimals), head married or not, household size, (log of household income, household composition such as number of children, women, working age people, and maximum education by any member in the household. Standard errors are clustered at the village level. The F-stat is from the first stage of the IV regression.

RI p-value is the randomization inference based p-values (with 1,000 replications) (Young, 2019). WY reports the Westfall and Young (1993) Family Wise Error Rate adjusted p-value for multiple hypothesis testing. 
Table 3: Nonlinearity in the ITT Effects of Treatment Intensity at Endline

\begin{tabular}{|c|c|c|c|c|c|}
\hline & (1) & (2) & (3) & (4) & (5) \\
\hline & Adoption & Yield & Revenue & Total Cost & Profit \\
\hline \multirow[t]{2}{*}{ U1 } & 5.665 & $0.205 * * *$ & $0.222 * * *$ & 0.177 & 0.273 \\
\hline & $(6.970)$ & $(0.075)$ & $(0.085)$ & $(0.116)$ & $(0.349)$ \\
\hline \multirow[t]{2}{*}{ One-time untreated (U1F) } & 8.218 & -0.139 & -0.115 & -0.094 & -0.155 \\
\hline & $(15.107)$ & $(0.165)$ & $(0.188)$ & $(0.263)$ & $(0.788)$ \\
\hline \multirow[t]{2}{*}{$\mathrm{U} 1 \mathrm{~F} x>70 \%$} & -0.666 & 0.004 & -0.052 & -0.165 & 0.128 \\
\hline & $(6.270)$ & $(0.077)$ & $(0.086)$ & $(0.147)$ & $(0.305)$ \\
\hline \multirow[t]{2}{*}{$\mathrm{T} 1$} & $49.180 * * *$ & $0.157^{*}$ & $0.155^{*}$ & 0.093 & 0.356 \\
\hline & $(13.243)$ & $(0.081)$ & $(0.089)$ & $(0.130)$ & $(0.367)$ \\
\hline \multirow[t]{2}{*}{ One-time treated $(\mathrm{T} 1 \mathrm{~F})$} & -26.405 & 0.009 & 0.070 & 0.196 & -0.262 \\
\hline & $(28.044)$ & $(0.153)$ & $(0.170)$ & $(0.258)$ & $(0.751)$ \\
\hline \multirow[t]{2}{*}{$\mathrm{T} 1 \mathrm{~F} \mathrm{x}>70 \%$} & $24.698 * *$ & -0.111 & $-0.174 * *$ & $-0.261 * *$ & 0.032 \\
\hline & $(11.009)$ & $(0.074)$ & $(0.082)$ & $(0.128)$ & $(0.299)$ \\
\hline \multirow[t]{2}{*}{$\mathrm{U} 2$} & 1.495 & $0.201 * *$ & $0.222 *$ & 0.191 & 0.286 \\
\hline & $(5.845)$ & $(0.101)$ & $(0.118)$ & $(0.136)$ & $(0.548)$ \\
\hline \multirow{2}{*}{ Two-time untreated (U2F) } & 17.391 & -0.109 & -0.104 & -0.074 & -0.045 \\
\hline & $(14.365)$ & $(0.212)$ & $(0.243)$ & $(0.244)$ & $(1.062)$ \\
\hline \multirow[t]{2}{*}{$\mathrm{U} 2 \mathrm{~F} \mathrm{x}>70 \%$} & $34.407 * *$ & -0.007 & -0.028 & -0.156 & 0.308 \\
\hline & $(\mathbf{1 3 . 3 6 6 )}$ & $(0.121)$ & $(0.138)$ & $(0.110)$ & $(0.411)$ \\
\hline \multirow[t]{2}{*}{$\mathrm{T} 2$} & $40.401 * *$ & $0.314 * * *$ & $0.355 * * *$ & 0.137 & $0.833 *$ \\
\hline & $(17.579)$ & $(0.105)$ & $(0.115)$ & $(0.176)$ & $(0.491)$ \\
\hline \multirow[t]{2}{*}{ Two-time treated (T2F) } & 12.972 & -0.286 & -0.324 & 0.068 & -0.986 \\
\hline & $(35.166)$ & $(0.208)$ & $(0.227)$ & $(0.323)$ & $(0.954)$ \\
\hline \multirow[t]{2}{*}{$\mathrm{T} 2 \mathrm{~F} x>70 \%$} & 17.584 & 0.091 & 0.074 & -0.088 & 0.397 \\
\hline & $(14.352)$ & $(0.077)$ & $(0.087)$ & $(0.137)$ & $(0.381)$ \\
\hline \multirow[t]{2}{*}{ Baseline outcome } & & $0.214 * * *$ & $0.210 * * *$ & 0.026 & $0.264 * * *$ \\
\hline & & $(0.031)$ & $(0.030)$ & $(0.033)$ & $(0.051)$ \\
\hline Observations & 10,286 & 8,626 & 8,626 & 8,626 & 8,626 \\
\hline Adjusted $\mathrm{R}^{2}$ & 0.304 & 0.088 & 0.104 & 0.063 & 0.042 \\
\hline p-value (U1F-T1F) & 0.17 & 0.30 & 0.23 & 0.11 & 0.86 \\
\hline p-value (U1F-U2F) & 0.66 & 0.91 & 0.97 & 0.96 & 0.93 \\
\hline p-value (T1F-T2F) & 0.38 & 0.26 & 0.17 & 0.76 & 0.55 \\
\hline p-value (U2F-T2F) & 0.89 & 0.32 & 0.25 & 0.51 & 0.17 \\
\hline RI p-values (U1) & 0.41 & 0.01 & 0.01 & 0.14 & 0.44 \\
\hline RI p-values (U1F) & 0.57 & 0.45 & 0.58 & 0.71 & 0.83 \\
\hline RI p-values (U1Fx) & 0.92 & 0.96 & 0.58 & 0.28 & 0.68 \\
\hline RI p-values (T1) & 0.00 & 0.05 & 0.08 & 0.50 & 0.33 \\
\hline RI p-values (T1F) & 0.33 & 0.95 & 0.68 & 0.49 & 0.75 \\
\hline RI p-values (T1Fx) & 0.02 & 0.13 & 0.03 & 0.05 & 0.90 \\
\hline RI p-values (U2) & 0.80 & 0.05 & 0.07 & 0.15 & 0.61 \\
\hline RI p-values (U2F) & 0.22 & 0.60 & 0.66 & 0.76 & 0.97 \\
\hline RI p-values (U2Fx) & 0.01 & 0.96 & 0.85 & 0.15 & 0.48 \\
\hline RI p-values (T2) & 0.03 & 0.00 & 0.00 & 0.44 & 0.11 \\
\hline RI p-values (T2F) & 0.71 & 0.20 & 0.18 & 0.83 & 0.32 \\
\hline RI p-values (T2Fx) & 0.23 & 0.24 & 0.40 & 0.52 & 0.31 \\
\hline WY multiple test of significance & 0.01 & 0.04 & 0.04 & 0.31 & 0.60 \\
\hline Control mean & 0.00 & 21.28 & 800.57 & 505.02 & 295.55 \\
\hline
\end{tabular}

Notes: Same as Table 2. 
Table 4: Input costs impacts of SRI by treatment intensity

\begin{tabular}{|c|c|c|c|c|c|c|c|c|c|}
\hline & (1) & (2) & (3) & (4) & (5) & (6) & (7) & $(8)$ & (9) \\
\hline Panel A: ITT & Seed cost & Inorganic & Organic & Irrigation & Pesticide & Other costs & Input cost & Hired labor & Family labor \\
\hline \multirow[t]{2}{*}{ One-time untreated (U1) } & 0.017 & 0.022 & $0.538 * *$ & $0.164 * * *$ & 0.054 & $0.183 * * *$ & $0.138^{* * *}$ & 0.036 & 0.146 \\
\hline & $(0.049)$ & $(0.030)$ & $(0.245)$ & $(0.062)$ & $(0.054)$ & $(0.033)$ & $(0.033)$ & $(0.163)$ & $(0.102)$ \\
\hline \multirow[t]{2}{*}{ One-time treated (T1) } & 0.009 & 0.008 & $0.830 * * *$ & $0.206^{* * *}$ & -0.053 & $0.117 * * *$ & $0.151^{* * *}$ & 0.160 & $0.195 * *$ \\
\hline & $(0.047)$ & $(0.026)$ & $(0.218)$ & $(0.053)$ & $(0.047)$ & $(0.032)$ & $(0.027)$ & $(0.162)$ & $(0.096)$ \\
\hline \multirow[t]{2}{*}{ Two-time untreated (U2) } & -0.004 & 0.012 & $0.428^{*}$ & $0.217 * * *$ & $-0.095 *$ & $0.145^{* * *}$ & $0.140 * * *$ & 0.111 & $0.264 * *$ \\
\hline & $(0.049)$ & $(0.031)$ & $(0.247)$ & $(0.073)$ & $(0.050)$ & $(0.038)$ & $(0.036)$ & $(0.168)$ & $(0.111)$ \\
\hline \multirow[t]{2}{*}{ Two-time treated (T2) } & 0.014 & -0.000 & $0.872 * * *$ & $0.191 * * *$ & $-0.213 * * *$ & $0.154 * * *$ & $0.146^{* * *}$ & 0.198 & $0.278 * * *$ \\
\hline & $(0.051)$ & $(0.026)$ & $(0.204)$ & $(0.058)$ & $(0.038)$ & $(0.031)$ & $(0.029)$ & $(0.174)$ & $(0.096)$ \\
\hline \multirow[t]{2}{*}{ Baseline outcome } & $0.027 * *$ & $0.034 * * *$ & $0.406 * * *$ & $0.108 * * *$ & $0.043 * * *$ & $0.023 * *$ & 0.014 & $0.272 * * *$ & $0.236^{* * *}$ \\
\hline & $(0.012)$ & $(0.008)$ & $(0.044)$ & $(0.017)$ & $(0.012)$ & $(0.011)$ & $(0.012)$ & $(0.051)$ & $(0.031)$ \\
\hline $\mathrm{R}^{2}$ & 0.012 & 0.013 & 0.146 & 0.057 & 0.029 & 0.018 & 0.051 & 0.062 & 0.107 \\
\hline p-value (U1-T1) & 0.81 & 0.47 & 0.10 & 0.25 & 0.02 & 0.07 & 0.51 & 0.15 & 0.42 \\
\hline p-value (U1-U2) & 0.65 & 0.77 & 0.73 & 0.50 & 0.03 & 0.40 & 0.96 & 0.66 & 0.32 \\
\hline p-value (T1-T2) & 0.91 & 0.77 & 0.88 & 0.79 & 0.00 & 0.32 & 0.83 & 0.83 & 0.41 \\
\hline p-value (U2-T2) & 0.67 & 0.58 & 0.03 & 0.63 & 0.01 & 0.78 & 0.83 & 0.40 & 0.85 \\
\hline RI p-values (U1) & 0.73 & 0.46 & 0.03 & 0.01 & 0.33 & 0.00 & 0.00 & 0.82 & 0.14 \\
\hline RI p-values (T1) & 0.86 & 0.75 & 0.00 & 0.00 & 0.26 & 0.00 & 0.00 & 0.31 & 0.04 \\
\hline RI p-values (U2) & 0.94 & 0.71 & 0.09 & 0.00 & 0.05 & 0.00 & 0.00 & 0.51 & 0.02 \\
\hline RI p-values (T2) & 0.81 & 0.99 & 0.00 & 0.00 & 0.00 & 0.00 & 0.00 & 0.26 & 0.01 \\
\hline WY multiple test of significance & 0.99 & 0.90 & 0.00 & 0.00 & 0.00 & 0.00 & 0.00 & 0.67 & 0.02 \\
\hline \multicolumn{10}{|l|}{ Panel B: LATE } \\
\hline \multirow[t]{2}{*}{ Adopted SRI (IV=Treatment Status) } & 0.021 & -0.008 & $1.624 * * *$ & $0.300 * * *$ & $-0.353 * * *$ & $0.177 * * *$ & $0.232 * * *$ & 0.373 & $0.406^{* * *}$ \\
\hline & $(0.077)$ & $(0.036)$ & $(0.279)$ & $(0.087)$ & $(0.064)$ & $(0.052)$ & $(0.048)$ & $(0.243)$ & $(0.129)$ \\
\hline \multirow[t]{2}{*}{ Baseline outcome } & $0.027 * *$ & $0.035 * * *$ & $0.357 * * *$ & $0.117 * * *$ & $0.047 * * *$ & $0.037 * * *$ & 0.009 & $0.290 * * *$ & $0.234 * * *$ \\
\hline & $(0.012)$ & $(0.008)$ & $(0.042)$ & $(0.018)$ & $(0.013)$ & $(0.012)$ & $(0.012)$ & $(0.050)$ & $(0.030)$ \\
\hline Observations & 8,626 & 8,626 & 8,626 & 8,626 & 8,626 & 8,626 & 8,626 & 8,626 & 8,626 \\
\hline Adjusted $\mathrm{R}^{2}$ & 0.00881 & 0.0124 & 0.183 & 0.0211 & 0.00605 & 0.00126 & -0.0114 & 0.0501 & 0.107 \\
\hline Hansen J & 0.00278 & 0.0657 & 0.536 & 0.783 & 3.691 & 0.166 & 1.297 & 0.00289 & 0.114 \\
\hline Prob $>J$ & 0.958 & 0.798 & 0.464 & 0.376 & 0.0547 & 0.684 & 0.255 & 0.957 & 0.736 \\
\hline F-stat & 112.5 & 115.6 & 121.9 & 116.7 & 113 & 118.9 & 116.2 & 118.4 & 101.5 \\
\hline Control mean & 9.09 & 36.79 & 5.16 & 59.77 & 5.20 & 19.56 & 135.57 & 187.59 & 103.32 \\
\hline
\end{tabular}




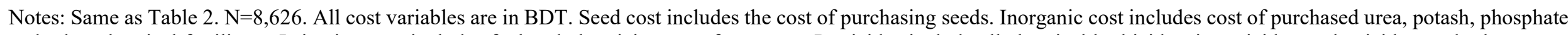
and other chemical fertilizers. Irrigation cost includes fuel and electricity costs for pumps. Pesticides include all chemical herbicides, insecticides, rodenticides, and other types.

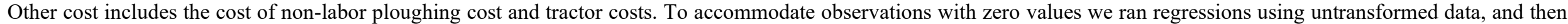
divide the estimated coefficients by the control group mean to obtain percentage change estimate comparable to those in the log-based regressions. 
Table 5: Estimated Well-being Effects of SRI by Endline

\begin{tabular}{|c|c|c|c|c|}
\hline & $(1)$ & $(2)$ & $(3)$ & $(4)$ \\
\hline Panel A: ITT (Treatment Status) & Savings $^{\mathrm{a}}$ & Hh status & Food security & Life satisfaction \\
\hline \multirow[t]{2}{*}{ One-time untreated (U1) } & $0.319^{*}$ & $0.183^{* *}$ & $0.257 * *$ & $0.237 *$ \\
\hline & $(0.188)$ & $(0.093)$ & $(0.126)$ & $(0.130)$ \\
\hline \multirow[t]{2}{*}{ One-time treated $(\mathrm{T} 1)$} & $0.370 * * *$ & $0.123 *$ & $0.481 * * *$ & $0.322 * * *$ \\
\hline & $(0.135)$ & $(0.073)$ & $(0.119)$ & $(0.111)$ \\
\hline \multirow[t]{2}{*}{ Two-time untreated (U2) } & $0.334 *$ & 0.014 & $0.264 * *$ & $0.304 * * *$ \\
\hline & $(0.170)$ & $(0.091)$ & $(0.119)$ & $(0.113)$ \\
\hline \multirow[t]{2}{*}{ Two-time treated (T2) } & $0.356^{* *}$ & 0.114 & $0.308 * * *$ & $0.287 * *$ \\
\hline & $(0.177)$ & $(0.072)$ & $(0.111)$ & $(0.118)$ \\
\hline \multirow[t]{2}{*}{ Baseline outcome } & $0.046^{* * *}$ & $0.420 * * *$ & 0.027 & $0.049 * * *$ \\
\hline & $(0.016)$ & $(0.035)$ & $(0.038)$ & $(0.016)$ \\
\hline $\mathrm{R}^{2} /$ Pseudo $\mathrm{R}^{2}$ & 0.038 & 0.174 & 0.060 & 0.019 \\
\hline p-value (U1-T1) & 0.76 & 0.50 & 0.02 & 0.25 \\
\hline p-value (U1-U2) & 0.95 & 0.13 & 0.95 & 0.57 \\
\hline p-value (T1-T2) & 0.94 & 0.90 & 0.11 & 0.74 \\
\hline p-value (U2-T2) & 0.89 & 0.18 & 0.59 & 0.82 \\
\hline RI p-values (U1) & 0.09 & 0.05 & 0.05 & 0.07 \\
\hline RI p-values (T1) & 0.01 & 0.09 & 0.00 & 0.01 \\
\hline RI p-values (U2) & 0.06 & 0.88 & 0.03 & 0.01 \\
\hline RI p-values (T2) & 0.05 & 0.12 & 0.01 & 0.01 \\
\hline WY multiple test of significance & 0.03 & 0.16 & 0.00 & 0.03 \\
\hline \multicolumn{5}{|l|}{ Panel B: LATE } \\
\hline \multirow[t]{2}{*}{ Adopted SRI (IV=Treatment status) } & $0.605^{* *}$ & 0.169 & $0.584 * * *$ & $0.382 * *$ \\
\hline & $(0.261)$ & $(0.126)$ & $(0.151)$ & $(0.158)$ \\
\hline \multirow[t]{2}{*}{ Baseline outcome } & $0.046^{* * *}$ & $0.419 * * *$ & 0.031 & $0.066^{* * *}$ \\
\hline & $(0.016)$ & $(0.035)$ & $(0.038)$ & $(0.015)$ \\
\hline Adjusted $\mathrm{R}^{2}$ & 0.024 & & & \\
\hline Hansen J & 0.217 & & & \\
\hline Prob $>\mathbf{J}$ & 0.641 & & & \\
\hline F-stat* & 119.1 & & & \\
\hline Control mean & 84.38 & 4.05 & 4.59 & 7.38 \\
\hline
\end{tabular}

Notes: $* * * \mathrm{p}<0.01, * * \mathrm{p}<0.05, * \mathrm{p}<0.1 . \mathrm{N}=3,403$. Standard errors are clustered at the village level. Saving is average monthly savings over the last one year, in Bangladesh Taka (BDT). Savings is calculated as the difference between average monthly income and expenditure over the last one year. Household status is "Compared to other people in your village, would you describe your household as .... (Cross one box)" [1] The poorest in the village, [2] Among the poorest in the village, [3] A little poorer than most households, [4] About average, [5] A little richer than most households, [6] Among the richest in the village, [7] The richest in the village. Food security is "How often in the last year did you have problems satisfying the food needs of the household?"[1] Always, [2] Often, [3] Sometimes, [4] Seldom, [5] Never. Life satisfaction is "All things considered, how satisfied are you with your life? Pick a number between 0 and 10 to indicate how satisfied you are. The more satisfied you are, the higher the number you should pick. The less satisfied you are, the lower the number." As some of the savings were negative; we ran normal regressions for the saving variables and present the estimated coefficients divided by the mean of the control group. Ordered Probit was used to estimate the effects of SRI training on household status, food security, life satisfaction and satisfaction with living standard in Panel A. Ordered Logit estimates yield similar marginal effects. 
Table 6: Village-level general equilibrium impacts at endline

\begin{tabular}{lcc}
\hline & & \\
Panel A: Treated villages only & Wage rate & Rice price \\
\hline Fraction sample treated & -20.412 & $-1.238^{*}$ \\
& $(13.468)$ & $(0.641)$ \\
Two-time training village (Ref: One-time) & 0.634 & 0.074 \\
& $(4.283)$ & $(0.206)$ \\
Observations & 120 & 120 \\
R-squared & 0.226 & 0.229 \\
\hline Panel B: All villages & & \\
& & \\
Fraction sample treated & -17.080 & $-1.091 *$ \\
& $(13.236)$ & $(0.619)$ \\
One-time training village (Ref: Control) & -0.383 & -0.137 \\
& $(7.008)$ & $(0.345)$ \\
Two-time training village & 0.256 & -0.022 \\
& $(8.010)$ & $(0.359)$ \\
Observations & 182 & 182 \\
R-squared & 0.323 & 0.250 \\
\hline Control villages endline mean & 340.32 & 15.06 \\
\hline
\end{tabular}

Note: We also control for other village level characteristics used in Table A4. Wage rate is the average of the modal wage rates for different pre-harvest and post-harvest activities (field preparation, transplanting, weeding, harvesting) while price is the average of the (mode) prices of different types of rice. Standard errors are robust. * $\mathrm{p}<0.01, * * \mathrm{p}<0.05, * \mathrm{p}<0.1$. All outcome variables are in BDT.

Table 7: SRI Adoption and Disadoption Transition Matrix

\begin{tabular}{|c|c|c|c|}
\hline \multirow{2}{*}{$\begin{array}{c}\text { SRI } \\
\text { Adoption } \\
\text { End of } \\
\text { Year } 1\end{array}$} & Did not Adopt & Total \\
\cline { 2 - 4 } $\begin{array}{c}\text { Did not } \\
\text { Adopt }\end{array}$ & (Never adopters) & Adopted & \\
& $1465(55.32 \%)$ & (Delayed adopters $)$ & 1779 \\
& $(\mathrm{U} 1=444, \mathrm{~T} 1=308, \mathrm{U} 2=383, \mathrm{~T} 2=330)$ & $(\mathrm{U} 1=28, \mathrm{~T} 1=101, \mathrm{U} 2=41, \mathrm{~T} 2=144)$ & $67.18 \%$ \\
\hline Adopted & $($ Disadopters) & $($ Persistent adopters $)$ & 869 \\
& $313(11.82 \%)$ & $556(21.00 \%)$ & $32.82 \%$ \\
\hline $\mathrm{N}$ & $(\mathrm{U} 1=16, \mathrm{~T} 1=186, \mathrm{U} 2=21, \mathrm{~T} 2=90)$ & $(\mathrm{U} 1=14, \mathrm{~T} 1=208, \mathrm{U} 2=12, \mathrm{~T} 2=322)$ & 2648 \\
\hline & 1778 & 870 & $100 \%$ \\
\hline
\end{tabular}

Note: Estimates are based on sample households who were surveyed in both year 1 and year 2. 
Table 8: Factors associated with disadoption, delayed adoption or persistent adoption

\begin{tabular}{|c|c|c|c|c|}
\hline Base category & \multicolumn{3}{|c|}{ vs. Never adopters } & \multirow{2}{*}{$\begin{array}{c}\text { vs. Persistent adopters } \\
\text { Disadopted } \\
\text { (4) }\end{array}$} \\
\hline Variables of Interest & $\begin{array}{c}\text { Disadopted } \\
\text { (1) }\end{array}$ & $\begin{array}{c}\text { Delayed } \\
\text { adopters } \\
(2)\end{array}$ & $\begin{array}{l}\text { Persistent } \\
\text { adopters } \\
\text { (3) }\end{array}$ & \\
\hline Log of baseline production & $\begin{array}{l}0.554 * \\
(0.302)\end{array}$ & $\begin{array}{c}-0.530 * * \\
(0.223)\end{array}$ & $\begin{array}{l}-0.306 \\
(0.255)\end{array}$ & $\begin{array}{l}0.934 * * * \\
(0.297)\end{array}$ \\
\hline $\begin{array}{l}\text { Log of baseline cost } \\
\text { (adjusted for family labour) }\end{array}$ & $\begin{array}{c}0.044 \\
(0.268)\end{array}$ & $\begin{array}{c}-0.567 * * \\
(0.281)\end{array}$ & $\begin{array}{l}-0.004 \\
(0.320)\end{array}$ & $\begin{array}{c}0.063 \\
(0.283)\end{array}$ \\
\hline $\mathrm{T} 1$ & $\begin{array}{l}2.809 * * * \\
(0.293)\end{array}$ & $\begin{array}{c}1.621 * * * \\
(0.247)\end{array}$ & $\begin{array}{c}3.114 * * * \\
(0.302)\end{array}$ & $\begin{array}{l}-0.488 \\
(0.487)\end{array}$ \\
\hline $\mathrm{U} 2$ & $\begin{array}{c}0.343 \\
(0.371)\end{array}$ & $\begin{array}{c}0.525 \\
(0.363)\end{array}$ & $\begin{array}{l}-0.071 \\
(0.477)\end{array}$ & $\begin{array}{c}0.263 \\
(0.629)\end{array}$ \\
\hline $\mathrm{T} 2$ & $\begin{array}{l}2.000 * * * \\
(0.319)\end{array}$ & $\begin{array}{c}1.951 * * * \\
(0.300)\end{array}$ & $\begin{array}{c}3.415^{* * * *} \\
(0.381)\end{array}$ & $\begin{array}{c}-1.603 * * * \\
(0.520)\end{array}$ \\
\hline Household head's age greater than 45 & $\begin{array}{l}-0.064 \\
(0.185)\end{array}$ & $\begin{array}{l}-0.002 \\
(0.183)\end{array}$ & $\begin{array}{c}-0.674 * * * \\
(0.173)\end{array}$ & $\begin{array}{c}0.678 * * * \\
(0.175)\end{array}$ \\
\hline Household head has primary education & $\begin{array}{c}0.057 \\
(0.183)\end{array}$ & $\begin{array}{c}0.087 \\
(0.179)\end{array}$ & $\begin{array}{c}0.284 \\
(0.173)\end{array}$ & $\begin{array}{l}-0.300 * \\
(0.181)\end{array}$ \\
\hline Baseline cultivable land above median & $\begin{array}{c}0.202 \\
(0.162)\end{array}$ & $\begin{array}{l}0.298 * \\
(0.172)\end{array}$ & $\begin{array}{l}0.393 * * \\
(0.156)\end{array}$ & $\begin{array}{l}-0.215 \\
(0.221)\end{array}$ \\
\hline Baseline monthly household income & $\begin{array}{c}-0.838 \\
(0.709)\end{array}$ & $\begin{array}{l}-2.370 \\
(1.501)\end{array}$ & $\begin{array}{c}-3.589 * * * \\
(1.353)\end{array}$ & $\begin{array}{c}2.382 * * \\
(0.963)\end{array}$ \\
\hline Observations & 2,562 & 2,562 & 2,562 & 853 \\
\hline
\end{tabular}

Notes: Columns 1-3 reports the coefficients from a multinomial logit model where the base category is never adopters. Column 4 shows the coefficients of a logit model where the base category is persistent adopters. Both the models control for all the household characteristics used in estimating the ITT effects. Standard errors are clustered at the village level. $* * * \mathrm{p}<0.01, * * \mathrm{p}<0.05, * \mathrm{p}<0.1$ 


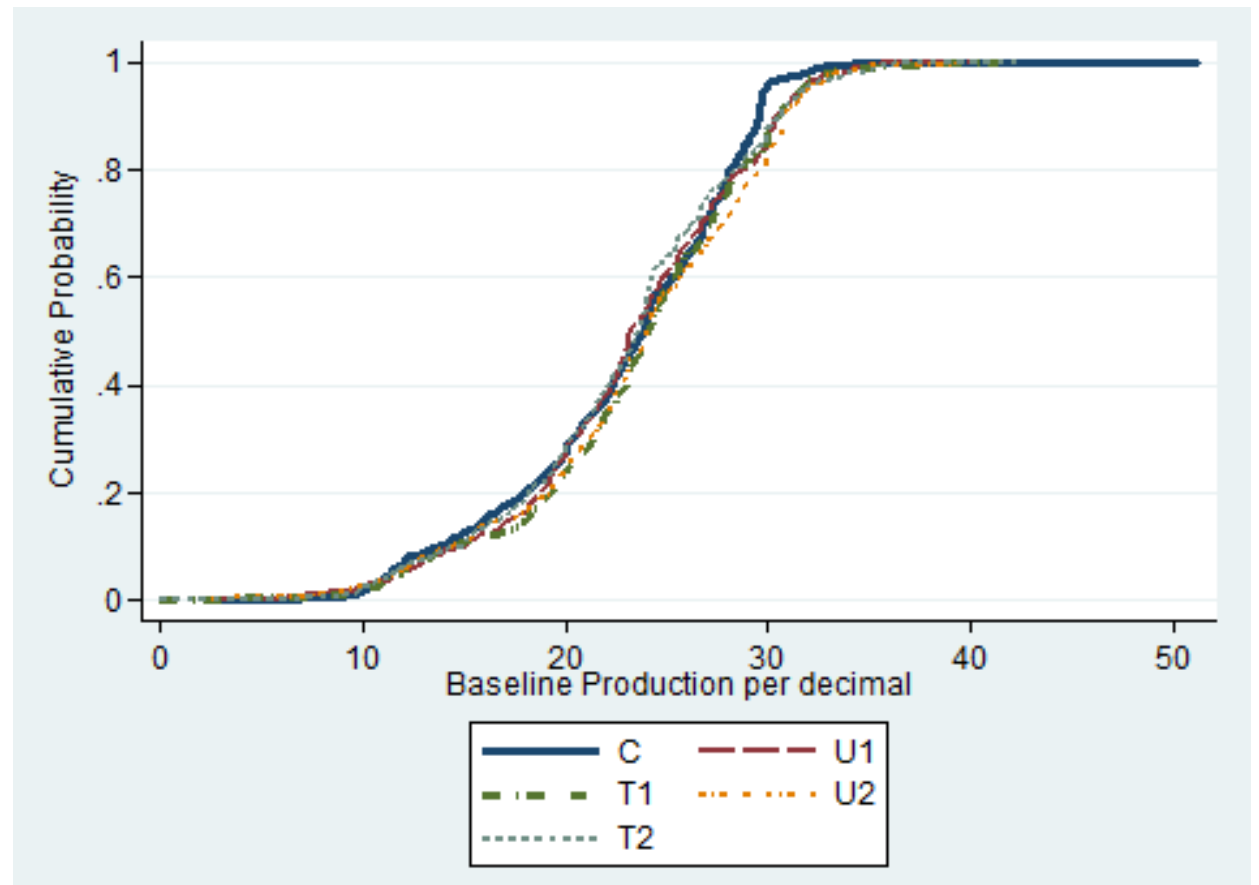

Note: None of the five groups stochastically dominates another based on Somers' D statistic.

Figure 1: Cumulative distribution function of baseline rice output per decimal of land

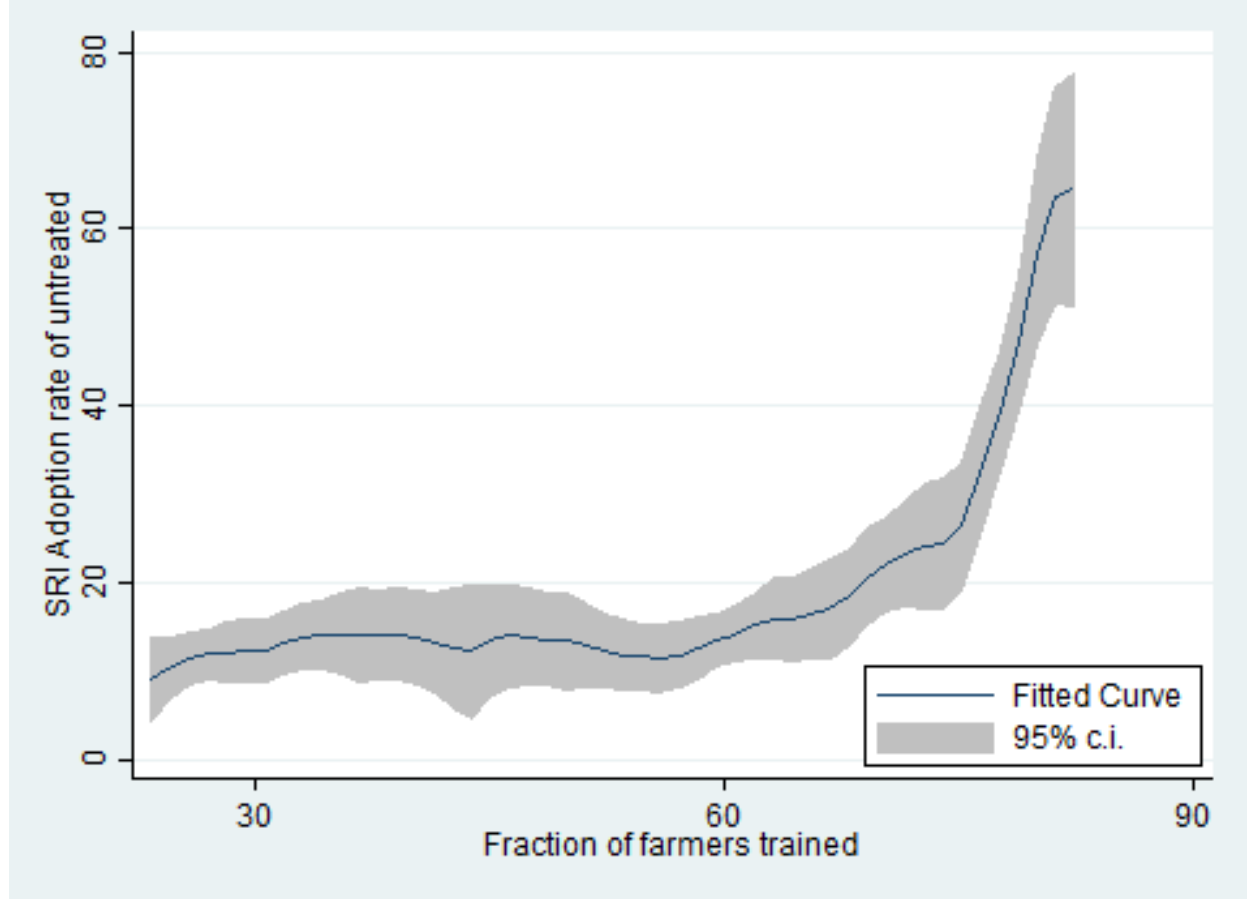

Figure 2: Village-level SRI adoption rate by proportion of treated farmers 


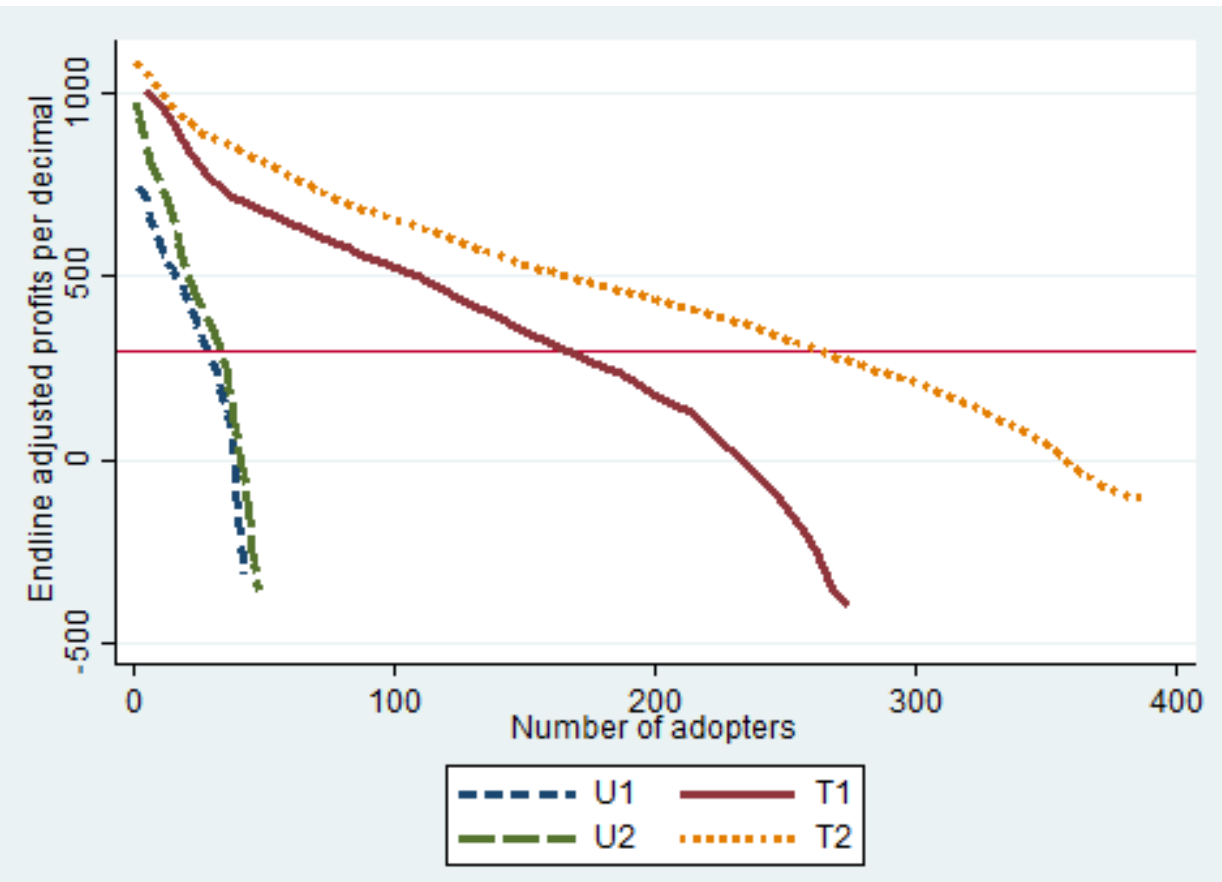

Note: The $\mathrm{x}$ axis shows the number of farmers who have adopted SRI, ranked from highest (1) to lowest (N) profitability within the treatment arm. The calculation of (endline) profits takes into account the imputed cost of family labour.

Figure 3: Ordered endline profits (adjusted for family labour) by treatment status

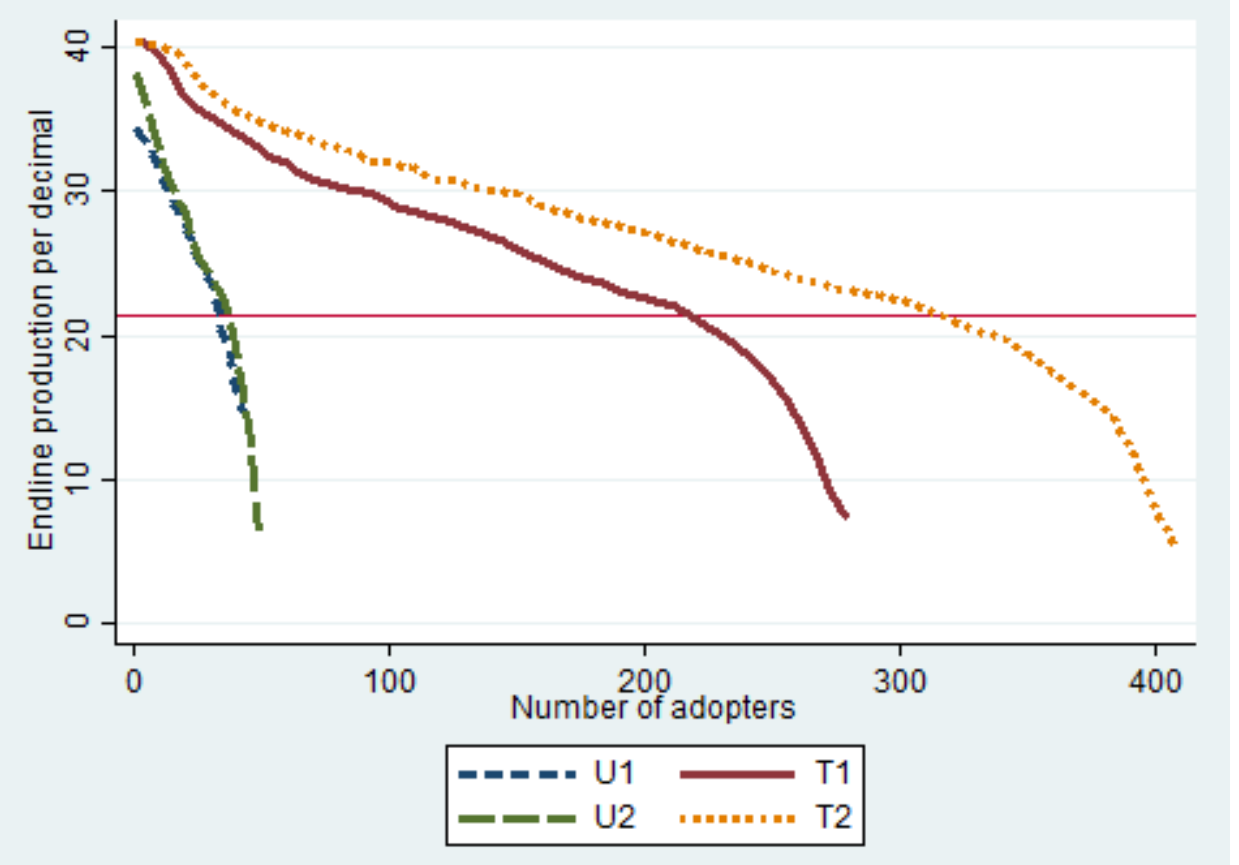

Note: The $\mathrm{x}$ axis shows the number of farmers who have adopted SRI, ranked from highest (1) to lowest (N) rice yield within the treatment arm.

Figure 4: Ordered endline yield by treatment status 

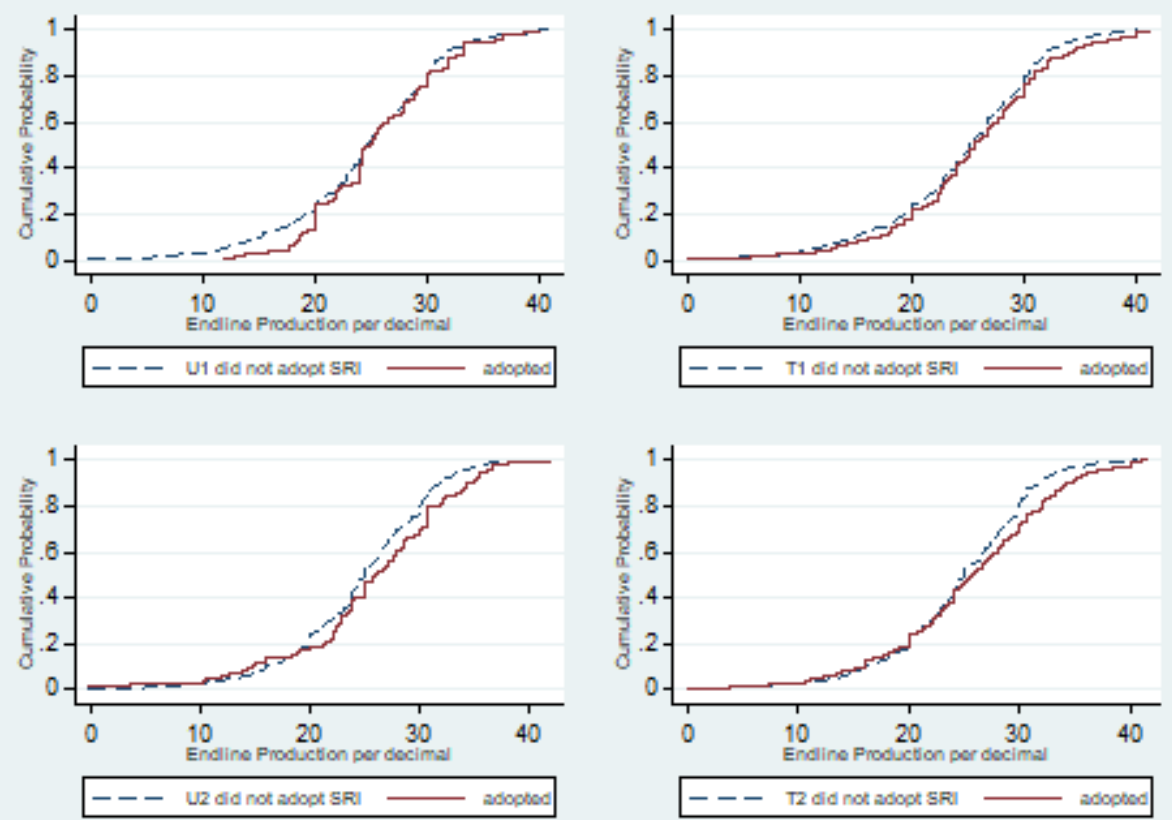

Notes: p-value associated with Somers' D test for first order stochastic dominance for U1(adopted-did not adopt $)=0.50, \mathrm{~T} 1$ (adopted-did not adopt $)=0.36$, U2 (adopted-did not adopt $)=0.44$ and $\mathrm{T} 2$ (adopted-did not adopt) $=0.22$. Tests for second and third order dominance likewise find no statistically significant ordering.

Figure 5: Cumulative distribution function of endline production per decimal of land by treatment and adoption status 
Online Appendix to

Experimental Evidence on Adoption and Impact of the System of Rice Intensification

January 2021 
Table A1: Sample distribution

\begin{tabular}{|c|c|c|c|c|}
\hline \multirow[t]{2}{*}{ Treatment status } & \multirow[b]{2}{*}{$\begin{array}{r}\text { No. of } \\
\text { Villages }\end{array}$} & \multirow{2}{*}{$\begin{array}{r}\text { Total } \\
\text { baseline } \\
\text { farmers }\end{array}$} & \multirow{2}{*}{$\begin{array}{r}\text { Total midline } \\
(2014-15) \\
\text { farmers }\end{array}$} & \multirow{2}{*}{$\begin{array}{r}\text { Total endline } \\
(2015-16) \\
\text { farmers }\end{array}$} \\
\hline & & & & \\
\hline \multirow[t]{2}{*}{ Control (C) } & 62 & 1856 & 1663 & 1464 \\
\hline & & (3983) & (3973) & $(3551)$ \\
\hline \multirow[t]{2}{*}{1 -year training villages } & $\underline{60}$ & $\underline{1805}$ & $\underline{1646}$ & $\underline{1313}$ \\
\hline & & $\underline{(3820)}$ & $\underline{(3776)}$ & $\underline{(3324)}$ \\
\hline \multirow[t]{2}{*}{ Trained farmers (T1) } & & 1060 & 993 & 806 \\
\hline & & (2330) & (2307) & (2063) \\
\hline \multirow[t]{2}{*}{ Untrained farmers (U1) } & & 745 & 653 & 507 \\
\hline & & (1490) & (1469) & (1261) \\
\hline \multirow[t]{2}{*}{ 2-year training villages } & $\underline{60}$ & $\underline{1825}$ & $\underline{1625}$ & $\underline{1354}$ \\
\hline & & $\underline{(3786)}$ & $\underline{(3766)}$ & $\underline{(3411)}$ \\
\hline \multirow[t]{2}{*}{ Trained farmers (T2) } & & 1166 & 1051 & 892 \\
\hline & & (2479) & (2468) & (2264) \\
\hline \multirow[t]{2}{*}{ Untrained farmers (U2) } & & 659 & 574 & 462 \\
\hline & & (1307) & (1298) & (1147) \\
\hline \multirow[t]{2}{*}{ Total } & 182 & 5486 & 4934 & 4131 \\
\hline & & (11589) & (11515) & (10286) \\
\hline
\end{tabular}

Notes: Number of plot level observations used for adoption are shown in parenthesis. Most farmers have multiple plots of land for cultivation (on average slightly more than 2 plots); hence the number of plot level observations are more than the number of farmers/households which are reported on top. 


\section{Randomization checks}

Appendix Table A2 (Panel A) reports the basic demographic and socio-economic characteristics of the treatment and control households using data from the baseline survey round. Household characteristics were similar between the treatment and control groups. There was no statistically significant difference at baseline between control and treatment households in farm size, family size, working age member, education, prior rice yields, costs, or profits, individually or jointly. The first-stage of randomization was therefore successful. In Panel B, we show the same characteristics but for farmers who were selected randomly for training and those left untreated within the treatment villages, the second stage of randomization. Again, there is also no statistically significant difference in these observable characteristics among the treated and untreated households within the treatment villages at baseline.

Appendix Table A3 compares the baseline characteristics of treated farmers in V1 and V2 villages. This comparison is relevant only for year 2 when we divided the treatment villages further, with the V2 villages selected for repeat training in year 2. We compare characteristics both at baseline and at midline, after all $\mathrm{T} 1$ and $\mathrm{T} 2$ households had received the same one year of training. The year 2 randomization was successful, as there are no significant differences of observable household characteristics between the T1 and T2 farmers at baseline (Panel A). Nor was there any significant difference in terms of rice yield, cost or profit between $\mathrm{T} 1$ and $\mathrm{T} 2$ farmers at either baseline (Panel B) or midline, following the year one harvest, before T2 farmers received their second training (Panel C).

Appendix Table A4 provides further evidence that the randomization was successful, now concerning village level characteristics. Panel A compares village level characteristics between year 1 treatment $(\mathrm{T})$ and control $(\mathrm{C})$ villages, while panel B compares V1 and V2 villages. There are no significant differences between either treatment and control villages, or between V1 and V2 villages in terms of the size of the village, accessibility, electricity connection, or presence of NGOs. 
Table A2: Baseline characteristics of farmers by treatment status

\begin{tabular}{|c|c|c|c|c|c|}
\hline \multirow{2}{*}{$\begin{array}{l}\text { Panel A } \\
\text { Household Characteristics }\end{array}$} & \multicolumn{2}{|c|}{ Treatment $(\mathrm{T})$} & \multicolumn{2}{|c|}{ Control (C) } & \multirow{2}{*}{$\begin{array}{c}\text { p-value } \\
(\mathrm{T}-\mathrm{C})\end{array}$} \\
\hline & Mean & Std.dev & Mean & Std.dev & \\
\hline Average Age of the household members (above 15 years) & 36.72 & 7.48 & 36.43 & 7.56 & 0.17 \\
\hline Average Education of the adult member of household (years) & 4.32 & 2.40 & 4.34 & 2.39 & 0.75 \\
\hline Farm size (cultivable) last Boro season (in decimals) & 163.37 & 159.76 & 165.93 & 126.51 & 0.55 \\
\hline Household size & 5.13 & 1.87 & 5.19 & 1.99 & 0.24 \\
\hline Maximum education by any household member & 8.53 & 3.57 & 8.66 & 3.68 & 0.21 \\
\hline F-stat for joint equality & \multicolumn{4}{|c|}{0.70} & \\
\hline $\mathrm{p}$-value for joint equality & \multicolumn{4}{|c|}{0.62} & \\
\hline \multicolumn{6}{|l|}{ Yield, Cost and Profit (per decimal) } \\
\hline Yield (kg) & 22.68 & 5.08 & 22.82 & 5.93 & 0.18 \\
\hline Total cost of production (BDT) & 368.30 & 119.88 & 366.22 & 136.31 & 0.41 \\
\hline Estimated profit (BDT) & 511.19 & 223.72 & 511.98 & 253.11 & 0.88 \\
\hline F-stat for joint equality & \multicolumn{4}{|c|}{1.05} & \\
\hline$p$-value for joint equality & \multicolumn{4}{|c|}{0.37} & \\
\hline \multirow[t]{2}{*}{ No. of observations } & \multicolumn{2}{|c|}{3630} & \multicolumn{2}{|c|}{1856} & \\
\hline & \multicolumn{5}{|c|}{ Treatment Villages Only } \\
\hline Panel B & \multicolumn{2}{|c|}{$\begin{array}{c}\text { Treated } \\
(\mathrm{T} 1 \text { and T2) } \\
\end{array}$} & \multicolumn{2}{|c|}{$\begin{array}{c}\text { Untreated } \\
\text { (U1 and U2) }\end{array}$} & $\begin{array}{l}\text { p-value } \\
\text { (T1/T2- }\end{array}$ \\
\hline Household Characteristics & Mean & Std.dev & Mean & Std.dev & U1/U2) \\
\hline Average Age of the household members (above 15 years) & 36.75 & 7.31 & 36.69 & 7.74 & 0.82 \\
\hline Average Education of the adult member of household (years) & 4.33 & 2.37 & 4.29 & 2.45 & 0.59 \\
\hline Farm size (cultivable) last Boro season (in decimals) & 161.47 & 140.84 & 166.39 & 185.86 & 0.37 \\
\hline Household size & 5.09 & 1.83 & 5.19 & 1.93 & 0.12 \\
\hline Maximum education by any household member & 8.54 & 3.51 & 8.52 & 3.66 & 0.85 \\
\hline F-stat for joint equality & \multicolumn{4}{|c|}{0.72} & \\
\hline p-value for joint equality & \multicolumn{4}{|c|}{0.61} & \\
\hline \multicolumn{6}{|l|}{ Yield, Cost and Profit (per decimal) } \\
\hline Yield (kg) & 22.69 & 5.11 & 22.66 & 5.03 & 0.78 \\
\hline Total cost of production (BDT) & 368.09 & 121.00 & 368.66 & 117.92 & 0.85 \\
\hline Estimated profit (BDT) & 512.08 & 220.43 & 509.59 & 229.57 & 0.69 \\
\hline F-stat for joint equality & \multicolumn{4}{|c|}{0.26} & \\
\hline $\mathrm{p}$-value for joint equality & \multicolumn{4}{|c|}{0.86} & \\
\hline No. of observations & \multicolumn{2}{|c|}{2226} & \multicolumn{2}{|c|}{1404} & \\
\hline
\end{tabular}

Notes: Panel A compares all farmers in treatment and control villages. Panel B compares only treated farmers with those untreated from the same villages. The reported p-values are from the two-tailed test with the null hypothesis that the group means are equal. P-value compares the treated and untreated households from the treatment villages. 
Table A3: Baseline characteristics of farmers by number of treatment rounds

\begin{tabular}{|c|c|c|c|c|c|}
\hline \multirow{3}{*}{$\begin{array}{l}\text { Variables of Interest } \\
\text { Panel A; Household Characteristics (Baseline) }\end{array}$} & \multicolumn{5}{|c|}{ Treatment Villages Only } \\
\hline & \multicolumn{2}{|c|}{$\begin{array}{l}\text { One-time } \\
\text { Training Village } \\
\text { (T1) }\end{array}$} & \multicolumn{2}{|c|}{$\begin{array}{c}\text { Two-time } \\
\text { Training Village } \\
\text { (T2) }\end{array}$} & \multirow[t]{2}{*}{$\begin{array}{l}\mathrm{p} \text {-value } \\
(\mathrm{T} 2-\mathrm{T} 1)\end{array}$} \\
\hline & Mean & Std.dev & Mean & Std.dev & \\
\hline Average Age of the household members (above 15 years) & 36.50 & 7.45 & 36.97 & 7.17 & 0.13 \\
\hline Average Education of the adult member of household (years) & 4.34 & 2.38 & 4.34 & 2.36 & 0.94 \\
\hline Farm size (cultivable) last Boro season (in decimals) & 163.11 & 137.61 & 159.98 & 143.76 & 0.60 \\
\hline Household size & 5.15 & 1.80 & 5.03 & 1.85 & 0.10 \\
\hline Maximum education by any household member & 8.61 & 3.54 & 8.48 & 3.48 & 0.38 \\
\hline F-stat for joint equality & \multicolumn{4}{|c|}{0.60} & \\
\hline $\mathrm{p}$-value for joint equality & \multirow{2}{*}{\multicolumn{4}{|c|}{0.70}} & \\
\hline No. of Observations & & & & & \\
\hline \multicolumn{6}{|l|}{ Panel B: Yield, Cost and Profit (Baseline, per decimal) } \\
\hline Yield (kg) & 22.80 & 4.97 & 22.59 & 5.24 & 0.14 \\
\hline Total cost of production (BDT) & 366.31 & 118.31 & 369.76 & 123.48 & 0.33 \\
\hline Estimated profit (BDT) & 515.95 & 212.08 & 508.53 & 227.82 & 0.31 \\
\hline F-stat for joint equality & \multicolumn{4}{|c|}{0.33} & \\
\hline $\mathrm{p}$-value for joint equality & \multicolumn{4}{|c|}{0.80} & \\
\hline No. of Observations & \multicolumn{2}{|c|}{1060} & \multicolumn{2}{|c|}{1166} & \\
\hline \multicolumn{6}{|l|}{ Panel C: Yield, Cost and Profit (Midline) } \\
\hline SRI Adoption & 49.72 & 50.01 & 49.15 & 50.00 & 0.69 \\
\hline Yield (kg/decimal) & 25.99 & 6.75 & 25.78 & 7.33 & 0.30 \\
\hline Total cost of production (BDT/decimal) & 312.99 & 104.87 & 308.45 & 109.99 & 0.15 \\
\hline Estimated profit (BDT/decimal) & 643.85 & 234.15 & 636.51 & 229.03 & 0.28 \\
\hline F-stat for joint equality & \multicolumn{4}{|c|}{0.36} & \\
\hline $\mathrm{p}$-value for joint equality & \multicolumn{4}{|c|}{0.84} & \\
\hline No. of Observations & \multicolumn{2}{|c|}{993} & \multicolumn{2}{|c|}{1051} & \\
\hline
\end{tabular}

Notes: Panel A compares baseline household level characteristics for one time and two-time training villages. Panel B compares the same for baseline output, profits, etc. Panel C shows the difference between one-time and two-time training farmers' adoption, yield, cost, etc. during midline to show that the farmers were otherwise similar. Standard errors are clustered at the village level. P-value shows level of significance for the difference between farmers in villages with one-time and two-time training. 
Table A4: Village level baseline characteristics- treatment and control villages

\begin{tabular}{|c|c|c|c|c|c|}
\hline \multirow[t]{2}{*}{ Panel A: Treatment vs Control } & \multicolumn{2}{|c|}{ Treat $(\mathrm{T})$} & \multicolumn{2}{|c|}{ Control (C) } & \multirow{2}{*}{$\frac{\mathrm{p} \text {-value }}{(\mathrm{T}-\mathrm{C})}$} \\
\hline & Mean & Std.dev & Mean & Std.dev & \\
\hline Transport System in village $(\operatorname{good}=1)$ & 0.325 & 0.04 & 0.403 & 0.06 & 0.30 \\
\hline Road in village (brick built=1) & 0.300 & 0.04 & 0.355 & 0.06 & 0.45 \\
\hline Road between village and Upazila (brick built $=1$ ) & 0.858 & 0.03 & 0.919 & 0.03 & 0.23 \\
\hline Distance between village and nearest Upazila $(\mathrm{km})$ & 11.52 & 0.98 & 12.35 & 1.48 & 0.63 \\
\hline Number of NGOs in the villages & 4.975 & 0.18 & 4.820 & 0.16 & 0.58 \\
\hline Number of households in the villages & 351.6 & 33.1 & 356.1 & 48.2 & 0.94 \\
\hline Electricity connection $($ yes $=1)$ & 0.900 & 0.03 & 0.919 & 0.03 & 0.67 \\
\hline F-stat for Joint equality & \multicolumn{4}{|c|}{0.85} & \\
\hline $\mathrm{p}$-value for Joint equality & \multicolumn{4}{|c|}{0.55} & \\
\hline \multirow[t]{2}{*}{ No. of Observations } & \multicolumn{2}{|c|}{120} & \multicolumn{2}{|c|}{62} & \\
\hline & \multicolumn{5}{|c|}{ Treatment Villages Only } \\
\hline \multirow[t]{2}{*}{ Panel B: V1 vs V2 } & \multicolumn{2}{|c|}{$\begin{array}{c}\text { Two-time } \\
\text { training Village (V2) }\end{array}$} & \multicolumn{2}{|c|}{$\begin{array}{c}\text { One-time } \\
\text { Training Village (V1) }\end{array}$} & $\begin{array}{l}\text { p-value } \\
\text { (V2-V1) }\end{array}$ \\
\hline & Mean & Std.dev & Mean & Std.dev & \\
\hline Transport System in village $(\operatorname{good}=1)$ & 0.350 & 0.06 & 0.300 & 0.06 & 0.56 \\
\hline Road in village (brick built $=1$ ) & 0.350 & 0.06 & 0.250 & 0.06 & 0.24 \\
\hline Road between village and Upazila (brick built $=1$ ) & 0.867 & 0.04 & 0.850 & 0.05 & 0.80 \\
\hline Distance between village and nearest Upazila $(\mathrm{km})$ & 11.23 & 1.34 & 11.81 & 1.41 & 0.76 \\
\hline Number of NGOs in the villages & 5.017 & 0.30 & 4.933 & 0.21 & 0.82 \\
\hline Number of households in the villages & 305.53 & 32.92 & 396.93 & 56.84 & 0.17 \\
\hline Electricity connection (yes=1) & 0.917 & 0.04 & 0.883 & 0.04 & 0.55 \\
\hline F-stat for Joint equality & \multirow{2}{*}{\multicolumn{4}{|c|}{$\begin{array}{l}1.24 \\
0.29\end{array}$}} & \\
\hline $\mathrm{p}$-value for Joint equality & & & & & \\
\hline No. of Observations & \multicolumn{2}{|c|}{60} & \multicolumn{2}{|c|}{60} & \\
\hline
\end{tabular}

Notes: The reported p-values are from the two-tailed test with the null hypothesis that the group means are equal.

All villages have presence of at least one NGO. 


\section{Attrition}

Appendix Table A5 reports balance tests to see if sample attrition occurred differentially among households with different treatment status. Panel A shows the attrition by treatment status in midline. Overall attrition was about 10\% (Table A1) but it was slightly, but statistically insignificantly, higher $(10.4 \%)$ in control villages than in treatment villages $(9.8 \%)$. There is no individually nor jointly significant difference in attrition in terms of observed baseline household characteristics between treatment and control villages. In panel $\mathrm{B}$, we examine the attrition at endline by the treatment status of villages: V1 versus V2 villages. Attrition was a bit higher from midline to endline (16.3\%, Table A1) than from baseline to midline, and also a bit (but insignificantly) higher in V1 villages than V2 villages. When we compare the attrition status based on observables at the baseline we again find no individually nor jointly significant difference among attritors between treatment and control villages or between V1 and V2 villages. We also checked whether attrition is different between farmers who received training (T1 and T2) versus those who did not (U1 and U2, panel C, Table A5). Again, there are no statistically significant differences across treatment groups.

We also examined the correlates of attrition using attrition status in each round as a dependent variable in a linear probability regression model. The results (Appendix Table A6) do not suggest any predictor for the attrition that differs by treatment status. We see that larger farms had a higher likelihood of attrition. But when we interacted land size with each treatment status, those interactions are not individually or jointly statistically significant (results not presented here). Thus, there was no obvious candidate for differential attrition due to different treatment statuses. Overall, Tables A5 and A6 strongly suggest that attrition is adequately random in our sample and should have no impact on causal inference based on the randomization. 
Table A5: Attrition by treatment status: Balance test

\begin{tabular}{|c|c|c|c|c|c|c|}
\hline & Control & Treat & \multicolumn{2}{|l|}{ p-value } & & \\
\hline Panel A: End of year 1 (Midline) & (1) & $(2)$ & \multicolumn{2}{|l|}{$(2)-(1)$} & & \\
\hline Average Age of the household members (above 15 years) & 37.01 & 37.04 & \multicolumn{2}{|l|}{0.96} & & \\
\hline Average Education of the adult member of household (years) & 4.36 & 4.55 & \multicolumn{2}{|l|}{0.41} & & \\
\hline Farm size (cultivable) last Boro season (in decimals) & 141.52 & 141.10 & \multicolumn{2}{|l|}{0.97} & & \\
\hline Number of People in the households & 4.68 & 4.91 & \multicolumn{2}{|l|}{0.19} & & \\
\hline Yield (kg/decimal) & 21.76 & 23.18 & \multicolumn{2}{|l|}{0.19} & & \\
\hline Total cost of production & 363.46 & 333.79 & \multicolumn{2}{|l|}{0.16} & & \\
\hline Estimated profit & 571.98 & 505.06 & \multicolumn{2}{|l|}{0.16} & & \\
\hline F-stat for joint equality & \multicolumn{2}{|c|}{0.58} & & & & \\
\hline p-value for joint equality & \multicolumn{2}{|c|}{0.68} & & & & \\
\hline No. of observations & 193 & 359 & & & & \\
\hline \multirow[t]{3}{*}{ Total sample at the baseline } & 1856 & 3630 & & & & \\
\hline & \multirow[b]{2}{*}{ Control } & \multicolumn{3}{|c|}{ Treatment villages } & \multicolumn{2}{|c|}{ p-value } \\
\hline & & All & $\mathrm{T} 1$ & $\mathrm{~T} 2$ & & (2) \\
\hline Average Age of the household members (above 15 years) & 36.49 & 36.83 & 36.93 & 37.42 & 0.58 & 0.55 \\
\hline Average Education of the adult member of household (years) & 4.12 & 4.13 & 4.20 & 3.89 & 0.97 & 0.24 \\
\hline Farm size (cultivable) last Boro season (in decimals) & 144.71 & 131.46 & 128.42 & 123.64 & 0.10 & 0.66 \\
\hline Number of People in the households & 4.99 & 4.83 & 4.81 & 4.78 & 0.23 & 0.87 \\
\hline Yield (kg/decimal) & 21.82 & 21.25 & 21.51 & 20.61 & 0.27 & 0.21 \\
\hline Total cost of production (BDT/decimal) & 357.28 & 353.15 & 336.36 & 355.20 & 0.75 & 0.13 \\
\hline Estimated profit (BDT/decimal) & 524.21 & 494.95 & 475.12 & 488.05 & 0.15 & 0.67 \\
\hline \multicolumn{7}{|l|}{ No. of observations } \\
\hline & 199 & 604 & 187 & 159 & & \\
\hline \multirow[t]{2}{*}{ Panel C: End of year 2 (Endline) } & Control & \multicolumn{4}{|c|}{ All treatment Households } & p-value \\
\hline & & Overall & Treated & $\begin{array}{c}\text { Untrea } \\
\text { ted }\end{array}$ & $(1)$ & (2) \\
\hline Average Age of the household members (above 15 years) & 36.49 & 36.83 & 37.16 & 36.40 & 0.23 & 0.90 \\
\hline Average Education of the adult member of household (years) & 4.12 & 4.13 & 4.06 & 4.22 & 0.41 & 0.67 \\
\hline Farm size (cultivable) last Boro season (in decimals) & 144.71 & 131.46 & 126.22 & 138.48 & 0.12 & 0.50 \\
\hline Number of People in the households & 4.99 & 4.83 & 4.79 & 4.88 & 0.50 & 0.48 \\
\hline Yield (kg/decimal) & 21.82 & 21.25 & 21.09 & 21.47 & 0.47 & 0.56 \\
\hline Total cost of production (BDT/decimal) & 357.28 & 353.15 & 344.87 & 364.22 & 0.14 & 0.69 \\
\hline Estimated profit (BDT/decimal) & 524.21 & 494.95 & 480.95 & 513.94 & 0.14 & 0.62 \\
\hline No. of observations & 199 & 604 & 346 & 258 & & \\
\hline
\end{tabular}

Notes: The reported p-values are from the two-tailed test with the null hypothesis that the group means are equal. In Panel A, the p-value compares control with all treatment households for year 1 attritors. T1 farmers received training in year 1 only. T2 received training in both years- year 1 and year 2. As for Panel B, p-value (1) compares control and all treatment households while p-value (2) compares one-time and two-time training households for year 2 attritors. In Panel C, p-value (1) compares treated and untreated households while p-value (2) compares control and untreated households for year 2 attritors. 
Table A6: Attrition Regressions

\begin{tabular}{|c|c|c|c|}
\hline & $(1)$ & $(2)$ & $(3)$ \\
\hline Variables of Interest & \multicolumn{3}{|c|}{ Incidence of Attrition } \\
\hline Treatment (Base: Control) & $\begin{array}{c}0.037 \\
(0.022)\end{array}$ & & \\
\hline One-Time training village (V1) (Base: Control) & & $\begin{array}{c}0.043 \\
(0.026)\end{array}$ & \\
\hline Two-Time training village (V2) & & $\begin{array}{c}0.031 \\
(0.027)\end{array}$ & \\
\hline Two-time treated (T2) (Base: T1) & & & $\begin{array}{l}-0.006 \\
(0.030)\end{array}$ \\
\hline Household head's age greater than 45 & $\begin{array}{c}0.202 * * * \\
(0.017)\end{array}$ & $\begin{array}{c}0.202 * * * \\
(0.017)\end{array}$ & $\begin{array}{c}0.173 * * * \\
(0.025)\end{array}$ \\
\hline Household head has primary education & $\begin{array}{c}0.211 * * * \\
(0.019)\end{array}$ & $\begin{array}{c}0.211 * * * \\
(0.019)\end{array}$ & $\begin{array}{c}0.141 * * * \\
(0.030)\end{array}$ \\
\hline Baseline cultivable land above median & $\begin{array}{c}-0.091 * * * \\
(0.013)\end{array}$ & $\begin{array}{c}-0.091 * * * \\
(0.013)\end{array}$ & $\begin{array}{c}-0.098 * * * \\
(0.021)\end{array}$ \\
\hline Baseline monthly household income & $\begin{array}{l}0.082 * \\
(0.042)\end{array}$ & $\begin{array}{l}0.083 * \\
(0.042)\end{array}$ & $\begin{array}{c}0.065 \\
(0.060)\end{array}$ \\
\hline $\begin{array}{l}\text { Observations } \\
\mathrm{R}^{2}\end{array}$ & $\begin{array}{l}5,486 \\
0,098\end{array}$ & $\begin{array}{l}5,486 \\
0,098\end{array}$ & $\begin{array}{l}2,226 \\
0,075\end{array}$ \\
\hline
\end{tabular}

Note: Attrition between baseline and endline. Note: other controls same as Table 2. Standard errors are clustered at the village level. $* * * \mathrm{p}<0.01, * * \mathrm{p}<0.05, * \mathrm{p}<0.1$. 
Table A7: ITT Effects of Treatment Saturation Intensity at Endline

\begin{tabular}{lccccc}
\hline & $(1)$ & $(2)$ & $(3)$ & $(4)$ & $(5)$ \\
\hline & Adoption & Yield & Revenue & Total Cost & Profit \\
\hline One-time untreated (U1) & 5.997 & $0.203^{* * *}$ & $0.239^{* * *}$ & $0.230^{* *}$ & 0.231 \\
& $(5.950)$ & $(0.064)$ & $(0.072)$ & $(0.106)$ & $(0.292)$ \\
U1F & 7.492 & -0.137 & -0.158 & -0.228 & -0.049 \\
& $(11.772)$ & $(0.129)$ & $(0.147)$ & $(0.225)$ & $(0.603)$ \\
One-time treated (T1) & $31.384^{* * *}$ & $0.235^{* * *}$ & $0.278^{* * *}$ & $0.277^{* *}$ & 0.335 \\
& $(11.750)$ & $(0.081)$ & $(0.090)$ & $(0.140)$ & $(0.309)$ \\
T1F & 13.488 & -0.167 & -0.205 & -0.216 & -0.213 \\
& $(22.757)$ & $(0.146)$ & $(0.166)$ & $(0.272)$ & $(0.562)$ \\
Two-time untreated (U2) & -12.342 & $0.203 * *$ & $0.235 * *$ & $0.262 * *$ & 0.146 \\
& $(7.481)$ & $(0.089)$ & $(0.104)$ & $(0.122)$ & $(0.449)$ \\
U2F & $49.981 * * *$ & -0.116 & -0.133 & -0.239 & 0.278 \\
& $(17.030)$ & $(0.174)$ & $(0.201)$ & $(0.205)$ & $(0.802)$ \\
Two-time treated (T2) & 21.727 & $0.215^{* * *}$ & $0.275^{* * *}$ & 0.233 & 0.405 \\
T2F & $(13.505)$ & $(0.069)$ & $(0.078)$ & $(0.154)$ & $(0.364)$ \\
& $51.698^{* *}$ & -0.083 & -0.158 & -0.129 & -0.103 \\
Baseline outcome & $(23.543)$ & $(0.117)$ & $(0.131)$ & $(0.270)$ & $(0.639)$ \\
& & $0.215^{* * *}$ & $0.213 * * *$ & 0.027 & $0.261 * * *$ \\
Observations & & $(0.031)$ & $(0.030)$ & $(0.033)$ & $(0.051)$ \\
Adjusted R & 10,286 & 8,626 & 8,626 & 8,626 & 8,626 \\
& 0.292 & 0.086 & 0.100 & 0.054 & 0.039 \\
p-value (U1F-T1F) & & & & & \\
p-value (U1F-U2F) & 0.77 & 0.82 & 0.75 & 0.95 & 0.75 \\
p-value (T1F-T2F) & 0.04 & 0.92 & 0.92 & 0.97 & 0.75 \\
p-value (U2F-T2F) & 0.24 & 0.65 & 0.82 & 0.82 & 0.90 \\
Control mean & 0.94 & 0.83 & 0.88 & 0.57 & 0.57 \\
\hline
\end{tabular}

Note 1: The treatment intensities are fractions of farmers trained in each village (between 0 and 1) and are the same for treated and untreated farmers within the same village, where the base category is the control group. Accordingly, $\mathrm{U} 1 \mathrm{~F}$ is the fraction of the farmers treated in a village multiplied by treatment dummy to denote whether a farmer from a V1 village belongs to the U1 treatment group or not, and so on. In the notation, we add the F suffix (e.g., $\mathrm{U} 1 \mathrm{~F}$ ), for frequency, so as to distinguish these intensity of treatment variables from the dummy treatment indicators used in Table 2.

Note 2: same as Table 2. 
Midline Treatment Effect Estimates

Table A8: ITT and LATE - Effects of Treatment Status at Midline

\begin{tabular}{|c|c|c|c|c|c|}
\hline & (1) & (2) & (3) & (4) & (5) \\
\hline Panel A: ITT & Adoption & Yield & Revenue & Total Cost & Profit \\
\hline One-time untreated (U1) & $\begin{array}{c}7.526 * * * \\
(1.222)\end{array}$ & $\begin{array}{c}0.118 * * * \\
(0.027)\end{array}$ & $\begin{array}{c}0.155^{* * * *} \\
(0.035)\end{array}$ & $\begin{array}{l}0.059 * \\
(0.032)\end{array}$ & $\begin{array}{c}0.318 * * * \\
(0.086)\end{array}$ \\
\hline One-time treated (T1) & $\begin{array}{c}51.139 * * * \\
(3.860)\end{array}$ & $\begin{array}{c}0.160 * * * \\
(0.025)\end{array}$ & $\begin{array}{c}0.190 * * * \\
(0.030)\end{array}$ & $\begin{array}{c}0.081 * * \\
(0.031)\end{array}$ & $\begin{array}{c}0.354 * * * \\
(0.077)\end{array}$ \\
\hline Two-time untreated (U2) & $\begin{array}{c}8.424 * * * \\
(1.506)\end{array}$ & $\begin{array}{c}0.156^{* * *} * \\
(0.024)\end{array}$ & $\begin{array}{c}0.184 * * * \\
(0.031)\end{array}$ & $\begin{array}{c}0.032 \\
(0.032)\end{array}$ & $\begin{array}{c}0.385 * * * \\
(0.068)\end{array}$ \\
\hline Two-time treated (T2) & $\begin{array}{c}49.260 * * * \\
(3.987)\end{array}$ & $\begin{array}{c}0.148 * * * \\
(0.028)\end{array}$ & $\begin{array}{c}0.166^{* * *} \\
(0.031)\end{array}$ & $\begin{array}{c}0.050 \\
(0.031)\end{array}$ & $\begin{array}{c}0.389 * * * \\
(0.076)\end{array}$ \\
\hline Baseline outcome & & $\begin{array}{c}0.147 * * * \\
(0.022)\end{array}$ & $\begin{array}{c}0.143 * * * \\
(0.022)\end{array}$ & $\begin{array}{c}0.149 * * * \\
(0.029)\end{array}$ & $\begin{array}{c}0.106 * * * \\
(0.031)\end{array}$ \\
\hline $\begin{array}{l}\text { Observations } \\
\mathrm{R}^{2}\end{array}$ & $\begin{array}{c}11,515 \\
0.324\end{array}$ & $\begin{array}{l}8,608 \\
0.090\end{array}$ & $\begin{array}{l}8,608 \\
0.106\end{array}$ & $\begin{array}{l}8,608 \\
0.086\end{array}$ & $\begin{array}{l}8,608 \\
0.104\end{array}$ \\
\hline $\begin{array}{l}\mathrm{p} \text {-value (U1-T1) } \\
\text { p-value (U1-U2) } \\
\text { p-value (T1-T2) } \\
\text { p-value (U2-T2) }\end{array}$ & $\begin{array}{l}0.00 \\
0.64 \\
0.73 \\
0.00\end{array}$ & $\begin{array}{l}0.04 \\
0.24 \\
0.72 \\
0.71\end{array}$ & $\begin{array}{l}0.14 \\
0.50 \\
0.56 \\
0.44\end{array}$ & $\begin{array}{l}0.18 \\
0.38 \\
0.29 \\
0.31 \\
\end{array}$ & $\begin{array}{l}0.52 \\
0.48 \\
0.71 \\
0.93\end{array}$ \\
\hline \multicolumn{6}{|l|}{ Panel B: LATE } \\
\hline Adopted SRI (IV=Treatment status) & & $\begin{array}{c}0.241 * * * \\
(0.043)\end{array}$ & $\begin{array}{c}0.267 * * * \\
(0.050)\end{array}$ & $\begin{array}{l}0.106 * * \\
(0.046)\end{array}$ & $\begin{array}{c}0.568 * * * \\
(0.117)\end{array}$ \\
\hline Baseline outcome & & $\begin{array}{c}0.172 * * * \\
(0.025)\end{array}$ & $\begin{array}{c}0.167 * * * \\
(0.026)\end{array}$ & $\begin{array}{c}0.160 * * * \\
(0.032)\end{array}$ & $\begin{array}{c}0.138 * * * \\
(0.036)\end{array}$ \\
\hline Observations & & 8,608 & 8,608 & 8,608 & 8,608 \\
\hline $\mathrm{R}^{2}$ & & -0.019 & -0.053 & 0.044 & -0.051 \\
\hline Adjusted $\mathrm{R}^{2}$ & & -0.0209 & -0.0556 & 0.0416 & -0.0528 \\
\hline Hansen $\mathrm{J}$ & & 1.356 & 1.507 & 1.970 & 0.153 \\
\hline Prob $>J$ & & 0.244 & 0.220 & 0.160 & 0.695 \\
\hline F-stat & & 117.2 & 118.6 & 116.7 & 119.9 \\
\hline Control mean & 0.00 & 22.36 & 825.60 & 442.58 & 383.02 \\
\hline
\end{tabular}

Notes: Family labor cost is included in the variables labor cost, total cost and profit using self-assessed wage. Yield, cost and revenue are expressed in logarithms. As some of the profits were negative, we ran normal regressions for the profit variables and present the estimated coefficients divided by the mean of the control group. The F-stat is from the first stage regression. Standard errors are clustered at the village level. $* * * \mathrm{p}<0.01, * * \mathrm{p}<0.05,{ }^{*} \mathrm{p}<0$. 
Table A9: ITT and IV - Effects Treatment Intensity at Midline

\begin{tabular}{|c|c|c|c|c|c|}
\hline & $(1)$ & (2) & (3) & (4) & $(5)$ \\
\hline Panel A: ITT & Adoption & Yield & Revenue & Total Cost & Profit \\
\hline \multirow[t]{2}{*}{ U1 } & $9.964 * *$ & 0.128 & 0.171 & -0.008 & 0.363 \\
\hline & $(4.357)$ & $(0.080)$ & $(0.113)$ & $(0.078)$ & $(0.264)$ \\
\hline \multirow[t]{2}{*}{ One-time untreated (U1F) } & -5.362 & -0.022 & -0.034 & 0.146 & -0.100 \\
\hline & $(9.342)$ & $(0.163)$ & $(0.227)$ & $(0.149)$ & $(0.532)$ \\
\hline \multirow[t]{2}{*}{$\mathrm{T} 1$} & $26.852 *$ & $0.209 * *$ & $0.270 * * *$ & 0.004 & $0.614 * * *$ \\
\hline & $(16.204)$ & $(0.084)$ & $(0.099)$ & $(0.075)$ & $(0.226)$ \\
\hline \multirow[t]{2}{*}{ One-time treated $(\mathrm{T} 1 \mathrm{~F})$} & 45.090 & -0.090 & -0.149 & 0.144 & -0.481 \\
\hline & $(31.041)$ & $(0.155)$ & $(0.183)$ & $(0.138)$ & $(0.415)$ \\
\hline \multirow[t]{2}{*}{$\mathrm{U} 2$} & -5.174 & $0.170 * *$ & $0.205 * *$ & 0.041 & $0.416^{* *}$ \\
\hline & $(7.140)$ & $(0.068)$ & $(0.095)$ & $(0.079)$ & $(0.190)$ \\
\hline \multirow[t]{2}{*}{ Two-time untreated (U2F) } & $27.554 *$ & -0.030 & -0.042 & -0.018 & -0.065 \\
\hline & $(15.681)$ & $(0.129)$ & $(0.177)$ & $(0.139)$ & $(0.348)$ \\
\hline \multirow[t]{2}{*}{$\mathrm{T} 2$} & 23.217 & $0.266 * * *$ & $0.347 * * *$ & 0.121 & $0.759 * * *$ \\
\hline & $(15.283)$ & $(0.074)$ & $(0.083)$ & $(0.080)$ & $(0.228)$ \\
\hline \multirow{2}{*}{ Two-time treated (T2F) } & $43.864 *$ & -0.198 & $-0.304 * *$ & -0.119 & -0.624 \\
\hline & $(25.730)$ & $(0.126)$ & $(0.136)$ & $(0.135)$ & $(0.384)$ \\
\hline \multirow[t]{2}{*}{ Baseline outcome } & & $0.146 * * *$ & $0.142 * * *$ & $0.148 * * *$ & $0.100 * * *$ \\
\hline & & $(0.022)$ & $(0.022)$ & $(0.029)$ & $(0.031)$ \\
\hline Observations & 11,515 & 8,608 & 8,608 & 8,608 & 8,608 \\
\hline $\mathrm{R}^{2}$ & 0.335 & 0.092 & 0.110 & 0.089 & 0.110 \\
\hline p-value (U1F-T1F) & 0.08 & 0.68 & 0.57 & 0.98 & 0.44 \\
\hline p-value (U1F-U2F) & 0.07 & 0.97 & 0.98 & 0.42 & 0.96 \\
\hline p-value (T1F-T2F) & 0.98 & 0.59 & 0.50 & 0.18 & 0.80 \\
\hline p-value (U2F-T2F) & 0.44 & 0.16 & 0.06 & 0.41 & 0.06 \\
\hline Control mean & 0.00 & 22.36 & 825.60 & 442.58 & 383.02 \\
\hline
\end{tabular}

Notes: Family labor cost is included in the variables labor cost, total cost and profit using self-assessed wage. Yield, cost and revenue are expressed in logarithms. As some of the profits were negative, we ran normal regressions for the profit variables and present the estimated coefficients divided by the mean of the control group. The treatment intensity is the fraction farmers trained within each village (between 0 and 1) multiplied by the treatment indicators where the base category is control group. The F-stat is from the first stage regression. Standard errors are clustered at the village level. $* * * \mathrm{p}<0.01, * * \mathrm{p}<0.05, * \mathrm{p}<0$. 


\section{Table A10: Nonlinearity in the ITT Effect of Treatment Intensity at Endline (cut-off intensity $=60 \%$ )}

\begin{tabular}{lccccc}
\hline & $(1)$ & $(2)$ & $(3)$ & $(4)$ & $(5)$ \\
\hline & Adoption & Yield & Revenue & Total Cost & Profit \\
\hline U1 & 6.262 & $0.218^{* * *}$ & $0.254^{* * *}$ & $0.213^{*}$ & 0.203 \\
One-time untreated (U1F) & $(7.723)$ & $(0.081)$ & $(0.093)$ & $(0.122)$ & $(0.388)$ \\
& 6.793 & -0.176 & -0.199 & -0.185 & 0.029 \\
U1F cut-off (more than 60\%) & $(18.175)$ & $(0.194)$ & $(0.223)$ & $(0.284)$ & $(0.904)$ \\
& 0.360 & 0.021 & 0.022 & -0.024 & -0.041 \\
T1 & $(6.347)$ & $(0.076)$ & $(0.089)$ & $(0.129)$ & $(0.375)$ \\
& $37.777^{*}$ & $0.292 * * *$ & $0.336^{* * *}$ & $0.333^{*}$ & 0.272 \\
One-time treated (T1F) & $(16.715)$ & $(0.099)$ & $(0.114)$ & $(0.175)$ & $(0.458)$ \\
& -2.218 & -0.308 & -0.348 & -0.356 & -0.057 \\
T1F cut-off (more than 60\%) & $(38.815)$ & $(0.213)$ & $(0.251)$ & $(0.379)$ & $(1.026)$ \\
& 5.743 & 0.052 & 0.052 & 0.050 & -0.057 \\
U2 & $(12.597)$ & $(0.071)$ & $(0.084)$ & $(0.111)$ & $(0.341)$ \\
& -10.466 & 0.063 & 0.082 & $0.373 * * *$ & -0.497 \\
Two-time untreated (U2F) & $(9.323)$ & $(0.105)$ & $(0.124)$ & $(0.134)$ & $(0.481)$ \\
U2F cut-off (more than 60\%) & $45.165 *$ & 0.238 & 0.253 & $-0.521 * *$ & $1.901 * *$ \\
& $(24.628)$ & $(0.233)$ & $(0.274)$ & $(0.263)$ & $(0.960)$ \\
T2 & 2.232 & $\mathbf{- 0 . 1 6 5 *}$ & $\mathbf{- 0 . 1 8 0 *}$ & 0.131 & $\mathbf{- 0 . 7 5 7 * *}$ \\
& $(9.395)$ & $\mathbf{( 0 . 0 9 3 )}$ & $\mathbf{( 0 . 1 0 7 )}$ & $(0.090)$ & $\mathbf{( 0 . 3 5 2 )}$ \\
Two-time treated (T2F) & 20.448 & 0.120 & 0.186 & $0.476 * *$ & -0.308 \\
& $(19.970)$ & $(0.102)$ & $(0.118)$ & $(0.203)$ & $(0.534)$ \\
T2F cut-off (more than 60\%) & 54.801 & 0.144 & 0.054 & $-0.713 *$ & 1.603 \\
Observations & $(44.817)$ & $(0.212)$ & $(0.245)$ & $(0.403)$ & $(1.101)$ \\
Control mean & -1.120 & -0.079 & -0.073 & $\mathbf{0 . 2 0 3 *}$ & $\mathbf{- 0 . 5 9 3 *}$ \\
& $(14.983)$ & $(0.074)$ & $(0.085)$ & $\mathbf{( 0 . 1 0 5 )}$ & $\mathbf{( 0 . 3 5 7 )}$ \\
& 10,286 & 8,626 & 8,626 & 8,626 & 8,626 \\
& 0.293 & 0.089 & 0.103 & 0.060 & 0.048 \\
& 0.00 & 21.28 & 800.57 & 505.02 & 295.55 \\
\hline
\end{tabular}

Notes: Family labor cost is included in the variables labor cost, total cost and profit using self-assessed wage. Yield, cost and revenue are expressed in logarithms. As some of the profits were negative, we ran normal regressions for the profit variables and present the estimated coefficients divided by the mean of the control group. The treatment intensities provide the interaction between treatment status and fraction trained within each village (between 0 and 1) where the base category is control group. Standard errors are clustered at the village level. $* * * p<0.01, * * p<0.05$, $* \mathrm{p}<0$. 
Robustness Checks Using Plot-level difference-in-differences

Table A11: Plot level difference-in-differences ITT estimates

\begin{tabular}{|c|c|c|c|c|c|}
\hline & $(1)$ & $(2)$ & (3) & $(4)$ & $(5)$ \\
\hline & Adoption & Yield & Revenue & Total Cost & Profit \\
\hline \multicolumn{6}{|l|}{ Treatment Status } \\
\hline U11 & $\begin{array}{c}7.089 * * * \\
(1.265)\end{array}$ & $\begin{array}{c}0.137 * * * \\
(0.038)\end{array}$ & $\begin{array}{c}0.175 * * * \\
(0.048)\end{array}$ & $\begin{array}{c}-0.010 \\
(0.036)\end{array}$ & $\begin{array}{c}0.296 * * * \\
(0.094)\end{array}$ \\
\hline U12 & $\begin{array}{c}9.193 * * * \\
(1.976)\end{array}$ & $\begin{array}{c}0.160 * * * \\
(0.036)\end{array}$ & $\begin{array}{c}0.183 * * * \\
(0.042)\end{array}$ & $\begin{array}{c}0.041 \\
(0.055)\end{array}$ & $\begin{array}{l}0.157 * \\
(0.085)\end{array}$ \\
\hline $\mathrm{U} 21$ & $\begin{array}{c}8.221^{* * *} \\
(1.450)\end{array}$ & $\begin{array}{c}0.160 * * * \\
(0.038)\end{array}$ & $\begin{array}{c}0.173 * * * \\
(0.050)\end{array}$ & $\begin{array}{c}-0.031 \\
(0.036)\end{array}$ & $\begin{array}{c}0.332 * * * \\
(0.089)\end{array}$ \\
\hline $\mathrm{U} 22$ & $\begin{array}{c}12.199 * * * \\
(2.655)\end{array}$ & $\begin{array}{c}0.152^{* * *} \\
(0.038)\end{array}$ & $\begin{array}{c}0.156^{* * *} \\
(0.046)\end{array}$ & $\begin{array}{c}0.064 \\
(0.058)\end{array}$ & $\begin{array}{c}0.185 * * \\
(0.094)\end{array}$ \\
\hline T11 & $\begin{array}{c}50.867^{* * *} \\
(4.003)\end{array}$ & $\begin{array}{c}0.142^{* * *} \\
(0.036)\end{array}$ & $\begin{array}{c}0.173 * * * \\
(0.046)\end{array}$ & $\begin{array}{c}-0.005 \\
(0.038)\end{array}$ & $\begin{array}{r}0.309 * * * \\
(0.090)\end{array}$ \\
\hline $\mathrm{T} 12$ & $\begin{array}{c}37.831 * * * \\
(3.685)\end{array}$ & $\begin{array}{c}0.141 * * * \\
(0.037)\end{array}$ & $\begin{array}{c}0.149 * * * \\
(0.042)\end{array}$ & $\begin{array}{c}0.056 \\
(0.058)\end{array}$ & $\begin{array}{c}0.146^{*} \\
(0.083)\end{array}$ \\
\hline $\mathrm{T} 21$ & $\begin{array}{c}49.165^{* * *} \\
(4.150)\end{array}$ & $\begin{array}{c}0.161 * * * \\
(0.040)\end{array}$ & $\begin{array}{c}0.173 * * * \\
(0.049)\end{array}$ & $\begin{array}{c}-0.021 \\
(0.040)\end{array}$ & $\begin{array}{c}0.348 * * * \\
(0.092)\end{array}$ \\
\hline $\mathrm{T} 22$ & $\begin{array}{c}52.868 * * * \\
(4.382)\end{array}$ & $\begin{array}{c}0.177 * * * \\
(0.036)\end{array}$ & $\begin{array}{c}0.183 * * * \\
(0.043)\end{array}$ & $\begin{array}{c}0.069 \\
(0.062)\end{array}$ & $\begin{array}{c}0.226 * * \\
(0.095)\end{array}$ \\
\hline Observations & 33,390 & 25,972 & 25,972 & 25,972 & 25,972 \\
\hline $\mathrm{R}^{2}$ & 0.342 & 0.042 & 0.070 & 0.024 & 0.110 \\
\hline Control mean & 0.00 & 22.21 & 806.97 & 435.13 & 371.84 \\
\hline p-value (U11-T11) & 0.00 & 0.81 & 0.94 & 0.80 & 0.82 \\
\hline p-value (U12-T12) & 0.00 & 0.43 & 0.18 & 0.68 & 0.81 \\
\hline p-value (T11-T12) & 0.00 & 0.98 & 0.54 & 0.14 & 0.02 \\
\hline p-value (U11-U12) & 0.21 & 0.54 & 0.84 & 0.22 & 0.05 \\
\hline p-value (U21-T21) & 0.00 & 0.95 & 0.99 & 0.71 & 0.72 \\
\hline p-value (U22-T22) & 0.00 & 0.27 & 0.33 & 0.88 & 0.48 \\
\hline p-value (T21-T22) & 0.27 & 0.66 & 0.77 & 0.04 & 0.06 \\
\hline p-value (U21-U22) & 0.15 & 0.82 & 0.65 & 0.04 & 0.04 \\
\hline
\end{tabular}

Note 1: Family labor cost is included in the variables labor cost, total cost and profit using self-assessed wage. Yield, cost and revenue are expressed in logarithms. As some of the profits were negative, we ran normal regressions for the profit variables and present the estimated coefficients divided by the mean of the control group. The row corresponding U11 indicates outcomes of untreated farmers from one-time treatment village at the midline, while U21 denotes the corresponding outcomes for the untreated farmers from two-time treatment villages at midline. Note 2: Same as Table 2. 
Table A12: Plot level difference-in-differences ITT estimates (with continuous treatment intensity)

\begin{tabular}{|c|c|c|c|c|c|}
\hline & (1) & $(2)$ & (3) & (4) & $(5)$ \\
\hline & Adoption & Yield & Revenue & Total Cost & Profit \\
\hline \multicolumn{6}{|l|}{ Treatment Status } \\
\hline $\mathrm{U} 11 \mathrm{~F}$ & $\begin{array}{c}10.683 * * * \\
(3.226)\end{array}$ & $\begin{array}{c}0.205^{* * *} \\
(0.073)\end{array}$ & $\begin{array}{c}0.253 * * * \\
(0.095)\end{array}$ & $\begin{array}{c}-0.024 \\
(0.076)\end{array}$ & $\begin{array}{c}0.442 * * \\
(0.183)\end{array}$ \\
\hline $\mathrm{U} 12 \mathrm{~F}$ & $\begin{array}{c}15.800 * * * \\
(4.007)\end{array}$ & $\begin{array}{c}0.239 * * * \\
(0.073)\end{array}$ & $\begin{array}{c}0.262 * * * \\
(0.086)\end{array}$ & $\begin{array}{c}0.003 \\
(0.117)\end{array}$ & $\begin{array}{c}0.235 \\
(0.166)\end{array}$ \\
\hline $\mathrm{U} 21 \mathrm{~F}$ & $\begin{array}{c}14.500 * * * \\
(4.255)\end{array}$ & $\begin{array}{c}0.256 * * * \\
(0.069)\end{array}$ & $\begin{array}{c}0.265 * * * \\
(0.088)\end{array}$ & $\begin{array}{c}-0.060 \\
(0.067)\end{array}$ & $\begin{array}{c}0.525 * * * \\
(0.161)\end{array}$ \\
\hline $\mathrm{U} 22 \mathrm{~F}$ & $\begin{array}{c}23.423 * * * \\
(5.949)\end{array}$ & $\begin{array}{c}0.229 * * * \\
(0.072)\end{array}$ & $\begin{array}{c}0.228 * * * \\
(0.084)\end{array}$ & $\begin{array}{c}0.060 \\
(0.102)\end{array}$ & $\begin{array}{l}0.323 * \\
(0.172)\end{array}$ \\
\hline $\mathrm{T} 11 \mathrm{~F}$ & $\begin{array}{c}88.845 * * * \\
(7.566)\end{array}$ & $\begin{array}{c}0.198 * * * \\
(0.063)\end{array}$ & $\begin{array}{c}0.232 * * * \\
(0.083)\end{array}$ & $\begin{array}{c}-0.018 \\
(0.070)\end{array}$ & $\begin{array}{c}0.430 * * * \\
(0.157)\end{array}$ \\
\hline $\mathrm{T} 12 \mathrm{~F}$ & $\begin{array}{c}64.219 * * * \\
(7.081)\end{array}$ & $\begin{array}{c}0.188 * * * \\
(0.070)\end{array}$ & $\begin{array}{c}0.189 * * \\
(0.081)\end{array}$ & $\begin{array}{c}0.026 \\
(0.115)\end{array}$ & $\begin{array}{c}0.218 \\
(0.143)\end{array}$ \\
\hline $\mathrm{T} 21 \mathrm{~F}$ & $\begin{array}{c}78.219 * * * \\
(6.886)\end{array}$ & $\begin{array}{c}0.214 * * * \\
(0.062)\end{array}$ & $\begin{array}{c}0.213 * * * \\
(0.079)\end{array}$ & $\begin{array}{l}-0.055 \\
(0.071)\end{array}$ & $\begin{array}{c}0.475 * * * \\
(0.145)\end{array}$ \\
\hline $\mathrm{T} 22 \mathrm{~F}$ & $\begin{array}{c}84.228 * * * \\
(7.139)\end{array}$ & $\begin{array}{c}0.241 * * * \\
(0.061)\end{array}$ & $\begin{array}{c}0.239 * * * \\
(0.074)\end{array}$ & $\begin{array}{c}0.052 \\
(0.114)\end{array}$ & $\begin{array}{c}0.356 * * \\
(0.155)\end{array}$ \\
\hline Observations & 33,390 & 25,972 & 25,972 & 25,972 & 25,972 \\
\hline $\mathrm{R}^{2}$ & 0.345 & 0.036 & 0.063 & 0.022 & 0.105 \\
\hline Control mean & 0.00 & 22.21 & 806.97 & 435.13 & 371.84 \\
\hline p-value (U11F-T11F) & 0.00 & 0.87 & 0.70 & 0.88 & 0.91 \\
\hline p-value (U12F-T12F) & 0.00 & 0.27 & 0.14 & 0.74 & 0.85 \\
\hline p-value (T11F-T12F) & 0.00 & 0.88 & 0.52 & 0.57 & 0.07 \\
\hline p-value (U11F-U12F) & 0.13 & 0.63 & 0.90 & 0.75 & 0.12 \\
\hline p-value (U21F-T21F) & 0.00 & 0.33 & 0.33 & 0.89 & 0.56 \\
\hline p-value (U22F-T22F) & 0.00 & 0.78 & 0.83 & 0.91 & 0.75 \\
\hline p-value (T21F-T22F) & 0.30 & 0.62 & 0.64 & 0.15 & 0.25 \\
\hline p-value (U21F-U22F) & 0.16 & 0.70 & 0.58 & 0.13 & 0.11 \\
\hline
\end{tabular}

Note: Family labor cost is included in the variables labor cost, total cost and profit using self-assessed wage. Yield, cost and revenue are expressed in logarithms. As some of the profits were negative, we ran normal regressions for the profit variables and present the estimated coefficients divided by the mean of the control group. Standard errors are clustered at the village level. $* * * \mathrm{p}<0.01, * * \mathrm{p}<0.05, * \mathrm{p}<0.1$ 
Table A13: Exploring the LATE exclusion criterion

\begin{tabular}{lcccc}
\hline & $(1)$ & $(2)$ & $(3)$ & $(4)$ \\
\cline { 2 - 5 } Variables of Interest & Yield & Revenue & $\begin{array}{c}\text { Total } \\
\text { Cost }\end{array}$ & Profit \\
\cline { 2 - 5 } U1 & $0.136^{* * *}$ & $0.164^{* * *}$ & $0.123 * * *$ & $0.210^{*}$ \\
T1 & $(0.031)$ & $(0.034)$ & $(0.046)$ & $(0.119)$ \\
& $0.126^{* * *}$ & $0.161^{* * *}$ & $0.146^{* * *}$ & $0.255^{*}$ \\
U2 & $(0.033)$ & $(0.036)$ & $(0.047)$ & $(0.133)$ \\
& $0.135^{* * *}$ & $0.160^{* * *}$ & $0.147^{* * *}$ & $0.259^{*}$ \\
T2 & $(0.035)$ & $(0.039)$ & $(0.050)$ & $(0.155)$ \\
& $0.145^{* * *}$ & $0.173^{* * *}$ & $0.172^{* * *}$ & $0.313^{*}$ \\
U1 X Adopted SRI & $(0.036)$ & $(0.039)$ & $(0.053)$ & $(0.164)$ \\
T1 X Adopted SRI & 0.051 & 0.020 & 0.027 & -0.007 \\
& $(0.032)$ & $(0.033)$ & $(0.064)$ & $(0.155)$ \\
U2 X Adopted SRI & $0.051^{* *}$ & 0.018 & 0.038 & -0.094 \\
& $(0.025)$ & $(0.027)$ & $(0.044)$ & $(0.115)$ \\
T2 X Adopted SRI & 0.077 & 0.065 & -0.031 & 0.194 \\
& $(0.066)$ & $(0.074)$ & $(0.073)$ & $(0.202)$ \\
Baseline outcome & 0.040 & 0.016 & -0.030 & 0.060 \\
& $(0.026)$ & $(0.028)$ & $(0.045)$ & $(0.124)$ \\
Observations & $0.219^{* * *}$ & $0.215^{* * *}$ & 0.023 & $0.263 * * *$ \\
R 2 & $(0.032)$ & $(0.030)$ & $(0.034)$ & $(0.051)$ \\
& & & & \\
& 8,626 & 8,626 & 8,626 & 8,626 \\
& 0.086 & 0.098 & 0.052 & 0.040 \\
\hline
\end{tabular}

Notes: See Table 2 notes. 
Table A14: Basic characteristics of different groups of farmer households by adoption status

\begin{tabular}{|c|c|c|c|c|c|c|c|c|}
\hline & \multirow{2}{*}{$\begin{array}{l}\text { Persistent } \\
\text { adopters }\end{array}$} & \multirow{2}{*}{ Disadopters } & \multirow{2}{*}{$\begin{array}{l}\text { Delayed } \\
\text { adopters }\end{array}$} & \multirow{2}{*}{ Never adopters } & \multicolumn{4}{|c|}{ p-value } \\
\hline & & & & & $(1)$ & (2) & (3) & (4) \\
\hline Household head age dummy (older than 45 yrs $=1$ ) & 0.49 & 0.65 & 0.61 & 0.61 & 0.00 & 0.69 & 0.63 & 0.00 \\
\hline Household head education dummy (have primary edu=1) & 0.58 & 0.52 & 0.54 & 0.49 & 0.00 & 0.24 & 0.42 & 0.11 \\
\hline Cultivable land dummy (land $>120$ decimals $=1$ ) & 0.62 & 0.58 & 0.57 & 0.53 & 0.00 & 0.10 & 0.70 & 0.41 \\
\hline Cultivable land (in decimals) & 177.68 & 177.06 & 179.97 & 166.29 & 0.02 & 0.06 & 0.16 & 0.74 \\
\hline Monthly Household income (in lakh BDT) & 0.11 & 0.13 & 0.12 & 0.14 & 0.00 & 0.37 & 0.09 & 0.01 \\
\hline Baseline production (in kg per decimal) & 22.35 & 23.43 & 21.55 & 22.72 & 0.23 & 0.00 & 0.00 & 0.00 \\
\hline Production at end of year 1 & 28.30 & 29.41 & 25.29 & 25.81 & 0.00 & 0.00 & 0.67 & 0.01 \\
\hline Production at end of year 2 & 26.04 & 24.45 & 26.77 & 24.76 & 0.01 & 0.84 & 0.00 & 0.04 \\
\hline Baseline cost of production & 484.48 & 486.82 & 447.25 & 469.18 & 0.15 & 0.06 & 0.01 & 0.66 \\
\hline Total cost at the end of year 1 & 485.67 & 519.20 & 440.92 & 456.12 & 0.03 & 0.00 & 0.00 & 0.00 \\
\hline Total cost at the end of year 2 & 565.70 & 571.43 & 660.70 & 613.52 & 0.00 & 0.00 & 0.14 & 0.56 \\
\hline Baseline profit & 381.27 & 461.75 & 404.31 & 440.83 & 0.00 & 0.07 & 0.01 & 0.00 \\
\hline Profit at end of year 1 & 544.15 & 618.50 & 509.03 & 543.81 & 0.89 & 0.00 & 0.28 & 0.00 \\
\hline Profit at end of year 2 & 404.03 & 385.23 & 374.66 & 355.12 & 0.02 & 0.15 & 0.36 & 0.69 \\
\hline Extent of risk aversion ${ }^{\mathrm{a}}$ (risk loving $=1$ ) & 0.54 & 0.62 & 0.67 & 0.81 & 0.08 & 0.98 & 0.85 & 0.18 \\
\hline Cognitive test ${ }^{\mathrm{a}}$ (on a scale of 0 to 10 ) & 4.37 & 4.59 & 4.38 & 4.70 & 0.01 & 0.52 & 0.07 & 0.16 \\
\hline Memory test ${ }^{\mathrm{a}}$ (on a scale of 0 to 10 ) & 5.45 & 5.74 & 5.01 & 5.37 & 0.43 & 0.00 & 0.00 & 0.01 \\
\hline Sample size- (number of farmers) & 556 & 313 & 314 & 1465 & & & & \\
\hline
\end{tabular}

Notes: p-value of the difference between (1) persistent adopters and never adopters, (2) disadopters and never adopters, (3) delayed adopters and never adopters, and (4)

disadopters and persistent adopters. ${ }^{\text {T}}$ These statistics are available only for the farmers who received SRI training, as these tests were conducted during the training activity. 
Table A15: Test for Heterogeneous ITT effects

\begin{tabular}{|c|c|c|c|c|c|}
\hline & Adoption & Yield & Revenue & Total Cost & Profit \\
\hline Baseline production (BY) & $\begin{array}{c}-0.566 \\
(0.484)\end{array}$ & $\begin{array}{c}0.050 \\
(0.034)\end{array}$ & $\begin{array}{c}0.043 \\
(0.035)\end{array}$ & $\begin{array}{c}0.155 * * * \\
(0.039)\end{array}$ & $\begin{array}{c}0.005 \\
(0.113)\end{array}$ \\
\hline $\mathrm{U}_{1} * \mathrm{BY}$ & $\begin{array}{c}2.561 \\
(3.845)\end{array}$ & $\begin{array}{c}0.007 \\
(0.044)\end{array}$ & $\begin{array}{c}0.023 \\
(0.046)\end{array}$ & $\begin{array}{c}-0.258 * * * \\
(0.058)\end{array}$ & $\begin{array}{c}0.455^{* * *} * \\
(0.154)\end{array}$ \\
\hline $\mathrm{T}_{1} * \mathrm{BY}$ & $\begin{array}{l}-5.949 \\
(4.597)\end{array}$ & $\begin{array}{l}-0.069 \\
(0.047)\end{array}$ & $\begin{array}{l}-0.055 \\
(0.052)\end{array}$ & $\begin{array}{c}-0.331 * * * \\
(0.050)\end{array}$ & $\begin{array}{c}0.501 * * * \\
(0.153)\end{array}$ \\
\hline $\mathrm{U}_{2} * \mathrm{BY}$ & $\begin{array}{l}-4.595 \\
(3.955)\end{array}$ & $\begin{array}{l}-0.051 \\
(0.049)\end{array}$ & $\begin{array}{c}-0.044 \\
(0.053)\end{array}$ & $\begin{array}{c}-0.264 * * * \\
(0.063)\end{array}$ & $\begin{array}{l}0.363 * \\
(0.211)\end{array}$ \\
\hline $\mathrm{T}_{2} * \mathrm{BY}$ & $\begin{array}{l}-7.633 \\
(5.738)\end{array}$ & $\begin{array}{l}-0.069 \\
(0.042)\end{array}$ & $\begin{array}{l}-0.062 \\
(0.045)\end{array}$ & $\begin{array}{c}-0.289 * * * \\
(0.052)\end{array}$ & $\begin{array}{c}0.371 * * \\
(0.147)\end{array}$ \\
\hline Observations & 10,215 & 8,626 & 8,626 & 8,626 & 8,626 \\
\hline $\mathrm{R}^{2}$ & 0.284 & 0.087 & 0.099 & 0.084 & 0.059 \\
\hline Baseline cultivable land (BCL) & $\begin{array}{c}0.265 \\
(0.521)\end{array}$ & $\begin{array}{c}0.067 * * * \\
(0.026)\end{array}$ & $\begin{array}{c}0.066^{* *} \\
(0.026)\end{array}$ & $\begin{array}{c}0.065 * * * \\
(0.023)\end{array}$ & $\begin{array}{c}0.040 \\
(0.070)\end{array}$ \\
\hline $\mathrm{U}_{1} * \mathrm{BCL}$ & $\begin{array}{c}0.797 \\
(2.960)\end{array}$ & $\begin{array}{l}-0.015 \\
(0.038)\end{array}$ & $\begin{array}{l}-0.020 \\
(0.039)\end{array}$ & $\begin{array}{l}-0.021 \\
(0.046)\end{array}$ & $\begin{array}{c}-0.028 \\
(0.128)\end{array}$ \\
\hline $\mathrm{T}_{1} * \mathrm{BCL}$ & $\begin{array}{c}2.939 \\
(4.489)\end{array}$ & $\begin{array}{c}-0.081 * * \\
(0.040)\end{array}$ & $\begin{array}{c}-0.096 * * \\
(0.042)\end{array}$ & $\begin{array}{c}-0.046 \\
(0.046)\end{array}$ & $\begin{array}{l}-0.208 \\
(0.133)\end{array}$ \\
\hline $\mathrm{U}_{2} * \mathrm{BCL}$ & $\begin{array}{c}10.965^{* * *} \\
(3.769)\end{array}$ & $\begin{array}{c}-0.052 \\
(0.044)\end{array}$ & $\begin{array}{l}-0.060 \\
(0.046)\end{array}$ & $\begin{array}{c}-0.005 \\
(0.044)\end{array}$ & $\begin{array}{c}-0.143 \\
(0.143)\end{array}$ \\
\hline $\mathrm{T}_{2} * \mathrm{BCL}$ & $\begin{array}{c}6.604 \\
(4.194)\end{array}$ & $\begin{array}{c}-0.068 * * \\
(0.032)\end{array}$ & $\begin{array}{c}-0.073 * * \\
(0.033)\end{array}$ & $\begin{array}{l}-0.028 \\
(0.040)\end{array}$ & $\begin{array}{l}-0.092 \\
(0.114)\end{array}$ \\
\hline Observations & 10,286 & 8,626 & 8,626 & 8,626 & 8,626 \\
\hline $\mathrm{R}^{2}$ & 0.283 & 0.086 & 0.100 & 0.051 & 0.040 \\
\hline Baseline Household size (BHS) & $\begin{array}{c}1.589 \\
(1.209)\end{array}$ & $\begin{array}{l}-0.004 \\
(0.017)\end{array}$ & $\begin{array}{l}-0.010 \\
(0.017)\end{array}$ & $\begin{array}{l}-0.027 \\
(0.024)\end{array}$ & $\begin{array}{c}0.024 \\
(0.058)\end{array}$ \\
\hline $\mathrm{U}_{1} * \mathrm{BHS}$ & $\begin{array}{l}-0.916 \\
(2.424)\end{array}$ & $\begin{array}{l}-0.057 * \\
(0.031)\end{array}$ & $\begin{array}{l}-0.055^{*} \\
(0.033)\end{array}$ & $\begin{array}{c}-0.013 \\
(0.049)\end{array}$ & $\begin{array}{l}-0.036 \\
(0.131)\end{array}$ \\
\hline $\mathrm{T}_{1} * \mathrm{BHS}$ & $\begin{array}{c}8.401 * * \\
(3.732)\end{array}$ & $\begin{array}{c}0.027 \\
(0.036)\end{array}$ & $\begin{array}{c}0.032 \\
(0.037)\end{array}$ & $\begin{array}{c}0.037 \\
(0.042)\end{array}$ & $\begin{array}{l}-0.032 \\
(0.121)\end{array}$ \\
\hline $\mathrm{U}_{2} * \mathrm{BHS}$ & $\begin{array}{l}-4.780 \\
(3.280)\end{array}$ & $\begin{array}{l}-0.029 \\
(0.035)\end{array}$ & $\begin{array}{l}-0.024 \\
(0.037)\end{array}$ & $\begin{array}{c}0.015 \\
(0.046)\end{array}$ & $\begin{array}{l}-0.078 \\
(0.134)\end{array}$ \\
\hline $\mathrm{T}_{2} * \mathrm{BHS}$ & $\begin{array}{l}-1.801 \\
(3.878)\end{array}$ & $\begin{array}{c}0.022 \\
(0.028)\end{array}$ & $\begin{array}{c}0.026 \\
(0.028)\end{array}$ & $\begin{array}{l}-0.028 \\
(0.040)\end{array}$ & $\begin{array}{c}0.106 \\
(0.095)\end{array}$ \\
\hline Observations & 10,286 & 8,626 & 8,626 & 8,626 & 8,626 \\
\hline $\mathrm{R}^{2}$ & 0.284 & 0.085 & 0.099 & 0.052 & 0.039 \\
\hline Baseline Working adults (BWA) & $\begin{array}{c}3.551 * * \\
(1.367)\end{array}$ & $\begin{array}{c}0.006 \\
(0.020)\end{array}$ & $\begin{array}{c}0.003 \\
(0.020)\end{array}$ & $\begin{array}{l}-0.016 \\
(0.024)\end{array}$ & $\begin{array}{c}0.056 \\
(0.060)\end{array}$ \\
\hline $\mathrm{U}_{1} * \mathrm{BWA}$ & $\begin{array}{l}-1.516 \\
(2.347)\end{array}$ & $\begin{array}{l}-0.029 \\
(0.032)\end{array}$ & $\begin{array}{l}-0.034 \\
(0.032)\end{array}$ & $\begin{array}{c}-0.003 \\
(0.046)\end{array}$ & $\begin{array}{l}-0.052 \\
(0.125)\end{array}$ \\
\hline $\mathrm{T}_{1} * \mathrm{BWA}$ & $\begin{array}{c}0.532 \\
(3.546)\end{array}$ & $\begin{array}{l}-0.014 \\
(0.035)\end{array}$ & $\begin{array}{l}-0.013 \\
(0.037)\end{array}$ & $\begin{array}{c}0.004 \\
(0.036)\end{array}$ & $\begin{array}{l}-0.083 \\
(0.109)\end{array}$ \\
\hline $\mathrm{U}_{2} * \mathrm{BWA}$ & $\begin{array}{c}1.532 \\
(3.593)\end{array}$ & $\begin{array}{l}-0.010 \\
(0.036)\end{array}$ & $\begin{array}{l}-0.008 \\
(0.038)\end{array}$ & $\begin{array}{c}0.048 \\
(0.048)\end{array}$ & $\begin{array}{l}-0.122 \\
(0.138)\end{array}$ \\
\hline $\mathrm{T}_{2} * \mathrm{BWA}$ & $\begin{array}{c}-8.803 * * \\
(3.952)\end{array}$ & $\begin{array}{l}-0.031 \\
(0.028)\end{array}$ & $\begin{array}{l}-0.024 \\
(0.029)\end{array}$ & $\begin{array}{c}0.014 \\
(0.032)\end{array}$ & $\begin{array}{l}-0.093 \\
(0.086)\end{array}$ \\
\hline Observations & 10,286 & 8,626 & 8,626 & 8,626 & 8,626 \\
\hline $\mathrm{R}^{2}$ & 0.283 & 0.084 & 0.097 & 0.051 & 0.039 \\
\hline
\end{tabular}




\begin{tabular}{lccccc}
\hline & Adoption & Yield & Revenue & Total Cost & Profit \\
\hline Baseline Household Income (BHI) & -1.012 & $0.052^{* *}$ & $0.060^{* * *}$ & $0.092^{* * *}$ & -0.052 \\
& $(0.721)$ & $(0.022)$ & $(0.023)$ & $(0.030)$ & $(0.072)$ \\
$\mathrm{U}_{1} * \mathrm{BHI}$ & $-6.552^{* *}$ & -0.013 & 0.005 & -0.061 & 0.128 \\
& $(3.315)$ & $(0.038)$ & $(0.039)$ & $(0.045)$ & $(0.119)$ \\
$\mathrm{T}_{1}{ }^{*} \mathrm{BHI}$ & -6.663 & 0.025 & 0.040 & $-0.076^{*}$ & $0.255^{* *}$ \\
& $(4.117)$ & $(0.036)$ & $(0.037)$ & $(0.043)$ & $(0.118)$ \\
$\mathrm{U}_{2} * \mathrm{BHI}$ & -1.041 & -0.004 & 0.013 & $-0.096^{* *}$ & $0.258^{*}$ \\
& $(4.497)$ & $(0.045)$ & $(0.049)$ & $(0.047)$ & $(0.155)$ \\
$\mathrm{T}_{2}{ }^{*} \mathrm{BHI}$ & $-13.760^{* * *}$ & 0.015 & 0.027 & -0.008 & 0.093 \\
& $(4.045)$ & $(0.032)$ & $(0.035)$ & $(0.044)$ & $(0.115)$ \\
Observations & 10,286 & 8,626 & 8,626 & 8,626 & 8,626 \\
$\mathrm{R}^{2}$ & 0.288 & 0.089 & 0.104 & 0.057 & 0.041 \\
\hline
\end{tabular}

Notes: Family labor cost is included in the variables labor cost, total cost and profit using self-assessed wage. Yield, cost and revenue are expressed in logarithms. As some of the profits were negative, we ran normal regressions for the profit variables and present the estimated coefficients divided by the mean of the control group. Standard errors are clustered at the village level. $* * * \mathrm{p}<0.01, * * \mathrm{p}<0.05, * \mathrm{p}<0.01$. We do not report the coefficients on the treatment status dummies. They are similar to those presented in Table 2 in all four regressions. 
Table A16: Quantile Regression Estimates

\begin{tabular}{lcccccc}
\hline & & Yield & \multicolumn{4}{c}{ Revenue } \\
\hline Panel A: Treatment Status & 0.25 & 0.5 & 0.75 & 0.25 & 0.5 & 0.75 \\
\hline One-time untreated (U1) & $0.143^{* * *}$ & $0.120^{* * *}$ & $0.143^{* * *}$ & $0.175^{* * *}$ & $0.133^{* * *}$ & $0.173^{* * *}$ \\
& $(0.015)$ & $(0.009)$ & $(0.010)$ & $(0.015)$ & $(0.008)$ & $(0.007)$ \\
One-time treated (T1) & $0.142^{* * *}$ & $0.127^{* * *}$ & $0.167^{* * *}$ & $0.166^{* * *}$ & $0.152^{* * *}$ & $0.191^{* * *}$ \\
& $(0.014)$ & $(0.007)$ & $(0.007)$ & $(0.021)$ & $(0.007)$ & $(0.008)$ \\
Two-time untreated (U2) & $0.143^{* * *}$ & $0.125^{* * *}$ & $0.159^{* * *}$ & $0.161^{* * *}$ & $0.145^{* * *}$ & $0.191^{* * *}$ \\
& $(0.018)$ & $(0.011)$ & $(0.010)$ & $(0.022)$ & $(0.012)$ & $(0.013)$ \\
Two-time treated (T2) & $0.157^{* * *}$ & $0.141^{* * *}$ & $0.174^{* * *}$ & $0.177^{* * *}$ & $0.157^{* * *}$ & $0.194^{* * *}$ \\
& $(0.013)$ & $(0.008)$ & $(0.009)$ & $(0.020)$ & $(0.010)$ & $(0.007)$ \\
Observations & 8,626 & 8,626 & 8,626 & 8,626 & 8,626 & 8,626 \\
\hline Panel B: & & Total Cost & & & Profit & \\
\hline One-time untreated (U1) & $0.153^{* * *}$ & $0.147^{* * *}$ & $0.162^{* * *}$ & 0.094 & $0.122^{* * *}$ & $0.329^{* * *}$ \\
& $(0.020)$ & $(0.020)$ & $(0.027)$ & $(0.073)$ & $(0.043)$ & $(0.064)$ \\
One-time treated (T1) & $0.150^{* * *}$ & $0.172^{* * *}$ & $0.238^{* * *}$ & -0.002 & $0.095^{* *}$ & $0.357^{* * *}$ \\
& $(0.014)$ & $(0.011)$ & $(0.016)$ & $(0.048)$ & $(0.038)$ & $(0.029)$ \\
Two-time untreated (U2) & $0.167^{* * *}$ & $0.146^{* * *}$ & $0.169^{* * *}$ & 0.040 & $0.184^{* * *}$ & $0.400^{* * *}$ \\
& $(0.015)$ & $(0.019)$ & $(0.021)$ & $(0.066)$ & $(0.058)$ & $(0.055)$ \\
Two-time treated (T2) & $0.149^{* * *}$ & $0.171^{* * *}$ & $0.211 * * *$ & -0.023 & $0.201 * * *$ & $0.404^{* * *}$ \\
& $(0.016)$ & $(0.014)$ & $(0.021)$ & $(0.053)$ & $(0.034)$ & $(0.033)$ \\
Observations & 8,626 & 8,626 & 8,626 & 8,626 & 8,626 & 8,626 \\
\hline
\end{tabular}

Note: Family labor cost is included in the variables labor cost, total cost and profit using self-assessed wage. Yield, cost and revenue are expressed in logarithms. As some of the profits were negative, we ran normal regressions for the profit variables and present the estimated coefficients divided by the mean of the control group. Standard errors are clustered at the village level. $* * * \mathrm{p}<0.01, * * \mathrm{p}<0.05, * \mathrm{p}<0.1$. 


\section{Farmers' adjustments of practices}

We explore the question of farmer learning by studying how adherence to the six SRI principles taught in BRAC training varies with exposure intensity, including one's own experience with the practice (i.e., learning by doing), from midline to endline. We have already established that the greater a farmer's exposure to SRI training, the more likely he is to adopt the SRI principles. But we have also seen that farmers do not fully adhere to the principles as taught. For example, while all the treatment arm groups transplant younger seedlings than do control farmers (Table 1), few go so far as to transplant as young as 20 days, the BRAC recommendation. By exploring farmers' adjustment of rice cultivation practices in response to SRI training exposure and own experience, we can perhaps gain some further insights on the learning processes occurring within this sample.

Toward that end, we estimate a plot-level panel regression using all three waves of data (i.e., baseline, midline, endline) following equation (3), with a binary variable for adoption of different SRI principles as the outcome variables of interest. The estimation results are presented in Tables A17 and A18. The takeaway from these tables is that learning the practices seems to occur mainly from direct training by BRAC agents, to a lesser degree from learning from other farmers, and least from learning by doing. Direct trainees are significantly more likely to follow each of the six recommended practices than are control farmers at midline, post-training. With the exception of using mechanical weeders or the AWD water management method, direct trainees are also statistically significantly more likely than untrained farmers in training villages to follow each principle at midline. But there was no statistically significant difference in compliance between $\mathrm{T} 1$ and $\mathrm{T} 2$ farmers at midline in any principle, consistent with them having received exactly the same exposure to SRI at that point in time. But other than modestly wider spacing among seedlings and increased use of mechanical weeders, the T1 farmers did not significantly increase adherence to SRI training between midline and endline, in the absence of further training. They exhibit little learning by doing nor from others following their and their neighbors' initial year of experience with SRI. The U1 and U2 farmers did see modest, but jointly statistically significant, increases in adherence to the key three SRI principles (age, number and spacing of transplanted seedlings) from midline to endline, consistent with the lagged adoption impacts observed earlier as these farmers learned SRI from their BRAC-trained neighbors.

By contrast, the T2 farmers significantly increased adherence to each of the six principles from midline to endline, with the exception of AWD water management, which increased, but insignificantly. Limited adherence to that specific principle may arise because coordinating 
irrigation among farmers proved an obstacle, as a number of participants told us. Increased adherence among the T2 farmers relative to $\mathrm{T} 1$ farmers from midline to endline suggests the importance of formal extension programming to advance learning about the method, even of the short duration in this experiment, much as Moser and Barrett (2006) found in observational data in Madagascar. Even so, these adjustments were far more modest than overall adoption, and outcomes did not improve significantly for $\mathrm{T} 2$ farmers from midline to endline, relative to the other groups (Table A17).

Overall, the story is one of limited independent learning outside of BRAC's formal SRI extension effort within villages. The lone exception is the spacing of seedlings, which, along with AWD water management, is the most easily visible change of practice from traditional to SRI rice cultivation and thus most likely to be absorbed through passive learning from others. 
Table A17: Plot level difference-in-differences estimates for SRI principles

\begin{tabular}{|c|c|c|c|c|c|c|}
\hline & $(1)$ & $(2)$ & (3) & $(4)$ & $(5)$ & $(6)$ \\
\hline & $\begin{array}{c}\text { Age of } \\
\text { seedlings }\end{array}$ & $\begin{array}{c}\text { No of } \\
\text { seedlings }\end{array}$ & $\begin{array}{c}\text { Distance } \\
\text { between } \\
\text { seedlings }\end{array}$ & $\begin{array}{c}\text { Alternate } \\
\text { drying \& } \\
\text { wetting }\end{array}$ & $\begin{array}{l}\text { Use of } \\
\text { organic } \\
\text { fertilizer }\end{array}$ & $\begin{array}{c}\text { Mechanical } \\
\text { weeding }\end{array}$ \\
\hline \multicolumn{7}{|l|}{ Treatment Status } \\
\hline \multirow[t]{2}{*}{ U11 } & -0.152 & 2.099 & $1.749 * *$ & $12.959 *$ & 1.740 & -1.714 \\
\hline & $(0.278)$ & $(3.853)$ & $(0.861)$ & $(6.867)$ & $(2.710)$ & $(1.062)$ \\
\hline \multirow[t]{2}{*}{ U12 } & $1.915^{*}$ & 2.886 & $5.719 * * *$ & 3.895 & $10.881 * *$ & $9.500 * * *$ \\
\hline & $(1.043)$ & $(4.013)$ & $(1.466)$ & $(7.504)$ & $(4.294)$ & $(3.255)$ \\
\hline \multirow[t]{2}{*}{$\mathrm{U} 21$} & 0.058 & 5.385 & $4.143 * * *$ & 11.568 & $4.670^{*}$ & $-2.201 * *$ \\
\hline & $(0.332)$ & $(4.174)$ & $(1.433)$ & $(7.157)$ & $(2.744)$ & $(0.970)$ \\
\hline \multirow[t]{2}{*}{$\mathrm{U} 22$} & 0.721 & $7.769 *$ & $9.774 * * *$ & $17.859 * *$ & $11.365 * * *$ & $4.617 * *$ \\
\hline & $(0.638)$ & $(4.646)$ & $(2.116)$ & $(7.347)$ & $(4.348)$ & $(2.008)$ \\
\hline \multirow[t]{2}{*}{ T11 } & $3.344 * * *$ & $15.138 * * *$ & $15.546 * * *$ & $20.315 * * *$ & $10.560 * * *$ & 0.519 \\
\hline & $(0.821)$ & (3.847) & (1.988) & $(6.541)$ & $(3.363)$ & $(1.567)$ \\
\hline \multirow[t]{2}{*}{$\mathrm{T} 12$} & $4.067 * * *$ & $20.486 * * *$ & $24.318 * * *$ & 11.245 & $14.480 * * *$ & $12.330 * * *$ \\
\hline & $(1.210)$ & $(4.701)$ & $(3.061)$ & $(7.366)$ & $(3.918)$ & $(3.579)$ \\
\hline \multirow[t]{2}{*}{$\mathrm{T} 21$} & $2.306 * * *$ & $15.008 * * *$ & $14.127 * * *$ & $18.304 * * *$ & $12.162 * * *$ & -0.741 \\
\hline & $(0.566)$ & $(3.851)$ & $(1.683)$ & $(6.528)$ & $(3.579)$ & $(1.145)$ \\
\hline \multirow[t]{2}{*}{$\mathrm{T} 22$} & $5.794 * * *$ & $24.850 * * *$ & $30.035 * * *$ & $22.394 * * *$ & $21.448 * * *$ & $9.075 * * *$ \\
\hline & $(1.316)$ & $(4.568)$ & $(3.256)$ & $(7.014)$ & $(3.996)$ & $(2.809)$ \\
\hline Observations & 32,244 & 32,244 & 32,244 & 32,244 & 32,244 & 32,244 \\
\hline $\mathrm{R}^{2}$ & 0.024 & 0.155 & 0.132 & 0.495 & 0.120 & 0.068 \\
\hline Control mean & 0.31 & 7.35 & 0.30 & 32.08 & 5.38 & 1.20 \\
\hline p-value (U11-T11) & 0.00 & 0.00 & 0.00 & 0.05 & 0.00 & 0.02 \\
\hline p-value (U12-T12) & 0.06 & 0.00 & 0.00 & 0.07 & 0.26 & 0.36 \\
\hline p-value (T11-T12) & 0.56 & 0.04 & 0.00 & 0.04 & 0.27 & 0.00 \\
\hline p-value (U11-U12) & 0.04 & 0.73 & 0.00 & 0.11 & 0.01 & 0.00 \\
\hline p-value (U21-T21) & 0.00 & 0.00 & 0.00 & 0.06 & 0.00 & 0.03 \\
\hline p-value (U22-T22) & 0.00 & 0.00 & 0.00 & 0.18 & 0.00 & 0.02 \\
\hline p-value (T21-T22) & 0.01 & 0.00 & 0.00 & 0.32 & 0.02 & 0.00 \\
\hline p-value (U21-U22) & 0.24 & 0.27 & 0.00 & 0.24 & 0.09 & 0.00 \\
\hline
\end{tabular}

Notes: The first character of the treatment status identifier indicates trained $(\mathrm{T})$ or untrained but resident in training village (U). The second character indicates the number of years of training in the village. The third character indicates year, either midline (1) or endline (2), as compared to the omitted baseline (0). Each of these outcome variables is a dummy variable (multiplied by 100) indicating if a farmer followed that principle as recommended by BRAC for SRI. Standard errors are clustered at the village level. $* * * \mathrm{p}<0.01, * * \mathrm{p}<0.05, * \mathrm{p}<0.1$. 
Table A18: Plot level difference-in-differences for different SRI principles (with continuous treatment intensity)

\begin{tabular}{|c|c|c|c|c|c|c|}
\hline & $(1)$ & $(2)$ & (3) & (4) & $(5)$ & $(6)$ \\
\hline & $\begin{array}{c}\text { Age of } \\
\text { seedlings }\end{array}$ & $\begin{array}{c}\text { No of } \\
\text { seedlings }\end{array}$ & $\begin{array}{l}\text { Distance } \\
\text { between } \\
\text { seedlings }\end{array}$ & $\begin{array}{c}\text { Alternate } \\
\text { drying \& } \\
\text { wetting }\end{array}$ & $\begin{array}{c}\text { Use of } \\
\text { organic } \\
\text { fertilizer }\end{array}$ & $\begin{array}{c}\text { Machine } \\
\text { based } \\
\text { weeding }\end{array}$ \\
\hline \multicolumn{7}{|l|}{ Treatment Status } \\
\hline U11F & $\begin{array}{c}-0.451 \\
(0.671)\end{array}$ & $\begin{array}{c}6.173 \\
(7.515)\end{array}$ & $\begin{array}{l}3.511 * \\
(1.938)\end{array}$ & $\begin{array}{c}18.103 \\
(12.392)\end{array}$ & $\begin{array}{c}3.090 \\
(5.069)\end{array}$ & $\begin{array}{l}-2.139 \\
(2.431)\end{array}$ \\
\hline $\mathrm{U} 12 \mathrm{~F}$ & $\begin{array}{c}5.190 * * \\
(2.136)\end{array}$ & $\begin{array}{c}5.214 \\
(7.222)\end{array}$ & $\begin{array}{c}10.085^{* * *} \\
(3.028)\end{array}$ & $\begin{array}{c}5.855 \\
(13.833)\end{array}$ & $\begin{array}{l}16.178 * \\
(8.221)\end{array}$ & $\begin{array}{c}16.494 * * * \\
(5.902)\end{array}$ \\
\hline $\mathrm{U} 21 \mathrm{~F}$ & $\begin{array}{c}0.179 \\
(0.890)\end{array}$ & $\begin{array}{l}11.243 \\
(7.253)\end{array}$ & $\begin{array}{c}8.541 * * * \\
(3.038)\end{array}$ & $\begin{array}{c}17.978 \\
(12.081)\end{array}$ & $\begin{array}{c}10.344^{*} \\
(5.497)\end{array}$ & $\begin{array}{c}-3.577 * * \\
(1.654)\end{array}$ \\
\hline $\mathrm{U} 22 \mathrm{~F}$ & $\begin{array}{c}2.746 \\
(1.810)\end{array}$ & $\begin{array}{l}15.113 * \\
(8.206)\end{array}$ & $\begin{array}{c}18.122 * * * \\
(4.452)\end{array}$ & $\begin{array}{c}28.746 * * \\
(12.911)\end{array}$ & $\begin{array}{c}15.694^{* *} \\
(7.303)\end{array}$ & $\begin{array}{c}6.936 \\
(4.710)\end{array}$ \\
\hline $\mathrm{T} 11 \mathrm{~F}$ & $\begin{array}{c}5.741 * * * \\
(1.442)\end{array}$ & $\begin{array}{c}28.543 * * * \\
(7.138)\end{array}$ & $\begin{array}{c}28.442 * * * \\
(3.706)\end{array}$ & $\begin{array}{c}32.140 * * * \\
(10.822)\end{array}$ & $\begin{array}{c}20.208 * * * \\
(6.590)\end{array}$ & $\begin{array}{c}2.424 \\
(3.418)\end{array}$ \\
\hline $\mathrm{T} 12 \mathrm{~F}$ & $\begin{array}{c}8.690 * * * \\
(2.599)\end{array}$ & $\begin{array}{c}38.283 * * * \\
(9.036)\end{array}$ & $\begin{array}{c}42.831 * * * \\
(6.020)\end{array}$ & $\begin{array}{c}16.671 \\
(12.341)\end{array}$ & $\begin{array}{c}21.566 * * * \\
(7.591)\end{array}$ & $\begin{array}{c}19.172 * * * \\
(7.239)\end{array}$ \\
\hline $\mathrm{T} 21 \mathrm{~F}$ & $\begin{array}{c}3.362 * * * \\
(0.847)\end{array}$ & $\begin{array}{c}25.777 * * * \\
(6.193)\end{array}$ & $\begin{array}{c}23.060 * * * \\
(2.888)\end{array}$ & $\begin{array}{c}25.361 * * \\
(9.926)\end{array}$ & $\begin{array}{c}20.987 * * * \\
(6.303)\end{array}$ & $\begin{array}{c}-0.432 \\
(1.801)\end{array}$ \\
\hline $\mathrm{T} 22 \mathrm{~F}$ & $\begin{array}{c}10.537 * * * \\
(2.642)\end{array}$ & $\begin{array}{c}41.021 * * * \\
(7.830)\end{array}$ & $\begin{array}{c}47.804 * * * \\
(5.676)\end{array}$ & $\begin{array}{c}33.846^{* * *} \\
(10.414)\end{array}$ & $\begin{array}{c}30.482 * * * \\
(6.652)\end{array}$ & $\begin{array}{c}12.980 * * \\
(5.177)\end{array}$ \\
\hline Observations & 32,244 & 32,244 & 32,244 & 32,244 & 32,244 & 32,244 \\
\hline $\mathrm{R}^{2}$ & 0.026 & 0.158 & 0.133 & 0.493 & 0.117 & 0.062 \\
\hline Control mean & 0.31 & 7.35 & 0.30 & 32.08 & 5.38 & 1.20 \\
\hline p-value (U11F-T11F) & 0.00 & 0.00 & 0.00 & 0.03 & 0.00 & 0.02 \\
\hline p-value (U12F-T12F) & 0.13 & 0.00 & 0.00 & 0.15 & 0.35 & 0.64 \\
\hline p-value (T11F-T12F) & 0.26 & 0.04 & 0.00 & 0.06 & 0.83 & 0.00 \\
\hline p-value (U11F-U12F) & 0.01 & 0.84 & 0.00 & 0.29 & 0.07 & 0.00 \\
\hline p-value (U21F-T21F) & 0.00 & 0.00 & 0.00 & 0.27 & 0.02 & 0.01 \\
\hline p-value (U22F-T22F) & 0.00 & 0.00 & 0.00 & 0.45 & 0.00 & 0.06 \\
\hline p-value (T21F-T22F) & 0.01 & 0.00 & 0.00 & 0.18 & 0.17 & 0.00 \\
\hline p-value (U21F-U22F) & 0.07 & 0.36 & 0.01 & 0.28 & 0.45 & 0.03 \\
\hline
\end{tabular}

Notes: Each of these outcome variables are dummy variables (multiplied by 100) indicating if a farmer followed that principle as recommended by BRAC for SRI. Standard errors are clustered at the village level. $* * * \mathrm{p}<0.01, * *$ $\mathrm{p}<0.05, * \mathrm{p}<0.1$. 


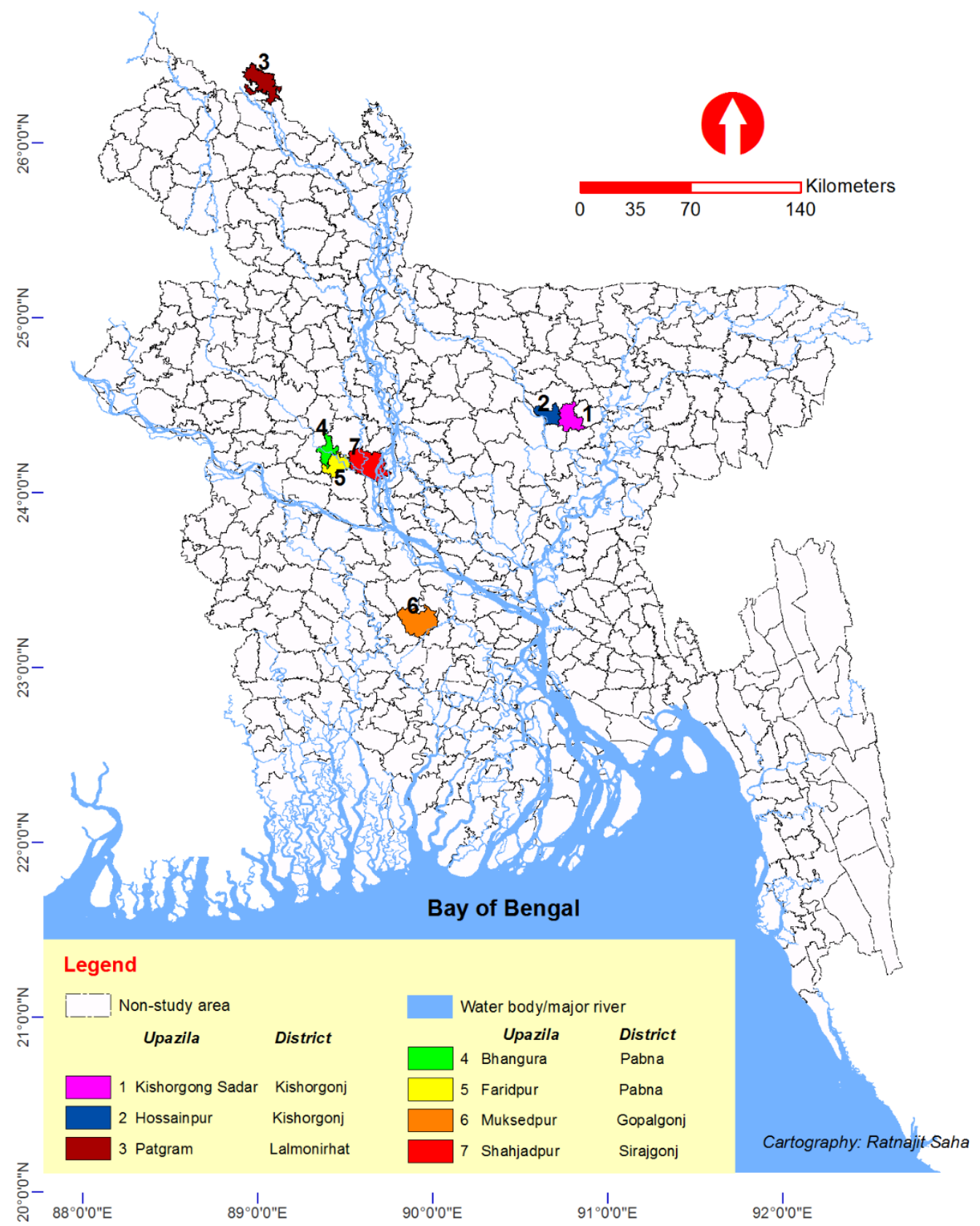

Figure A1: Map of survey villages 


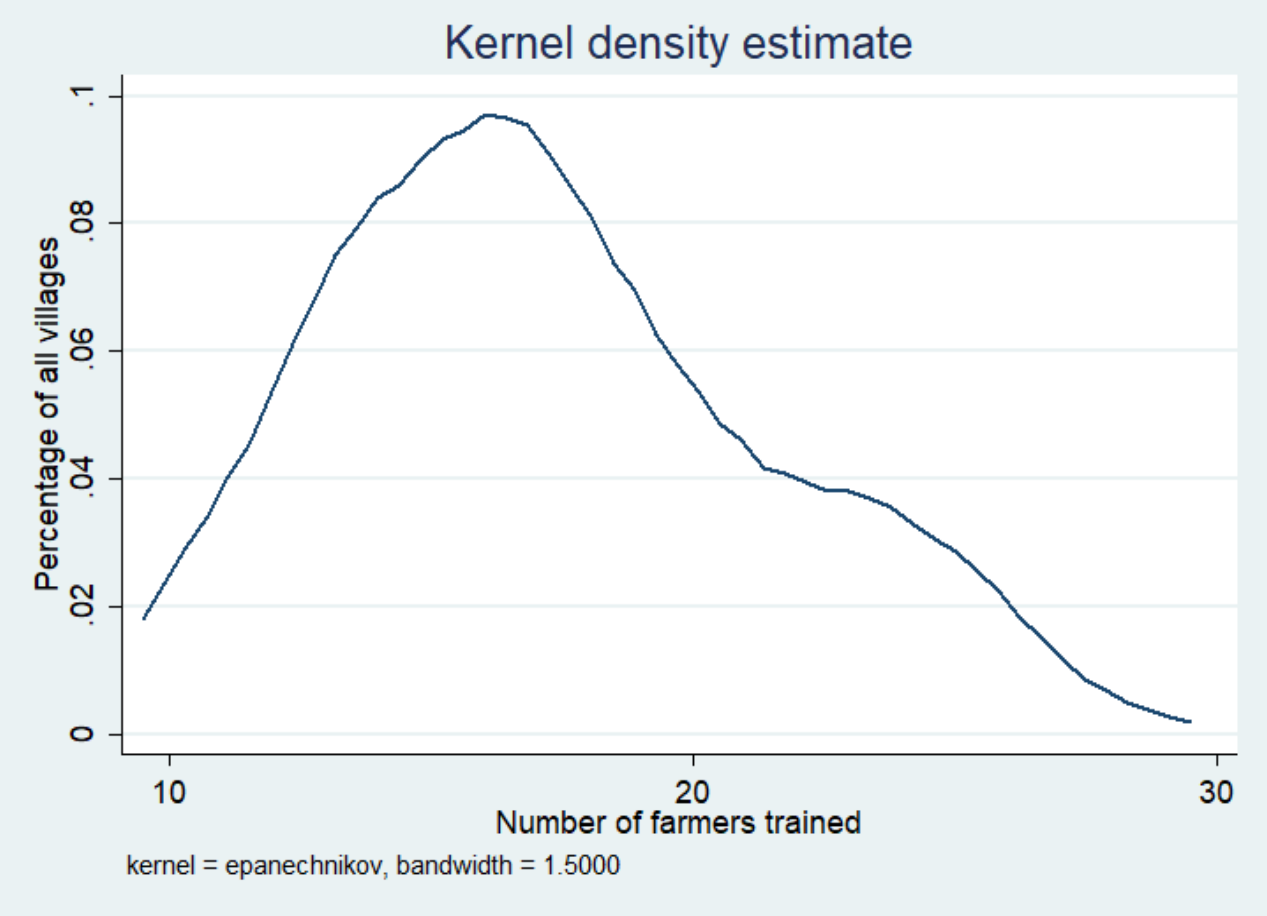

Figure A2: The distribution of the number of treated farmers across treated villages

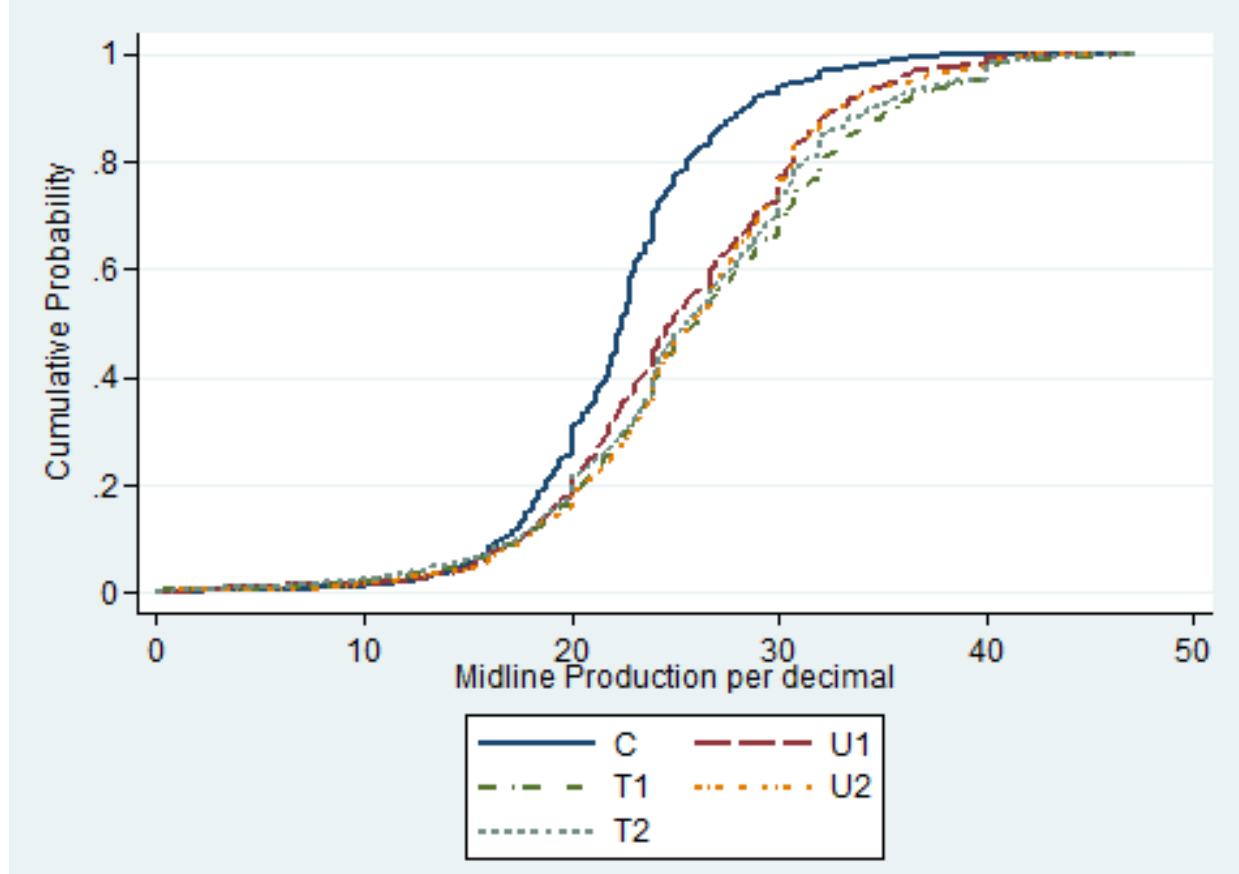

Note: Each of the four treatment groups (U1, U2, T1 and T2) first order stochastically dominates the control group (C) based on Somers' D statistic. But none of the treatment groups first, second, or third order stochastically dominates any other treatment group.

Figure A3: Cumulative distribution function of midline production per decimal of land 


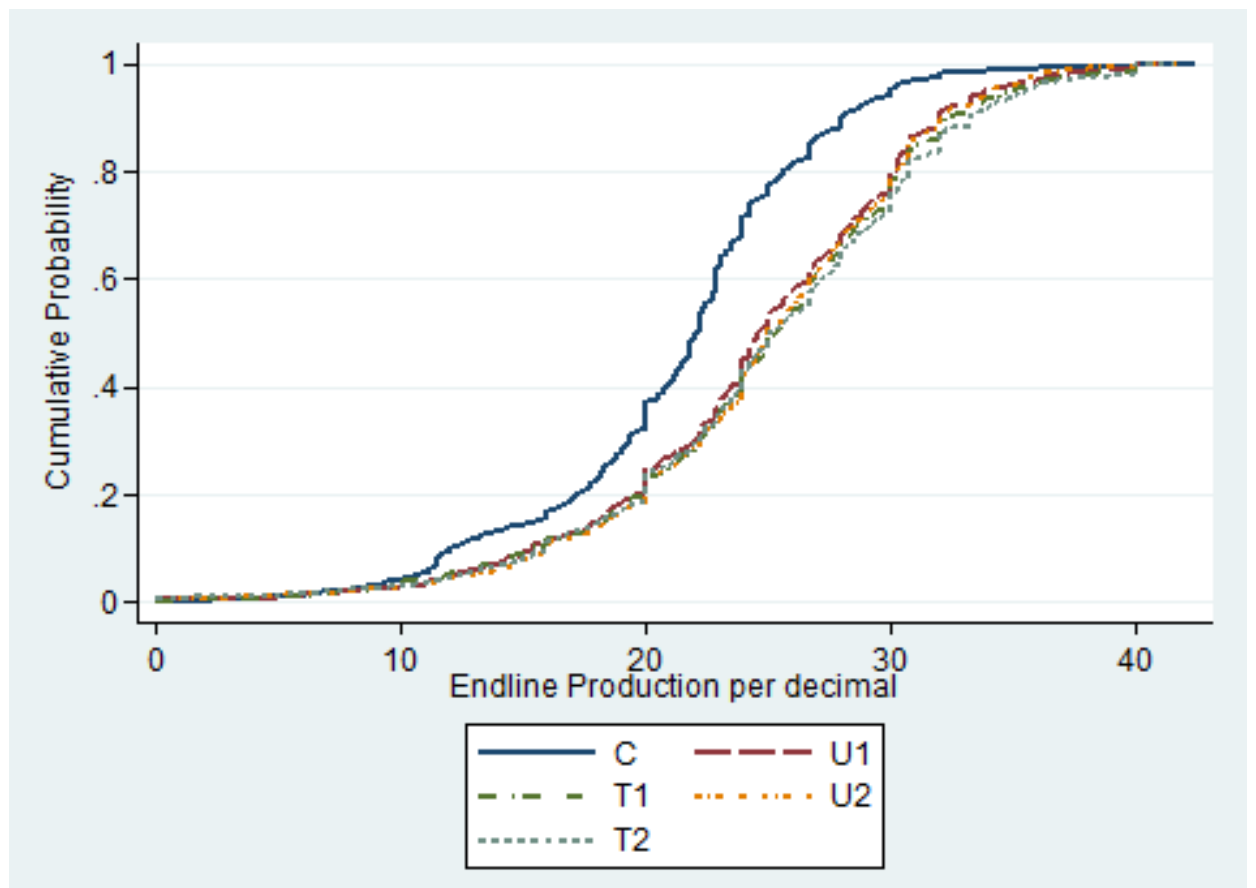

Note: Each of the four treatment groups (U1, U2, T1 and T2) first order stochastically dominates the control group (C) based on Somers' D statistic. But none of the treatment groups first, second, or third order stochastically dominates any other treatment group.

\section{Figure A4: Cumulative distribution function of endline production per decimal of land}

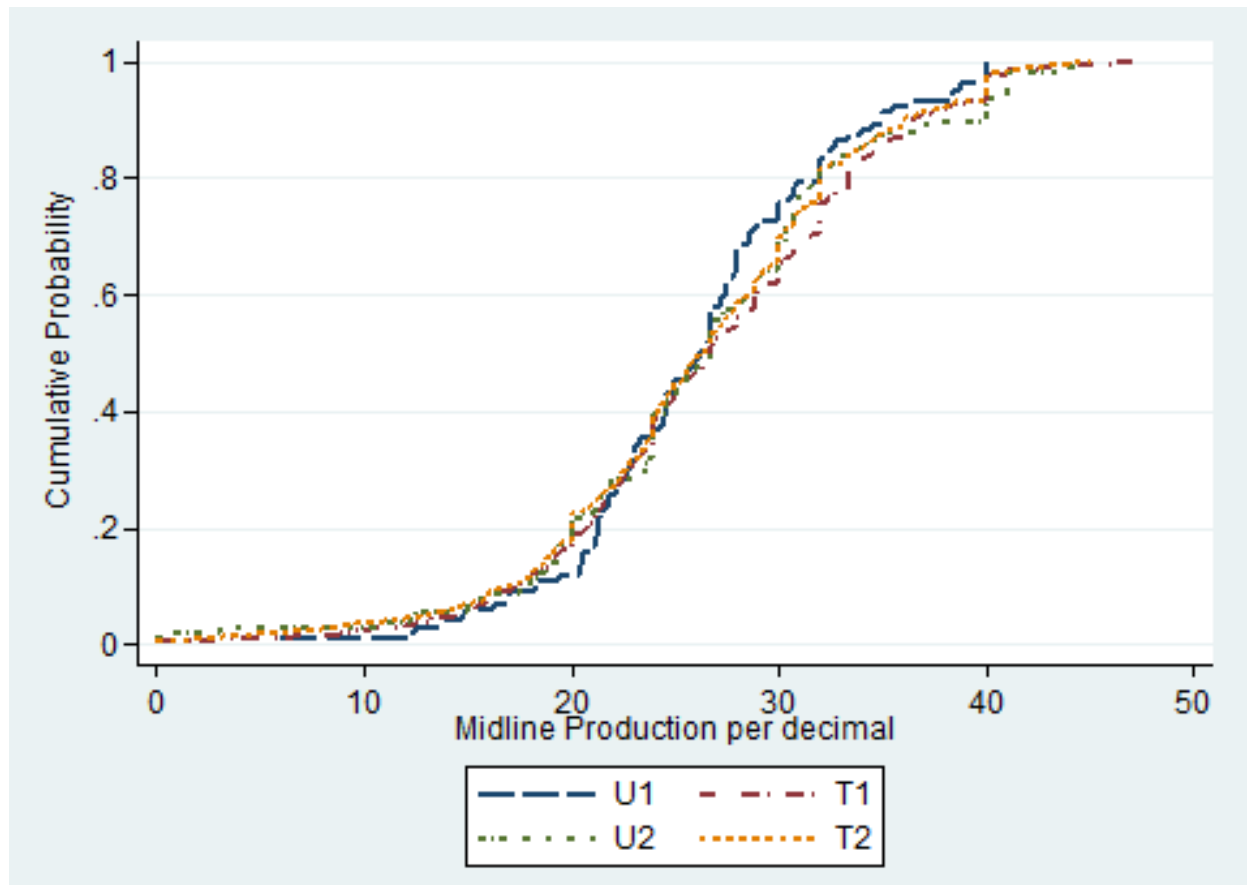

Note: None of the treatment groups first, second, or third order stochastically dominates any other treatment group.

Figure A5: Cumulative distribution function of midline production per decimal of land for SRI adopters 


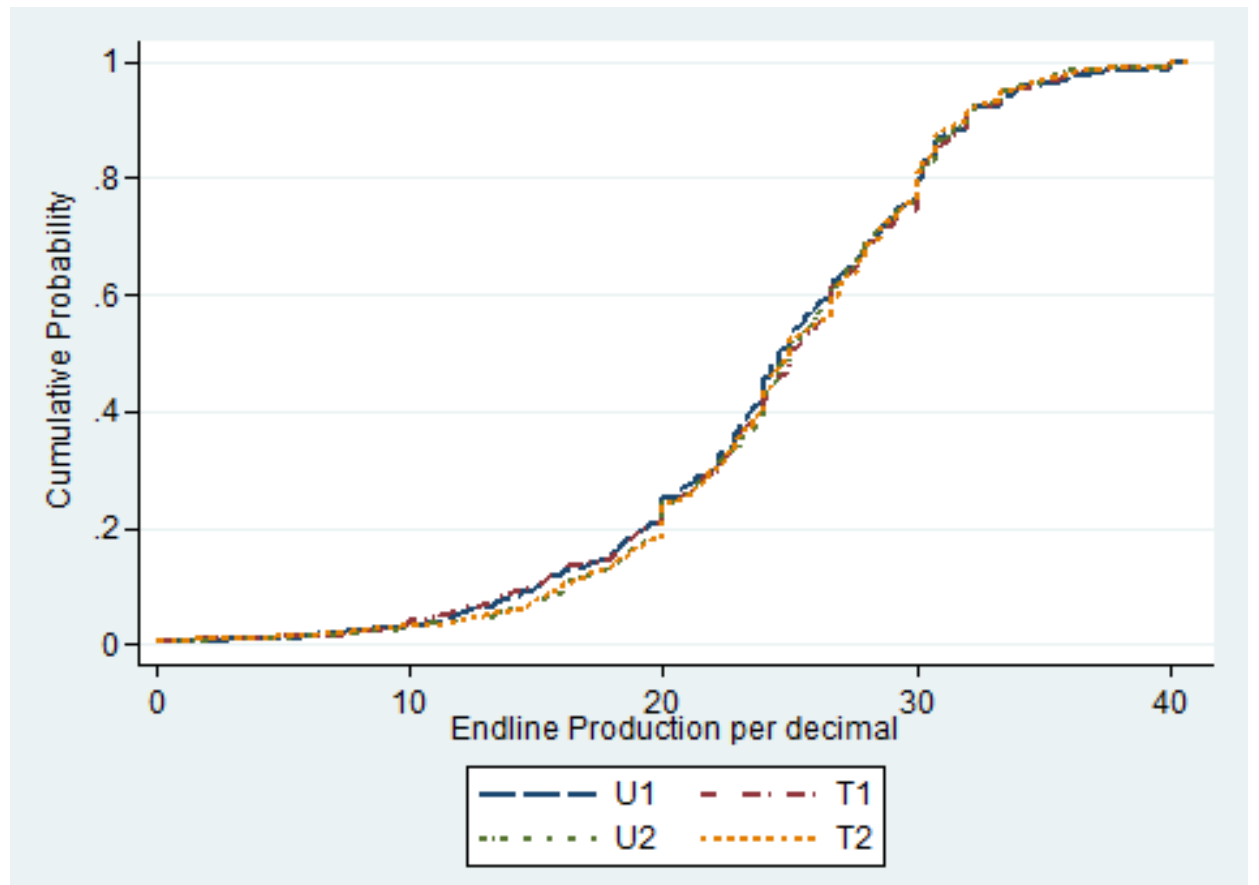

Note: None of the treatment groups first, second, or third order stochastically dominates any other treatment group.

Figure A6: Cumulative distribution function of endline production per decimal of land for non-adopters
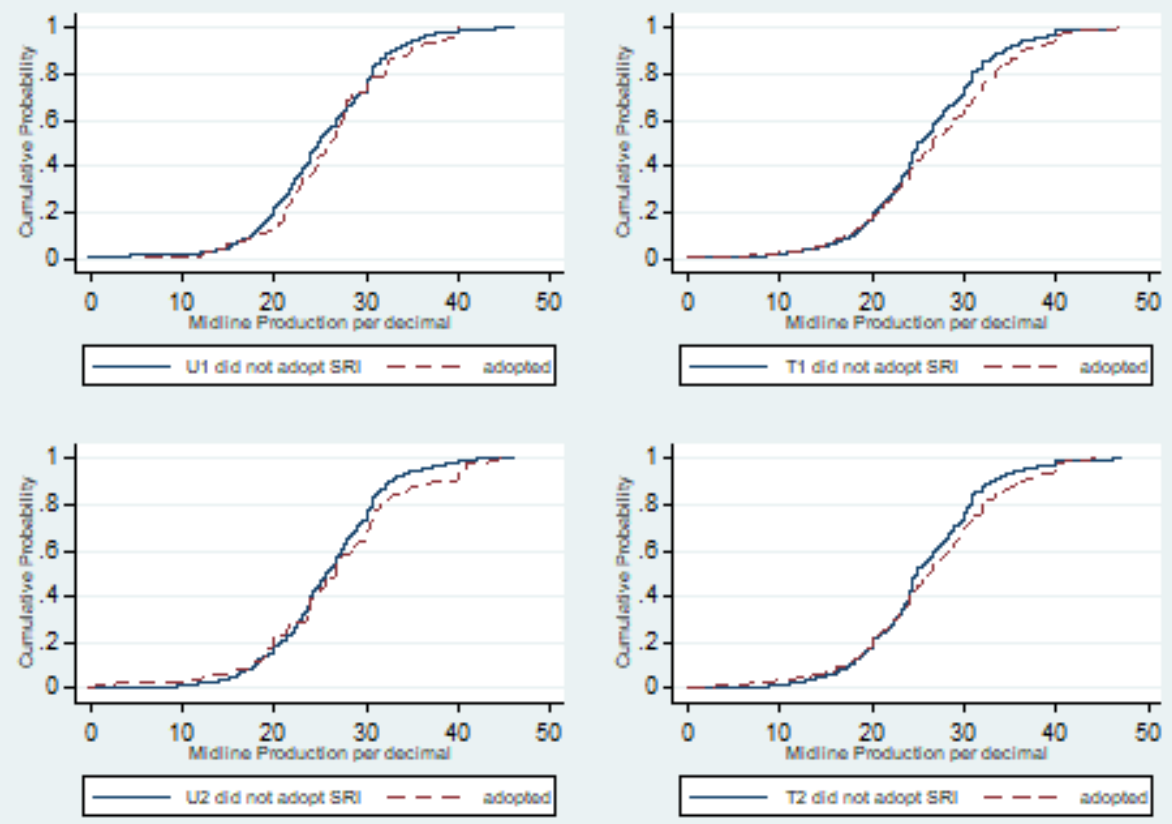

Notes: p-value associated with Somers' D test for first order stochastic dominance for U1(adopted-did not adopt) $=0.38$, T1 $($ adopted-did not adopt $)=0.07$, U2 (adopted-did not adopt $)=0.51$ and T2 $($ adopted-did not adopt $)=0.16$. No second or third order stochastic dominance exists either.

Figure A7: Cumulative distribution function of midline production per decimal of land by treatment and adoption status 

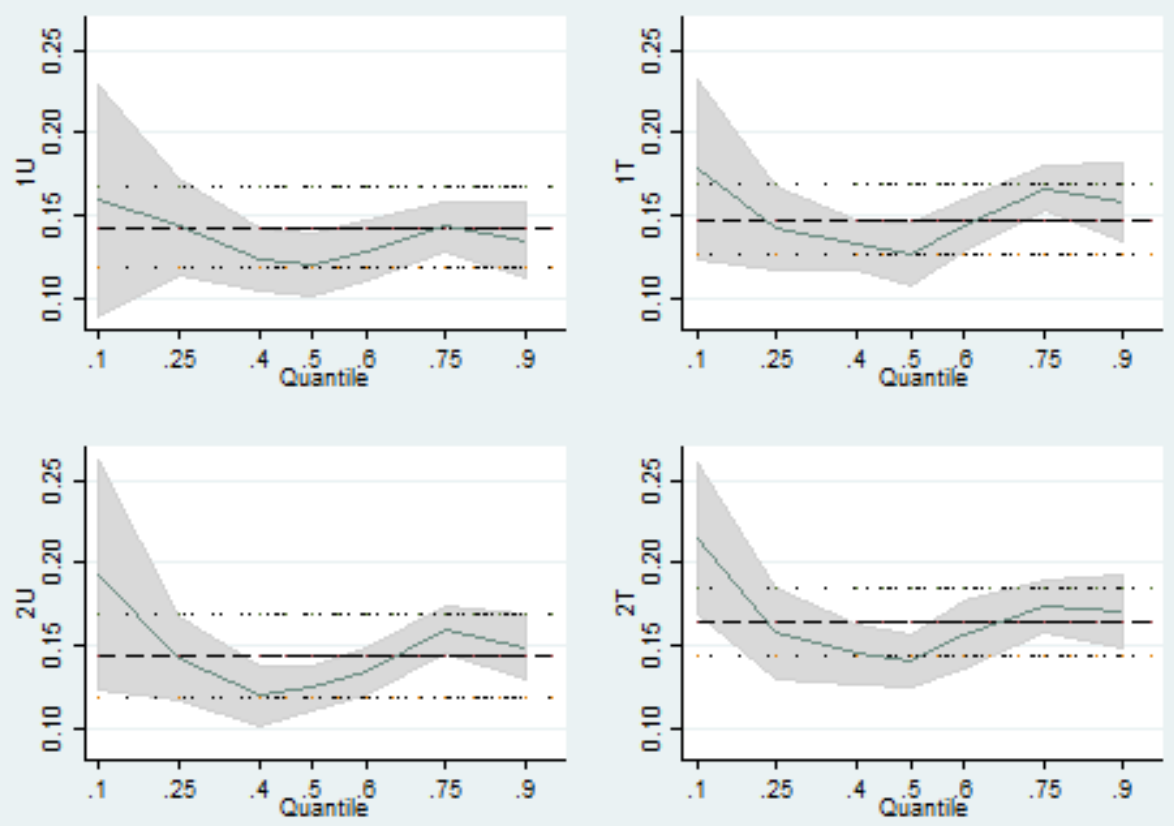

Figure A8: Quantile regression for endline yield
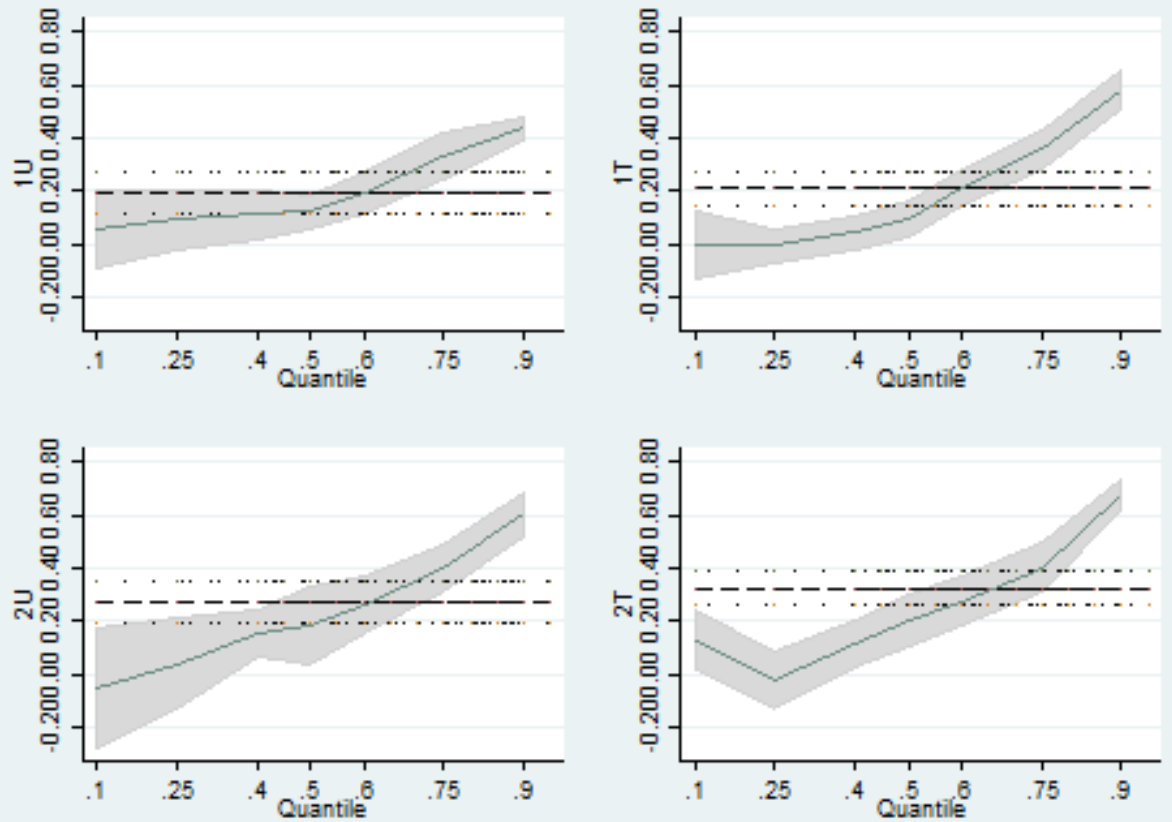

Note: The endline profits using profit which consider the imputed cost of family labour.

Figure A9: Quantile regression based on end profits (adjusted for family labor) 

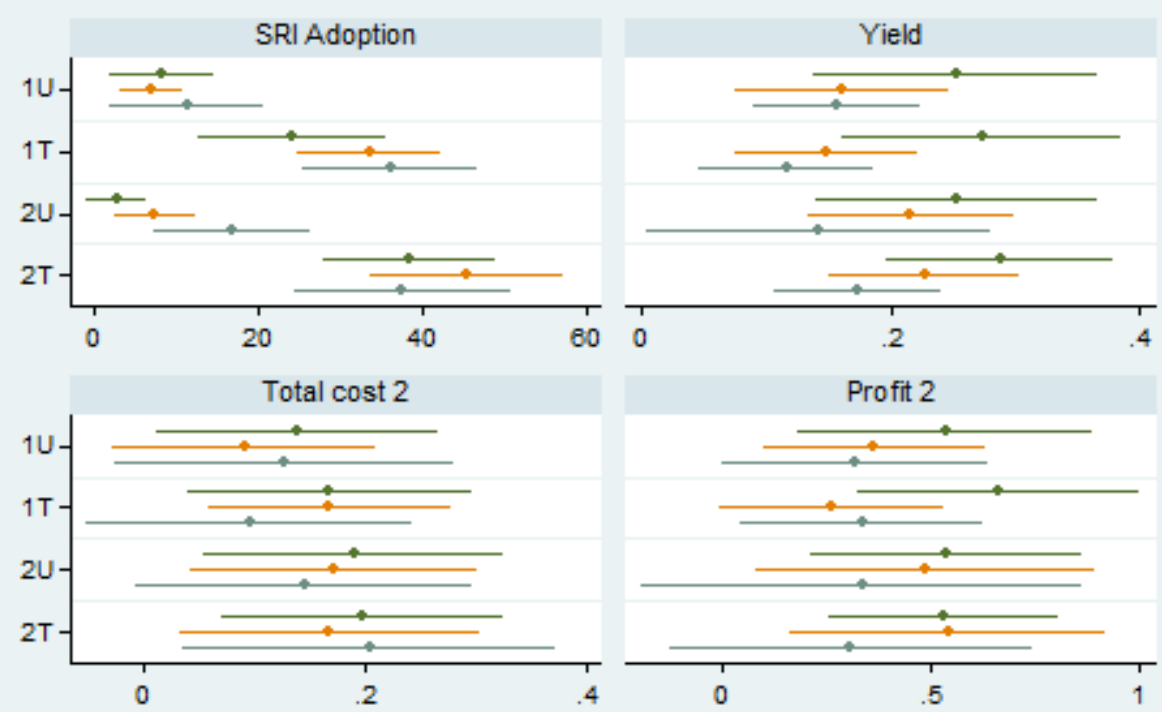

- Bottom 25\%

- Middle 50\%

- Top $25 \%$

Figure A10: Quartile regressions based on baseline land size

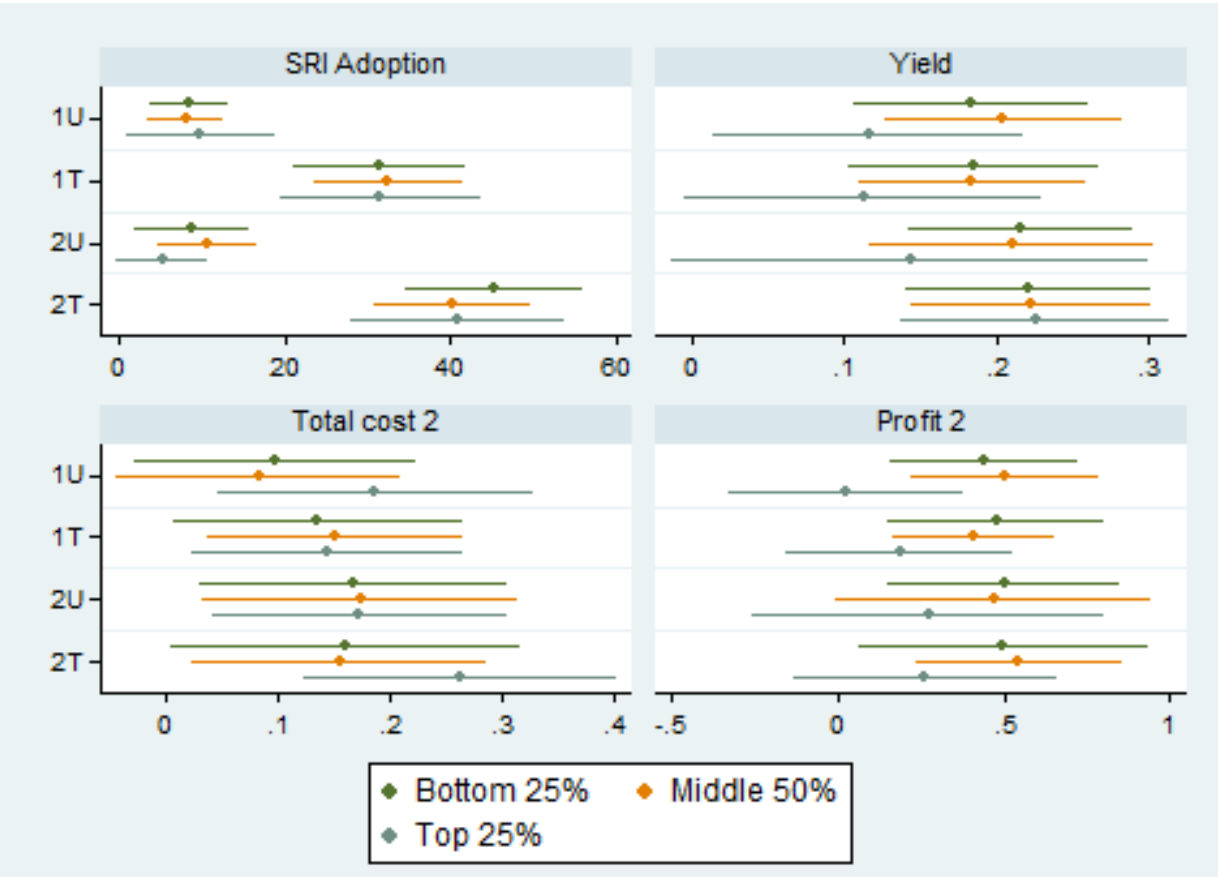

Figure A11: Quartile regressions based on adult working members 


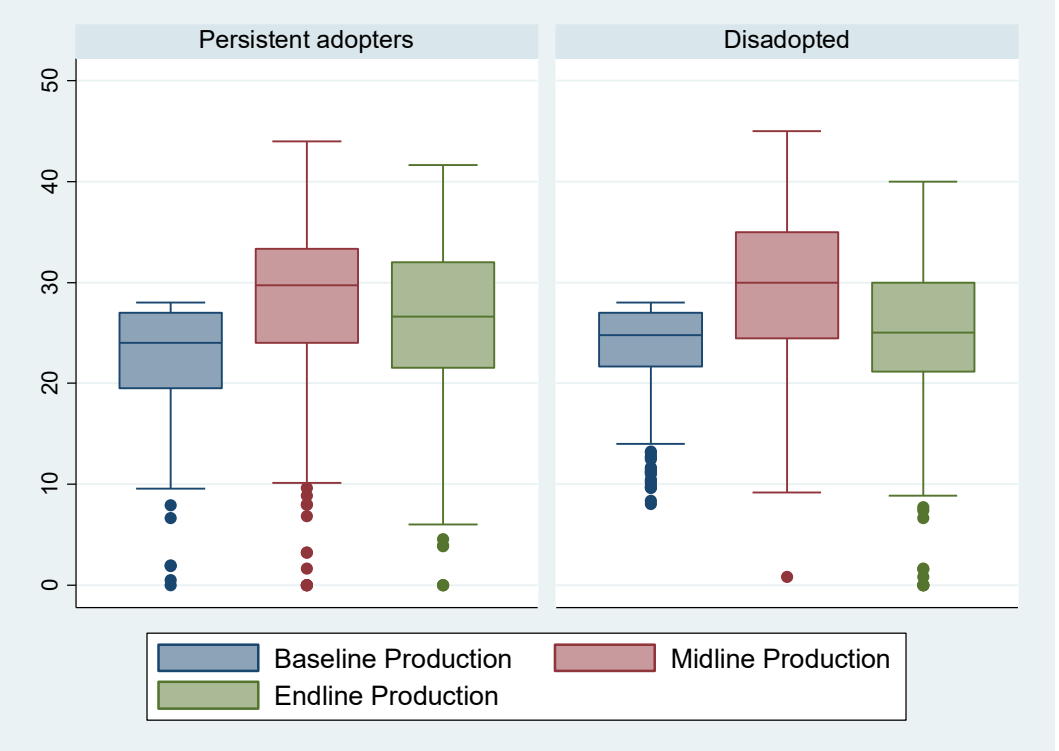

Figure A12: Productivity by disadoption status 